\title{
Design and Experimental Results for the S809 Airfoil
}

Dan M. Somers

Airfoils, Incorporated

State College, Pennsylvania

NREL technical monitor: James Tangler

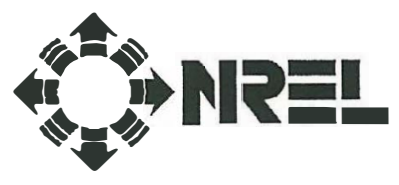

National Renewable Energy Laboratory 1617 Cole Boulevard Golden, Colorado 80401-3393

A national laboratory of the U.S. Department of Energy Managed by Midwest Research Institute for the U.S. Department of Energy under contract No. DE-AC36-83CH10093

Work performed under task number WE711110 January 1997 


\section{NOTICE}

This report was prepared as an account of work sponsored by an agency of the United States government. Neither the United States government nor any agency thereof, nor any of their employees, makes any warranty, express or implied, or assumes any legal liability or responsibility for the accuracy, completeness, or usefulness of any information, apparatus, product, or process disclosed, or represents that its use would not infringe privately owned rights. Reference herein to any specific commercial product, process, or service by trade name, trademark, manufacturer, or otherwise does not necessarily constitute or imply its endorsement, recommendation, or favoring by the United States govemment or any agency thereof. The views and opinions of authors expressed herein do not necessarily state or reflect those of the United States government or any agency thereof.

Available to DOE and DOE contractors from:

Office of Scientific and Technical Information (OSTI)

P.O. Box 62

Oak Ridge, TN 37831

Prices available by calling (423) 576-8401

Available to the public from:

National Technical Information Service (NTIS)

U.S. Department of Commerce

5285 Port Royal Road

Springfield, VA 22161

(703) $487-4650$ 


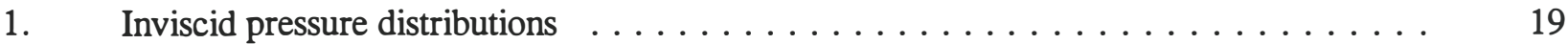

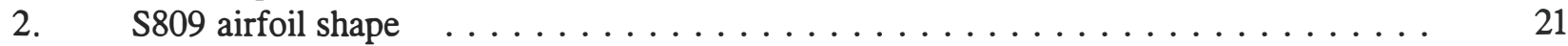

3. Delft University of Technology $1.80-\times 1.25$-m low-speed wind tunnel . . . . . . . 22

4. Model and wake rakes mounted in test section. All dimensions are in mm . . . . . . 23

5. Photograph of wake rakes mounted on strut . . . . . . . . . . . . . . . . 24

6. Wake rakes ................................. 25

7. Static-pressure, integrating, and total-pressure wake-rake tubes. All

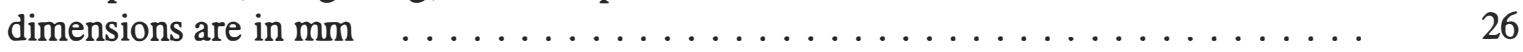

8. Pressure distributions for $R=2,000,000$. Arrows indicate direction of angle-of-attack change (for determination of hysteresis) $\ldots \ldots \ldots \ldots \ldots \ldots$

9. Oil-flow photographs of upper surface for $\mathrm{R}=1,000,000 \ldots \ldots \ldots$

10. Oil-flow photographs of upper surface for $R=2,000,000 \ldots \ldots \ldots \ldots$. . . . . . 41

11. Oil-flow photographs of upper surface for $\mathrm{R}=3,000,000 \ldots \ldots \ldots$. . . . . . . 49

12. Oil-flow photographs of lower surface for $\mathrm{R}=1,000,000 \ldots \ldots \ldots \ldots 2$

13. Oil-flow photographs of lower surface for $\mathrm{R}=2,000,000 \ldots \ldots \ldots \ldots$

14. Oil-flow photographs of lower surface for $\mathrm{R}=3,000,000 \ldots \ldots \ldots \ldots$

15. Transition location. Bars extend from beginning to end of transition . . . . . . . . 58

16. Spanwise drag coefficients for $\mathrm{R}=2,000,000 \ldots \ldots \ldots 6$

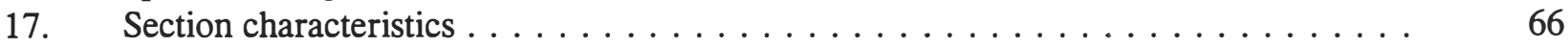

18. Effect of roughness on section characteristics $\ldots \ldots \ldots \ldots \ldots \ldots \ldots \ldots \ldots \ldots$

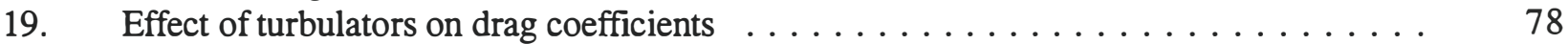

20. Effect of turbulators on section characteristics for $\mathrm{R}=1,000,000 \ldots \ldots 80$

21. Comparison of theoretical and experimental pressure distributions . . . . . . . . 81

22. Comparison of theoretical and experimental section characteristics with transition free . . . . . . . . . . . . . . . . . . . . . . . 84

23. Comparison of theoretical and experimental section characteristics with transition fixed . . . . . . . . . . . . . . . . . . . . . . . . 90

24. Comparison of section characteristics of S809 and NACA 4421 airfoils

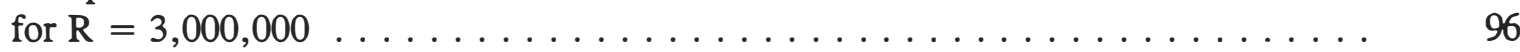

25. Comparison of section characteristics of S809 and NACA 23021 airfoils for $\mathrm{R}=3,000,000 \ldots \ldots \ldots \ldots \ldots \ldots$ 


\title{
Foreword
}

Validation of the Eppler Airfoil Design and Analysis Code has been a goal of several NREL-sponsored, two-dimensional investigations in the low-turbulence wind tunnel of the Delft University of Technology Low Speed Laboratory, The Netherlands. Initial validation of the code with respect to wind-turbine airfoils was based on data acquired for low maximum-lift-coefficient airfoils of the thin- and thick-airfoil families. The first of these tests was conducted in 1985 upon completion of the design effort for a thin-airfoil family for stall-regulated rotors. The primary airfoil of this family, the 13.5-percent-thick S805, was tested and the results showed that the Eppler Code predicted all the section characteristics well except the profile-drag coefficient. The drag coefficient was under predicted as a result of underestimating the significance of the laminar separation bubbles, through which the laminar flow transitioned to turbulent flow. The design of the subsequent thick-airfoil family included an adjustment to the design methodology that accounted for this bias error. In 1986, this adjustment was verified in a wind-tunnel test of the 21-percent-thick S809, the primary airfoil of this thick-airfoil family. Through these tests, the Eppler Code was "validated" so future airfoils, of moderate thickness, could be designed with greater confidence. For wind-turbine blades, moderate-thickness airfoils are typically used for the outboard portion of the blade.

\author{
James L.Tangler \\ Wind Technology Division \\ National Renewable Energy Laboratory \\ 1617 Cole Blvd. \\ Golden, Colorado 80401 USA \\ Internet Address: tanglerj@tcplink.nrel.gov
}

Phone 303-384-6934

FAX 303-384-6901 


\section{Contents}

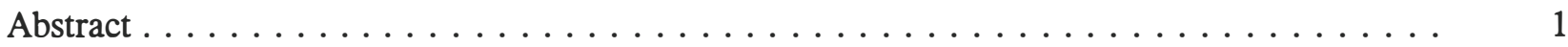

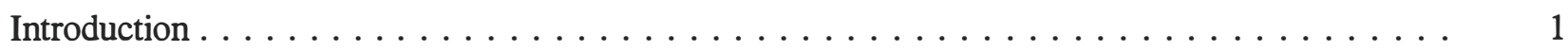

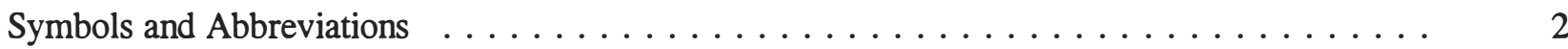

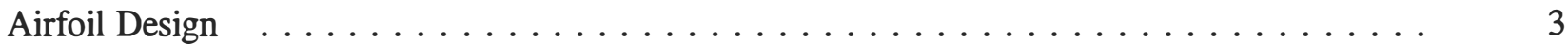

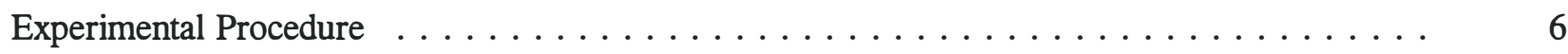

Discussion of Results $\ldots \ldots \ldots \ldots \ldots \ldots \ldots \ldots \ldots \ldots \ldots \ldots \ldots$

Concluding Remarks $\ldots \ldots \ldots \ldots \ldots \ldots \ldots \ldots \ldots \ldots \ldots \ldots \ldots \ldots \ldots \ldots$

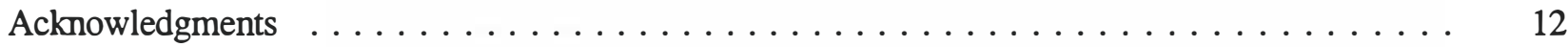

References. .............................. 12

Table 1. Airfoil Design Specifications $\ldots \ldots \ldots \ldots \ldots \ldots \ldots \ldots \ldots \ldots$

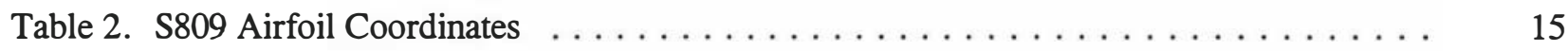

Table 3. Model Orifice Locations $\ldots \ldots \ldots \ldots \ldots \ldots \ldots \ldots \ldots \ldots \ldots \ldots \ldots \ldots$

Table 4. Roughness Size and Location $\ldots \ldots \ldots \ldots \ldots \ldots \ldots \ldots \ldots \ldots \ldots$ 


\title{
Design and Experimental Results for the S809 Airfoil
}

\author{
Dan M. Somers $\dagger$
}

March 1989

\begin{abstract}
$\underline{\text { Abstract }}$
A 21-percent-thick, laminar-flow airfoil, the $\$ 809$, for horizontal-axis wind-turbine applications, has been designed and analyzed theoretically and verified experimentally in the low-turbulence wind tunnel of the Delft University of Technology Low Speed Laboratory, The Netherlands. The two primary objectives of restrained maximum lift, insensitive to roughness, and low profile drag have been achieved. The airfoil also exhibits a docile stall. Comparisons of the theoretical and experimental results show good agreement. Comparisons with other airfoils illustrate the restrained maximum lift coefficient as well as the lower profile-drag coefficients, thus confirming the achievement of the primary objectives.
\end{abstract}

\section{Introduction}

The majority of the airfoils in use on horizontal-axis wind turbines today were originally developed for airplanes. The design requirements for these airfoils, primarily National Advisory Committee for Aeronautics (NACA) and National Aeronautics and Space Administration (NASA) airfoils (refs. 1-6), are significantly different from those for wind-turbine airfoils. Accordingly, two sets of thick airfoils were designed, using the method of references 7 and 8, specifically for horizontal-axis wind-turbine applications. (See ref. 9.) The major, distinguishing feature between the two sets is the maximum lift coefficients of the airfoils for the outboard portion of the wind-turbine blade. The first set produces relatively low ("restrained") maximum lift coefficients outboard whereas the second set produces maximum lift coefficients outboard that are 0.2 higher than those produced by the first set.

In conjunction with this effort, the primary airfoil ( 0.75 blade radial station) of the first set was selected for experimental verification. In 1986, an investigation was conducted in the low-turbulence wind tunnel of the Delft University of Technology Low Speed Laboratory (ref. 10), The Netherlands, to obtain the basic, low-speed, two-dimensional aerodynamic characteristics of this airfoil. The results have been compared with the predictions from the method of references 7 and 8 and also with data from another lowturbulence wind tunnel for other airfoils.

The specific tasks performed under this study are described in Solar Energy Research Institute (SERI) Subcontract Number HK-6-06075-1.

$\dagger$ President, Airfoils, Incorporated, State College, Pennsylvania 


\section{Symbols and Abbreviations}

Values are given in both SI and U.S. Customary Units. Measurements and calculations were made in SI Units.

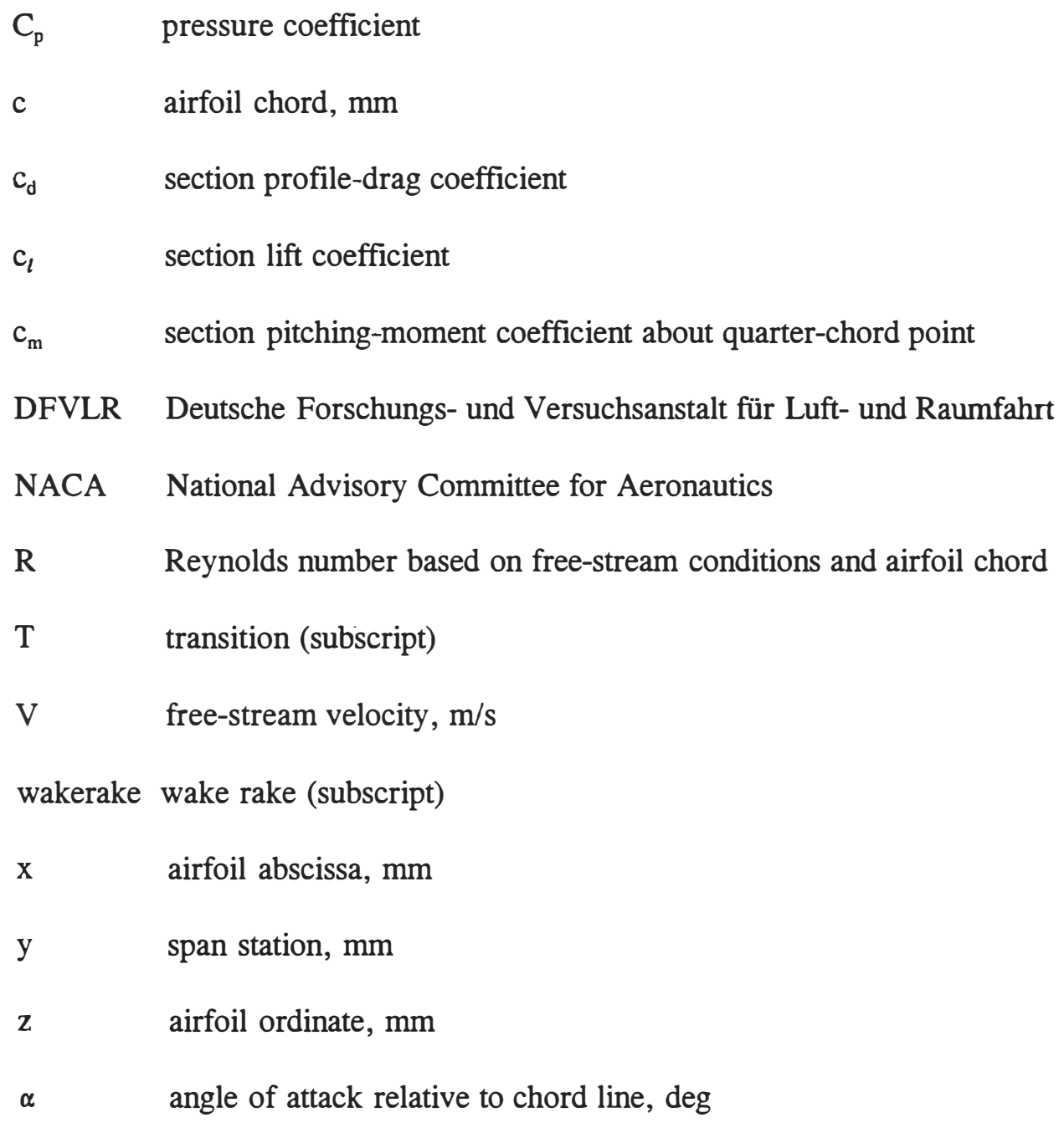




\section{Airfoil Design}

\section{Objectives and Constraints}

Two primary objectives are evident from the design specifications for this airfoil (table 1). The first objective was to achieve a maximum lift coefficient that is relatively low (restrained). A requirement related to this objective was that the maximum lift coefficient not decrease with transition fixed near the leading edge on both surfaces. The second objective was to obtain low profile-drag coefficients over the range of lift coefficients from 0.2 to 0.8 for a Reynolds number of $2.0 \times 10^{6}$.

Two major constraints were placed on the design of this airfoil. First, the zero-lift pitching-moment coefficient must be no more negative than -0.05 . Second, the airfoil thickness must be 21 -percent chord.

\section{Philosophy}

Given the above objectives and constraints, certain characteristics of the design are evident. The following sketch illustrates the desired polar that meets the goals for this design.

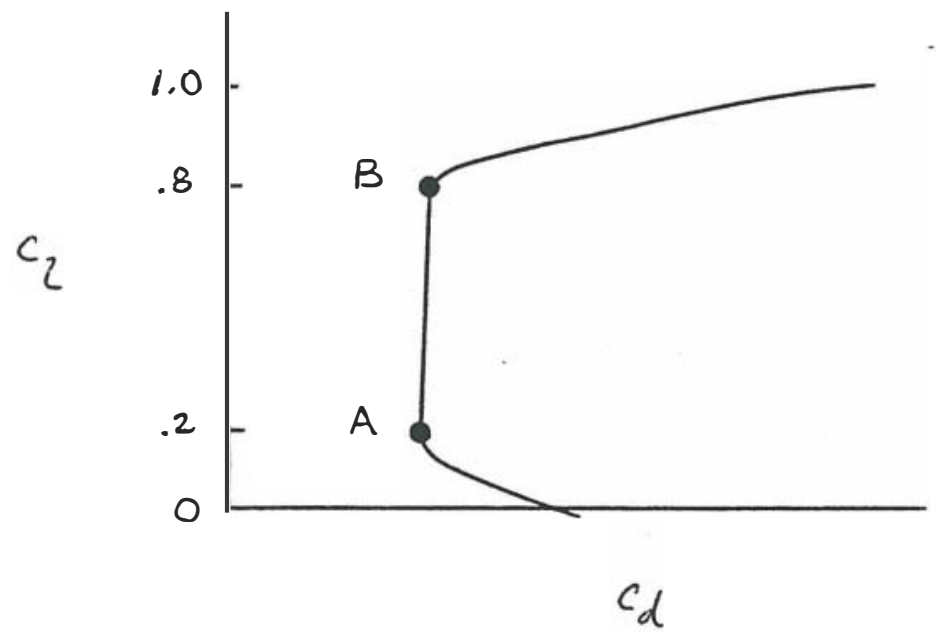

Sketch 1

The desired airfoil shape can be related to the pressure distributions that occur at the various points in the sketch. Point $\mathrm{A}$ is the lower limit of the laminar bucket; point $\mathrm{B}$, the upper limit. The values of the drag coefficients at both points are nearly equal and are determined by the extents of laminar flow on the upper and lower surfaces. The drag increases very rapidly outside the laminar bucket because the transition point moves quickly toward the leading edge. This feature results in a rather sharp leading edge that produces a suction peak at the higher lift coefficients. This peak limits the maximum lift coefficient and assures that transition will occur very near the leading edge. Thus, the maximum lift coefficient occurs with turbulent flow along the entire upper surface, and, therefore, the addition of roughness at the leading edge should 
have little influence on the boundary-layer development along the upper surface and, accordingly, the maximum lift coefficient.

Because the great airfoil thickness allows a wider laminar bucket to be achieved than that specified, point A should not be the lower limit of the bucket but, instead, near the middle. From the preceding discussion, the pressure distributions at points $\mathrm{A}$ and $\mathrm{B}$ can be deduced. The pressure distribution at point $\mathrm{A}$ should look something like this:

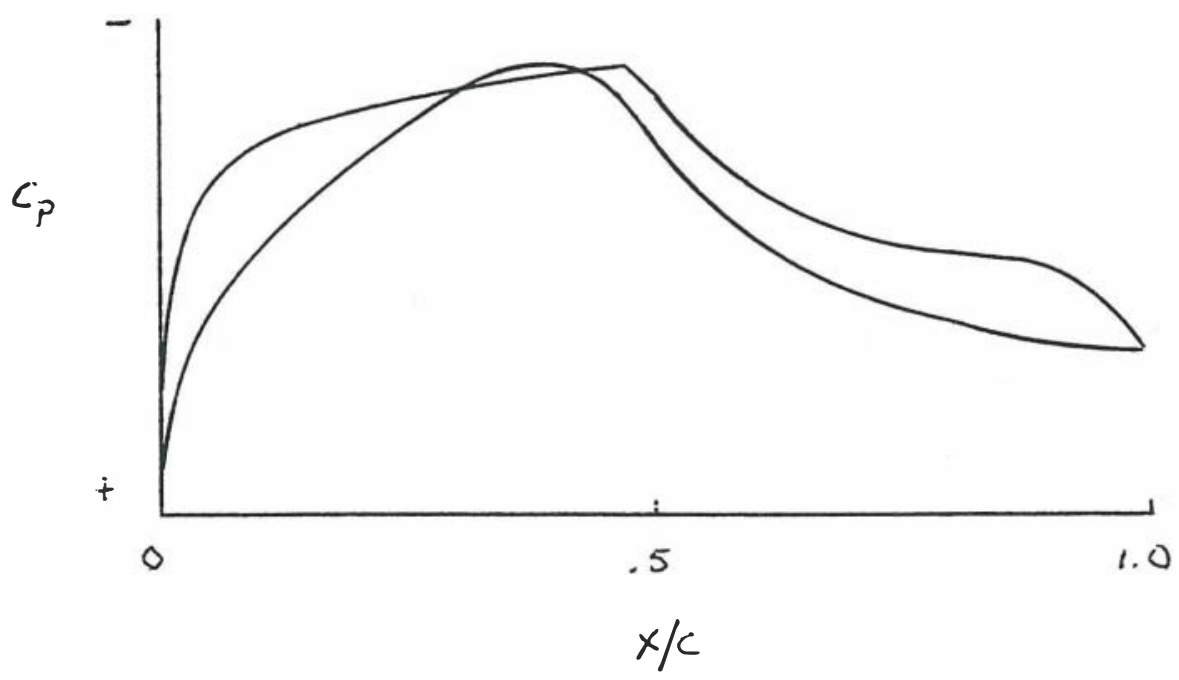

Sketch 2

To achieve low drag, a favorable pressure gradient is desirable along the upper surface to about $0.5 \mathrm{c}$. Aft of this point, a short region of adverse pressure gradient ("transition ramp") is desirable to promote the efficient transition from laminar to turbulent flow. Thus, the initial slope of the pressure recovery is relatively shallow. This short region is followed by a steeper concave pressure recovery that produces lower drag and has less tendency to separate than the corresponding linear or convex pressure recovery (ref. 11).

A favorable pressure gradient is desirable along the lower surface to about $0.4 \mathrm{c}$ to achieve low drag. The initial slope of the pressure recovery is very shallow in order to inhibit the formation of significant laminar separation bubbles.

The amounts of pressure recovery on the two surfaces are determined by the pitching-moment constraint and the airfoil thickness. 
At point $\mathrm{B}$, the pressure distribution should look like this:

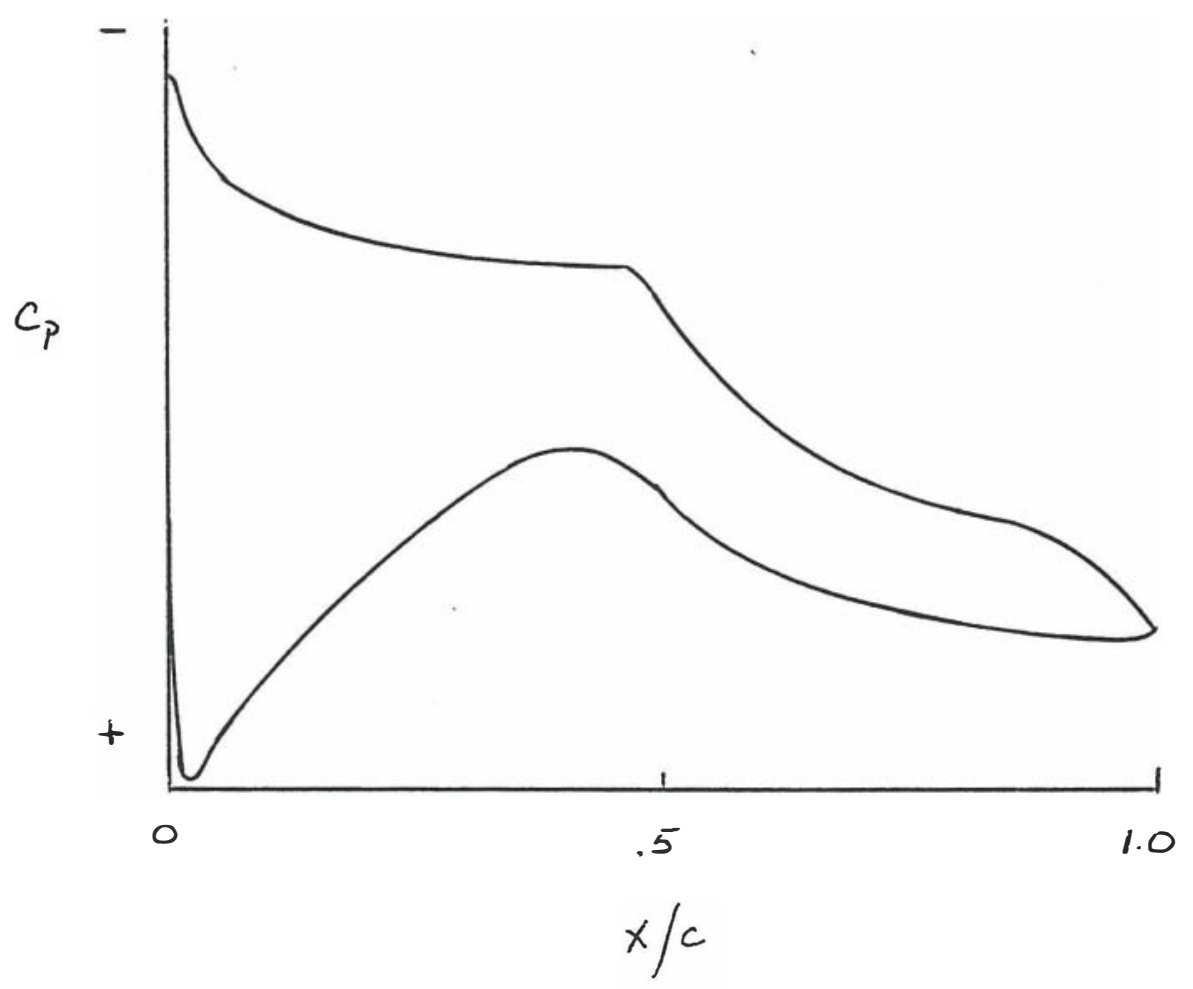

Sketch 3

No suction spike exists at the leading edge. Instead, the peak occurs just aft of the leading edge. This feature is the result of incorporating increasingly favorable pressure gradients toward the leading edge. It is quite important in that it allows a wider laminar bucket to be achieved.

\section{Execution}

Given the pressure distributions for lift coefficients of 0.2 and 0.8 , the design of the airfoil is reduced to the inverse problem of transforming the pressure distributions into an airfoil shape. The Eppler Airfoil Design and Analysis Program (refs. 7 and 8) was used because of confidence gained during the design, analysis, and experimental verification of several other airfoils.

The airfoil is designated the S809. The inviscid pressure distributions computed by the method of references 7 and 8 for lift coefficients of 0.2 and 0.8 are shown in figures 1(a) and 1(b), respectively. The airfoil shape is shown in figure 2 and the coordinates are contained in table 2 . 


\title{
Experimental Procedure
}

\author{
Wind Tunnel
}

The low-turbulence wind tunnel (ref. 10) of the Delft University of Technology Low Speed Laboratory, The Netherlands, is a closed-throat, single-return, atmospheric tunnel (fig. 3). The turbulence level in the test section varies from 0.02 percent at $10 \mathrm{~m} / \mathrm{s}(33 \mathrm{ft} / \mathrm{s})$ to 0.04 percent at $60 \mathrm{~m} / \mathrm{s}(200 \mathrm{ft} / \mathrm{s})$.

The octagonal test section is $180.0 \mathrm{~cm}$ (70.87 in.) wide by $125.0 \mathrm{~cm}$ (49.21 in.) high. Electrically actuated turntables provide positioning and attachment for the two-dimensional model. The turntables are flush with the top and bottom tunnel walls and rotate with the model. The axis of rotation coincided with the quarter chord of the model which was mounted vertically between the turntables. (See fig. 4.) The gaps between the model and the turntables were sealed.

\section{Model}

The aluminum, wind-tunnel model was constructed by the Deutsche Forschungs- und Versuchsanstalt für Luft- und Raumfahrt e.V. (DFVLR), Braunschweig, Federal Republic of Germany. The model had a chord of $600.00 \mathrm{~mm}$ (23.622 in.) and a span of $1248 \mathrm{~mm}$ (49.13 in.). Chordwise orifices were located in the upper and lower surfaces to one side of the midspan at the staggered positions listed in table 3 . Spanwise orifices were located in the upper surface only in order to monitor the two-dimensionality of the flow at high angles of attack. All the orifices were $0.40 \mathrm{~mm}(0.016 \mathrm{in}$.) in diameter with their axes perpendicular to the surface. The measured model contour was generally within $0.1 \mathrm{~mm}(0.004 \mathrm{in}$.) of the prescribed shape.

\section{Wake Rake}

A total-pressure, a static-pressure, and an integrating wake rake were mounted on a strut between the tunnel sidewalls (figs. 4 and 5). The strut could be positioned spanwise and streamwise in the test section. Movement of the strut provided positioning of the wake rakes normal to the sidewalls. The details of the wake rakes are shown in figures 6 and 7. The integrating wake rake was not used in this investigation.

\section{Instrumentation}

Measurements of the basic tunnel pressures, the static pressures on the model surfaces, and the wake-rake pressures were made by a multitube manometer which was read automatically using photoelectric cells. Data were obtained and recorded by an electronic data-acquisition system.

\section{Methods}

The static-pressure measurements on the model surface were reduced to standard pressure coefficients and numerically integrated to obtain section normal-force coefficients and section pitching-moment coefficients about the quarter-chord point. Section profile-drag coefficients were computed from the wake-rake total and static pressures by the method of reference 12. Standard, low-speed, wind-tunnel boundary corrections (ref. 13) have been applied to the data. The following procedure was used. The uncorrected force, moment, and pressure coefficients were referred to the apparent dynamic pressure as measured tunnel 
empty at the model position. The lift, profile-drag, pitching-moment, and airfoil pressure coefficients and the angle of attack were then corrected by the method of reference 13. The corrected values were plotted. Finally, as a check, the corrected airfoil pressure distribution was numerically integrated to obtain the corrected normal-force (and pitching-moment) coefficient which, together with the corrected profile-drag coefficient and angle of attack, yields the corrected lift coefficient (and chord-force coefficient).

At high angles of attack, the wake becomes wider than the wake rake. When this occurs, the drag is obtained from a parabolic extrapolation of the measured wake pressures. At even higher angles of attack, the total-pressure coefficients measured in the wake become negative, making calculation of the drag impossible. In these cases, an uncorrected profile-drag coefficient of 0.2 (estimated from ref. 14) is assumed.

Tests

The model was tested at Reynolds numbers based on airfoil chord from $1.0 \times 10^{6}$ to $3.0 \times 10^{6}$. The model was tested smooth (transition free) and with transition fixed by roughness at $0.02 \mathrm{c}$ on the upper surface and $0.05 \mathrm{c}$ on the lower surface. The grit roughness was sized by the method of reference 15 and sparsely distributed along 3-mm (0.1-in.) wide strips applied to the model with lacquer. (See table 4.)

Starting from $0^{\circ}$, the angle of attack was increased until the entire upper surface was separated and then decreased to determine hysteresis. The same procedure was followed for the negative angles of attack. For the Reynolds numbers of $2.5 \times 10^{6}$ and $3.0 \times 10^{6}$, the static pressures on the upper surface could not be measured by the manometer at high angles of attack because the differences between those pressures and the free-stream static pressure were too great.

For several test runs, the model surfaces were coated with oil to determine the location, as well as the nature, of the boundary-layer transition from laminar to turbulent flow (ref.16). Transition was also located using a probe containing a microphone, which was positioned near the leading edge and then moved slowly downstream along the model surface. Two span stations, corresponding to the wake-rake position and the chordwise orifice row, were surveyed. The beginning of the turbulent boundary layer was detected as an increase in noise level over that for the laminar boundary layer which was essentially silent. (See ref. 17.)

Two turbulators, zigzag tape (ref. 18), were placed on the model, one between $0.43 \mathrm{c}$ and $0.45 \mathrm{c}$ on the upper surface and the other between $0.42 \mathrm{c}$ and $0.44 \mathrm{c}$ on the lower surface, to determine their effect on laminar separation bubbles and section characteristics. The details of the 0.25 - $\mathrm{mm}(0.010$-in.) thick tape are shown in the following sketch.

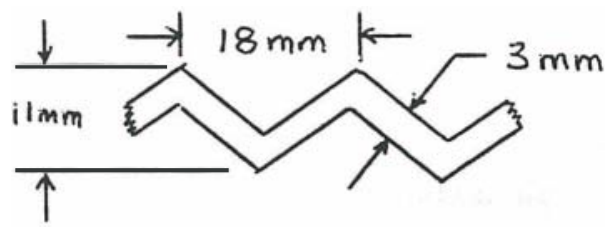

Sketch 4 


\title{
Discussion of Results
}

Experimental Results

\author{
Pressure Distributions
}

The pressure distributions at various angles of attack for a Reynolds number of $2.0 \times 10^{6}$ are shown in figure 8. At an angle of attack of $-0.01^{\circ}$ (fig. 8(a)), a laminar separation bubble is evident on the upper surface around midchord and on the lower surface just forward of midchord. As the angle of attack is increased, the bubble on the upper surface decreases in length. At an angle of attack of $5.13^{\circ}$ (fig. 8(b)), the bubble on the upper surface has almost disappeared. The lift coefficient at this angle of attack corresponds approximately to the upper limit of the laminar bucket. As the angle of attack is increased further, turbulent, trailing-edge separation occurs on the upper surface. The amount of separation increases slowly with increasing angle of attack. At an angle of attack of $9.22^{\circ}$ (fig. 8(b)), the maximum lift coefficient occurs. As the angle of attack is increased to $10.21^{\circ}$ (fig. 8(c)), the separation point jumps forward to about midchord where it remains through $15.24^{\circ}$ (fig. 8(d)). As the angle of attack is increased further, the separation point again migrates forward (fig. 8(d)).

As the angle of attack is decreased from $20.14^{\circ}$ (fig. 8(e)), the pressure distributions are almost identical to those that occur with increasing angle of attack (fig. 8(d)). Thus, almost no hysteresis occurs with respect to separation on the upper surface.

As the angle of attack is decreased from $0^{\circ}$ (fig. 8(f)), the laminar separation bubble on the lower surface decreases in length until it has disappeared at an angle of attack of $-5.14^{\circ}$ (fig. 8(g)). The lift coefficient at this angle of attack corresponds approximately to the lower limit of the laminar bucket. As the angle of attack is decreased further, turbulent separation occurs around midchord. At an angle of attack of $-14.23^{\circ}$ (fig. 8(h)), which corresponds to the minimum lift coefficient, a long laminar separation bubble has formed near the leading edge. As the angle of attack is decreased still further (fig. 8(i)), the long bubble on the lower surface increases in length.

As the angle of attack is increased from $-17.17^{\circ}$ (fig. 8(i)), the pressure distributions (fig. 8(j)) are almost identical to those that occur with decreasing angle of attack (fig. 8(i)) except for $-13.23^{\circ}$ (fig. 8(j)) which still exhibits a long separation bubble. Thus, only a small amount of hysteresis occurs with respect to separation on the lower surface.

\section{Transition Location}

Oil-flow photographs of the upper and lower surfaces at various angles of attack for Reynolds numbers of $1.0 \times 10^{6}, 2.0 \times 10^{6}$, and $3.0 \times 10^{6}$ are shown in figures 9 through 14 . For a Reynolds number of $1.0 \times 10^{6}$, the mechanism of the boundary-layer transition from laminar to turbulent flow on the upper surface, at an angle of attack of $0.0^{\circ}$, was a laminar separation bubble (fig. 9(a)). As the angle of attack is increased, the bubble decreases in length (figs. 9(b)-9(d)).

For a Reynolds number of $2.0 \times 10^{6}$, the mechanism of transition on the upper surface, at an angle of attack of $0.0^{\circ}$, was again a laminar separation bubble (fig. 10(a)). The bubble for this Reynolds number is, however, shorter in length than the corresponding bubble for a Reynolds number of $1.0 \times 10^{6}$ (fig. 9(a)). As the angle of attack is increased, the bubble decreases in length (figs. 10(b) and 10(c)). At any given angle of attack, the bubble is shorter for the higher Reynolds number. At an angle of attack of $5.1^{\circ}$ (fig. 10(d)), the bubble has almost disappeared. As the angle of attack is increased further, no bubble 
is evident and the transition location moves steadily forward (figs. 10(e)-10(h)). (The turbulent wedge in fig. 10(e) was caused by a contaminant in the oil.)

For a Reynolds number of $3.0 \times 10^{6}$, the mechanism of transition on the upper surface, at an angle of attack of $0.0^{\circ}$, was again a laminar separation bubble (fig. 11(a)). The bubble for this Reynolds number is shorter than the corresponding bubble for a Reynolds number of $2.0 \times 10^{6}$ (fig. (10a)). As the angle of attack is increased, the bubble decreases in length and has almost disappeared at an angle of attack of 4.1 $1^{\circ}$ (fig. 11(c)). (The turbulent wedge in fig. 11(b) was caused by a contaminant in the oil.) At any given angle of attack, the bubble is shorter for the higher Reynolds number.

For a Reynolds number of $1.0 \times 10^{6}$, the mechanism of transition on the lower surface, at an angle of attack of $0.0^{\circ}$, was a laminar separation bubble (fig. 12(a)). The bubble on the lower surface is comparable in length to the one on the upper surface at this angle of attack. As the angle of attack is increased, the bubble moves downstream while remaining essentially constant in length (fig. 12(b)).

For a Reynolds number of $2.0 \times 10^{6}$, the mechanism of transition on the lower surface, at an angle of attack of $0.0^{\circ}$, was again a laminar separation bubble (fig. 13(a)). The bubble for this Reynolds number is, however, shorter in length than the corresponding bubble for a Reynolds number of $1.0 \times 10^{6}$ (fig. 12(a)). As the angle of attack is increased, the bubble moves downstream while remaining essentially constant in length (fig. 13(b)).

For a Reynolds number of $3.0 \times 10^{6}$, the mechanism of transition on the lower surface, at an angle of attack of $0.0^{\circ}$, was again a laminar separation bubble (fig. 14(a)). (The turbulent wedge in fig. 14(a) was caused by a contaminant in the oil.) The bubble for this Reynolds number is shorter than the corresponding bubble for a Reynolds number of $2.0 \times 10^{6}$ (fig. 13(a)). As the angle of attack is increased, the bubble moves downstream while remaining essentially constant in length (fig. 14(b)).

The variation of transition location with angle of attack, as detennined by microphone measurements, is shown in figure 15. It should be remembered that only attached turbulent flow can be detected using this technique. Thus, for an angle of attack at which a laminar separation bubble is present, the transition location measured corresponds to the turbulent-reattachment point. The symbols represent conditions where the onset of turbulence was sudden. These conditions occur at the turbulent-reattachment point or where natural transition occurs rapidly. The bars represent conditions where natural transition occurs over some length. The bars extend from the beginning of transition (defined here as the point where turbulent bursts are first detected) to the end of transition (defined here as the point where individual bursts can no longer be distinguished). The chordwise orifices generally had little influence on the transition location (forward shift s 0.01c) except where natural transition occurred over some length, in which case, the orifices caused transition to occur somewhat further forward. For these cases, the influence decreased with increasing Reynolds number. It should be noted that wind-tunnel boundary corrections have not been applied to the angle of attack shown in figure 15 only.

\section{Section Characteristics}

Spanwise drag measurements.- The variation of profile-drag coefficient with span station at three angles of attack is shown for a Reynolds number of $2.0 \times 10^{6}$ in figure 16 . The three angles of attack, $0.0^{\circ}$, $3.1^{\circ}$, and $5.4^{\circ}$, correspond approximately to the middle, the upper middle, and the upper limit of the laminar bucket, respectively, for this Reynolds number. The greatest drag variation occurs in the vicinity of the stations that correspond to the chordwise pressure orifices in the model $(44.3$ to $51.6 \mathrm{~cm})$. A large drag variation is only evident at the upper limit of the laminar bucket (fig. 16(c)). A total-pressure wake- 
rake position of $26.0 \mathrm{~cm}$, which is $5.6 \mathrm{~cm}$ below the tunnel centerline, was selected for all succeeding drag measurements because it resulted in a drag coefficient representative of the mean value at each of the three angles of attack.

Reynolds number effects.- The section characteristics are shown in figure 17. For the design Reynolds number $\left(\mathrm{R}=2.0 \times 10^{6}\right)$ (fig. $17(\mathrm{c})$ ), the maximum lift coefficient was approximately 1.01 , which is essentially equal to the design objective of 1.0. (Note that none of the higher lift coefficients was interpreted as the maximum lift coefficient because of the large amount of separation present at all angles of attack greater than that for the previously-mentioned maximum lift coefficient. See figs. 8(c) and 8(d). Such massive separation suggests that the validity of the data is suspect.) The trailing-edge stall was very docile. Almost no hysteresis occurred at angles of attack greater than that for maximum lift and less than that for minimum lift; a small amount of hysteresis occurred at angles of attack somewhat greater than that for minimum lift. Low drag coefficients were obtained over the range of lift coefficients from about -0.45 to 0.77 . Thus, the lower limit of the laminar bucket is well below that specified $(0.2)$ and the upper limit is just below that specified (0.8). The slightly curved shape of the polar (higher drag between the limits than at them) indicates that the laminar separation bubbles, shown in figures 8,10 , and 13, adversely affected the drag. The magnitude of this effect decreased with increasing Reynolds number. The zero-lift pitching-moment coefficient was approximately -0.041 , which satisfies the design constraint $(z-0.05)$.

Effect of roughness.- The effect of roughness on the section characteristics is shown in figure 18. The angle of attack for zero lift coefficient as well as the pitching-moment coefficients generally increased with transition fixed, whereas the lift-curve slope decreased. All these results are partly a consequence of the boundary-layer-displacement effect which decambers the airfoil slightly, the displacement thickness being greater for the transition-fixed condition than for the transition-free condition. Increasing Reynolds number decreases the displacement thickness and, therefore, the displacement effect. In addition, the lift-curve slopes and magnitude of the pitching-moment coefficients are probably too low with transition fixed. For many conditions, the Reynolds number, based on local conditions and boundary-layer momentum thickness, at the roughness location is too low to support turbulent flow. Accordingly, in order to force transition, the roughness must increase the momentum thickness, which increases the extent of the turbulent, trailing-edge separation on the upper surface and, therefore, reduces the magnitudes of the lift and pitching-moment coefficients.

The angle of attack for zero lift coefficient did not increase with transition fixed for the Reynolds number of $1.0 \times 10^{6}$ (fig. 18(a)). For this Reynolds number, the roughness was too small to force transition on the upper surface at low lift coefficients. Thus, the laminar separation bubble on the upper surface was not eliminated, whereas the one on the lower surface was. The elimination of the lower-surface bubble resulted in an increase in lift compared to the transition-free condition, which was counterbalanced by the decambering effect of the increased boundary-layer displacement thickness.

Of more importance, however, is the effect of roughness on the maximum lift coefficient and on the drag coefficients. The addition of roughness had no major effect on the maximum lift coefficient for any of the Reynolds numbers. The minor reductions in maximum lift coefficient with transition fixed are partially due to the abnormal roughness effect noted previously. Thus, one of the most important design requirements has been achieved. The drag coefficients were, of course, adversely affected by the roughness. It should be noted, however, that the drag coefficients with transition fixed are probably too high at low and high lift coefficients. This result is obtained because the height of the roughness was similar to the boundary-layer thickness on the upper surface at low lift coefficients and on the lower surface at high lift coefficients. Therefore, the drag coefficients at these lift coefficients contain an additional (pressure-drag) contribution due to the roughness itself. This effect is larger for higher Reynolds numbers (figs. 18(c)-18(e)). 
Effect of turbulators.- The effect of turbulators on the drag coefficients at lift coefficients of 0.5 and 0.7 is shown in figure 19. The addition of a turbulator to the upper surface lowered the drag at the lower Reynolds numbers but increased it at the higher Reynolds numbers. The addition of a turbulator to the lower surface produced similar results but of lower magnitude. Because the turbulators lowered the drag at both lift coefficients for a Reynolds number of $1.0 \times 10^{6}$ only, the effect of the turbulators on the section characteristics for this Reynolds number alone is shown in figure 20. The turbulators, which eliminated the laminar separation bubbles on the upper and lower surfaces, had no major effect on any of the characteristics except the drag coefficients. The elimination of the upper-surface bubble altered the pressure distribution in such a way that the lift was decreased and the pitching moment, increased. The elimination of the lower-surface bubble produced similar results but of lower magnitude. Both effects were, however, small. Thus, the elimination of the bubbles changed the lift and pitching-moment coefficients little but modified the boundary-layer developments substantially. The influence on the uppersurface drag was larger than on the lower-surface drag. Thus, a significant drag reduction over the entire width of the laminar bucket was produced by the upper-surface turbulator, whereas a smaller drag reduction was produced by the lower-surface turbulator.

\section{Comparison of Theoretical and Experimental Results}

\section{Pressure Distributions}

The comparison of theoretical and experimental pressure distributions is shown in figure 21 . The pressure distributions predicted by the method of references 7 and 8 are inviscid and incompressible. The experimental pressure distributions were obtained for a Reynolds number of $2.0 \times 10^{6}$. At a lift coefficient of 0.27 (fig. 21(a)), the agreement between the theoretical predictions and the experimental data is very good except in those regions where laminar separation bubbles are present. These bubbles are not modeled in the method of references 7 and 8. At a lift coefficient of 0.77 (fig. 21(b)), the decambering viscous effects have become more apparent and the disparities include differences in the pressure gradients as well as in the magnitudes of the pressure coefficients. At a lift coefficient of 1.01 (fig. 21(c)), which corresponds to the experimental maximum lift coefficient, the agreement is relatively poor primarily because of the upper-surface, trailing-edge separation which is not modeled in the pressure distributions predicted by the method of references 7 and 8 .

\section{Section Characteristics}

The comparison of theoretical and experimental section characteristics with transition free is shown in figure 22. The drag coefficients are underpredicted by the method of references 7 and 8 , especially for the lower Reynolds numbers. It should be noted, however, that significant, upper-surface laminar separation bubbles are predicted by the method for a Reynolds number of $1.0 \times 10^{6}$ (fig. 22(a)). The abnormal growth of the boundary layer that occurs within the laminar separation bubble is not accurately predicted by the method and, therefore, the drag coefficient is underpredicted. The affected drag coefficients are indicated in figure 22 by triangles. As the Reynolds number is increased, the laminar separation bubbles decrease in size and the agreement between the theoretical and experimental drag coefficients improves significantly. The upper limit of the laminar bucket is generally overpredicted. The magnitudes of the angle of attack for zero lift coefficient and the pitching-moment coefficients are overpredicted because the boundary-layer-displacement-iteration option of the method was not used. The agreement between the theoretical and experimental lift-curve slopes and maximum lift coefficients is good. 
The comparison of theoretical and experimental section characteristics with transition fixed is shown in figure 23. The drag coefficients appear to be generally underpredicted at low and high lift coefficients because the experimental drag coefficients are probably too high because of the additional (pressure-drag) contribution due to the roughness itself, as previously discussed. Conversely, the experimental drag coefficients at lift coefficients below 0.2 for a Reynolds number of $1.0 \times 10^{6}$ (fig. 23(a)), below 0.1 for a Reynolds number of $1.5 \times 10^{6}$ (fig. 23(b)), and below -0.2 for a Reynolds number of $2.0 \times 10^{6}$ (fig. 23(c)) are too low because the roughness was too small to force transition on the upper surface. The magnitude of the angle of attack for zero lift coefficient is overpredicted because the boundary-layerdisplacement-iteration option of the method was not used. The lift-curve slopes are predicted well in spite of the fact that the experimental lift coefficients are probably too low because of the abnormal roughness effect noted previously. The maximum lift coefficients appear to be generally overpredicted because of this effect. The magnitude of the pitching-moment coefficients is also overpredicted because of this effect and because the displacement-iteration option was not used.

\section{Comparisons with Other Airfoils}

The comparisons of the section characteristics of the S809 airfoil and the NACA 4421 and 23021 airfoils (ref. 4) with transition free for a Reynolds number of $3.0 \times 10^{6}$ are shown in figures 24 and 25 , respectively. The S809 airfoil exhibits a lower maximum lift coefficient (restrained) and lower drag coefficients than do the NACA airfoils. The $\$ 809$ airfoil produces less negative pitching-moment coefficients than does the NACA 4421 airfoil and more negative ones than does the NACA 23021 airfoil. These comparisons confirm the achievement of the design objectives.

\section{Concluding Remarks}

A 21-percent-thick, laminar-flow airfoil, the $\$ 809$, for horizontal-axis wind-turbine applications has been designed and analyzed theoretically and verified experimentally in the low-turbulence wind tunnel of the Delft University of Technology Low Speed Laboratory, The Netherlands. The two primary objectives of restrained maximum lift, insensitive to roughness, and low profile drag have been achieved. In addition, the airfoil exhibits a docile stall. Comparisons of the theoretical and experimental results show good agreement. Comparisons with other airfoils illustrate the restrained maximum lift coefficient as well as the lower profile-drag coefficients, thus confirming the achievement of the primary objectives.

\section{Acknowledgments}

The assistance of the staff of the Low Speed Laboratory of the Delft University of Technology is gratefully acknowledged. In particular, the meticulous and persistent efforts of Loek M. M. Boermans are sincerely appreciated. Finally, the able assistance of James L. Tangler of the Solar Energy Research Institute is gladly noted.

\section{$\underline{\text { References }}$}

1. Jacobs, Eastman N.; Ward, Kenneth E.; and Pinkerton, Robert M.: The Characteristics of 78 Related Airfoil Sections from Tests in the Variable-Density Wind Tunnel. NACA Rep. 460, 1933.

2. Jacobs, Eastman N.; and Pinkerton, Robert M.: Tests in the Variable-Density Wind Tunnel of Related Airfoils Having the Maximum Camber Unusually far Forward. NACA Rep. 537, 1935. 
3. Jacobs, Eastman N.; Pinkerton, Robert M.; and Greenberg, Harry: Tests of Related Forward-Camber Airfoils in the Variable-Density Wind Tunnel. NACA Rep. 610, 1937.

4. Abbott, Ira H.; Von Doenhoff, Albert E.; and Stivers, Louis S., Jr.: Surnmary of Airfoil Data. NACA Rep. 824, 1945. (Supersedes NACA WR L-560.)

5. Abbott, Ira H.; and Von Doenhoff, Albert E.: Theory of Wing Sections. Dover Publ., Inc., c.1959.

6. McGhee, Robert J.; Beasley, William D.; and Whitcomb, Richard T.: NASA Low- and MediumSpeed Airfoil Development. NASA TM-78709, 1979.

7. Eppler, Richard; and Somers, Dan M.: A Computer Program for the Design and Analysis of LowSpeed Airfoils. NASA TM-80210, 1980.

8. Eppler, Richard; and Somers, Dan M.: Supplement To: A Computer Program for the Design and Analysis of Low-Speed Airfoils. NASA TM-81862, 1980.

9. Somers, Dan M.: The S809 through S813 Airfoils. Airfoils, Inc., 1988. [Proprietary to NREL]

10. van Ingen, J. L.; Boermans, L. M. M.; and Blom, J. J. H.: Low-Speed Airfoil Section Research at Delft University of Technology. ICAS-80-10.1, Munich, Oct. 1980.

11. Wortmann, F. X.: Experimental Investigations on New Laminar Profiles for Gliders and Helicopters. TIL/T.4906, British Minist. Aviat., Mar. 1960. (Translated from Z. Flugwissenschaften, Bd. 5, Heft 8, Aug. 1957, S. 228-243.)

12. The Cambridge University Aeronautics Laboratory: The Measurement of Profile Drag by the PitotTraverse Method. R. \& M. No. 1688, British A.R.C., 1937.

13. Allen, H. Julian; and Vincenti, Walter G.: Wall Interference in a Two-Dimensional-Flow Wind Tunnel, With Consideration of the Effect of Compressibility. NACA Rep. 782, 1944. (Supersedes NACA WR A-63.)

14. Hoerner, Sighard F.: Fluid-Dynamic Drag. Published by the author (Midland Park, New Jersey), 1965.

15. Braslow, Albert L; and Knox, Eugene C.: Simplified Method for Determination of Critical Height of Distributed Roughness Particles for Boundary-Layer Transition at Mach Numbers From 0 to 5. NACA TN 4363, 1958.

16. Loving, Donald L.; and Katzoff, S.: The Fluorescent-Oil Film Method and Other Techniques for Boundary-Layer Flow Visualization. NASA MEMO 3-17-59L, 1959.

17. Pfenninger, Werner: Investigations on Reductions of Friction on Wings, in Particular by Means of Boundary Layer Suction. NACA TM 1181, 1947.

18. van Ingen, J. L.; and Boermans, L. M. M.: Research on Laminar Separation Bubbles at Delft University of Technology in Relation to Low Reynolds Number Airfoil Aerodynamics. Proceedings of the Conference on Low Reynolds Number Airfoil Aerodynamics, UNDAS-CP-77B123, Univ. of Notre Dame, June 1985, pp. 89-124. 
Table 1. Airfoil Design Specifications

\begin{tabular}{l|c}
\hline \hline Minimum lift coefficient & - \\
\hline Maximum lift coefficient & 1.0 \\
\hline "Design" lift coefficient & 0.5 \\
\hline Lower limit of laminar bucket & 0.2 \\
\hline Upper limit of laminar bucket & 0.8 \\
\hline Zero-lift pitching-moment coefficient & $2-0.05$ \\
\hline Reynolds number & $2.0 \times 10^{6}$ \\
\hline Thickness & $0.21 \mathrm{c}$ \\
\hline \hline
\end{tabular}


Table 2. S809 Airfoil Coordinates

\begin{tabular}{|c|c|c|c|}
\hline \multicolumn{2}{|c|}{ Upper Surface } & \multicolumn{2}{|c|}{ Lower Surface } \\
\hline$x / c$ & $\mathrm{z} / \mathrm{c}$ & $x / c$ & $\mathrm{z} / \mathrm{c}$ \\
\hline 0.00037 & 0.00275 & 0.00140 & -0.00498 \\
\hline .00575 & .01166 & .00933 & -.01272 \\
\hline .01626 & .02133 & .02321 & -.02162 \\
\hline .03158 & .03136 & .04223 & -.03144 \\
\hline .05147 & .04143 & .06579 & -.04199 \\
\hline .07568 & .05132 & .09325 & -.05301 \\
\hline .10390 & .06082 & .12397 & -.06408 \\
\hline .13580 & .06972 & .15752 & -.07467 \\
\hline .17103 & .07786 & .19362 & -.08447 \\
\hline .20920 & .08505 & .23175 & -.09326 \\
\hline .24987 & .09113 & .27129 & -.10060 \\
\hline .29259 & .09594 & .31188 & -.10589 \\
\hline .33689 & .09933 & .35328 & -.10866 \\
\hline .38223 & .10109 & .39541 & -.10842 \\
\hline .42809 & .10101 & .43832 & -.10484 \\
\hline .47384 & .09843 & .48234 & -.09756 \\
\hline .52005 & .09237 & .52837 & -.08697 \\
\hline .56801 & .08356 & .57663 & -.07442 \\
\hline .61747 & .07379 & .62649 & -.06112 \\
\hline .66718 & .06403 & .67710 & -.04792 \\
\hline .71606 & .05462 & .72752 & -.03558 \\
\hline .76314 & .04578 & .77668 & -.02466 \\
\hline .80756 & .03761 & .82348 & -.01559 \\
\hline .84854 & .03017 & .86677 & -.00859 \\
\hline .88537 & .02335 & .90545 & -.00370 \\
\hline .91763 & .01694 & .93852 & -.00075 \\
\hline .94523 & .01101 & .96509 & .00054 \\
\hline .96799 & .00600 & .98446 & .00065 \\
\hline .98528 & .00245 & .99612 & .00024 \\
\hline .99623 & .00054 & 1.00000 & .00000 \\
\hline 1.00000 & .00000 & & \\
\hline
\end{tabular}


Table 3. Model Orifice Locations

\begin{tabular}{|c|c|c|c|c|c|}
\hline \multicolumn{3}{|c|}{ Upper Surface } & \multicolumn{3}{|c|}{ Lower Surface } \\
\hline $\mathrm{x} / \mathrm{c}$ & $\mathrm{x}, \mathrm{mm}$ & $\mathrm{y}, \mathrm{mm}$ & $\mathrm{x} / \mathrm{c}$ & $\mathrm{x}, \mathrm{mm}$ & $\mathrm{y}, \mathrm{mm}$ \\
\hline 0.000 & 0.0 & 127.0 & 0.002 & 1.2 & 128.0 \\
\hline .002 & 1.2 & 200.0 & .004 & 2.4 & 129.0 \\
\hline .004 & 2.4 & 199.0 & .006 & 3.6 & 130.0 \\
\hline .006 & 3.6 & 198.0 & .008 & 4.8 & 131.0 \\
\hline .008 & 4.8 & 197.0 & .012 & 7.2 & 132.0 \\
\hline .012 & 7.2 & 196.0 & .016 & 9.6 & 133.0 \\
\hline .016 & 9.6 & 195.0 & .020 & 12.0 & 134.0 \\
\hline .020 & 12.0 & 194.0 & .024 & 14.4 & 135.0 \\
\hline .024 & 14.4 & 193.0 & .028 & 16.8 & 136.0 \\
\hline .028 & 16.8 & 192.0 & .032 & 19.2 & 137.0 \\
\hline .032 & 19.2 & 191.0 & .040 & 24.0 & 138.0 \\
\hline .040 & 24.0 & 190.0 & .048 & 28.8 & 139.0 \\
\hline .048 & 28.8 & 189.0 & .064 & 38.4 & 141.0 \\
\hline .064 & 38.4 & 187.0 & .100 & 60.0 & 145.0 \\
\hline .100 & 60.0 & 183.0 & .150 & 90.0 & 150.0 \\
\hline .150 & 90.0 & 178.0 & .200 & 120.0 & 155.0 \\
\hline .200 & 120.0 & 173.0 & .250 & 150.0 & 160.0 \\
\hline .250 & 150.0 & 168.0 & .300 & 180.0 & 165.0 \\
\hline .300 & 180.0 & 163.0 & .350 & 210.0 & 170.0 \\
\hline .350 & 210.0 & 158.0 & .400 & 240.0 & 175.0 \\
\hline .400 & 240.0 & 153.0 & .410 & 246.0 & 176.0 \\
\hline .450 & 270.0 & 148.0 & .420 & 252.0 & 177.0 \\
\hline .460 & 276.0 & 147.0 & .430 & 258.0 & 178.0 \\
\hline .470 & 282.0 & 146.0 & .440 & 264.0 & 179.0 \\
\hline .480 & 288.0 & 145.0 & .450 & 270.0 & 180.0 \\
\hline .490 & 294.0 & 144.0 & .460 & 276.0 & 181.0 \\
\hline .500 & 300.0 & 143.0 & .470 & 282.0 & 182.0 \\
\hline .510 & 306.0 & 142.0 & .480 & 288.0 & 183.0 \\
\hline .520 & 312.0 & 141.0 & .490 & 294.0 & 184.0 \\
\hline .530 & 318.0 & 140.0 & .500 & 300.0 & 185.0 \\
\hline .540 & 324.0 & 139.0 & .510 & 306.0 & 186.0 \\
\hline
\end{tabular}


Table 3. Model Orifice Locations (Concluded)

\begin{tabular}{|c|c|c|c|c|c|}
\hline \multicolumn{3}{|c|}{ Upper Surface } & \multicolumn{3}{|c|}{ Lower Surface } \\
\hline $\mathrm{x} / \mathrm{c}$ & $\mathrm{x}, \mathrm{mm}$ & $\mathrm{y}, \mathrm{mm}$ & $\mathrm{x} / \mathrm{c}$ & $\mathrm{x}, \mathrm{mm}$ & $\mathrm{y}, \mathrm{mm}$ \\
\hline .550 & 330.0 & 138.0 & .520 & 312.0 & 187.0 \\
\hline .560 & 336.0 & 137.0 & .530 & 318.0 & 188.0 \\
\hline .570 & 342.0 & 136.0 & .540 & 324.0 & 189.0 \\
\hline .580 & 348.0 & 135.0 & .550 & 330.0 & 190.0 \\
\hline .590 & 354.0 & 134.0 & .560 & 336.0 & 191.0 \\
\hline .600 & 360.0 & 133.0 & .570 & 342.0 & 192.0 \\
\hline .610 & 366.0 & 132.0 & .580 & 348.0 & 193.0 \\
\hline .620 & 372.0 & 131.0 & .590 & 354.0 & 194.0 \\
\hline .630 & 378.0 & 130.0 & .600 & 360.0 & 195.0 \\
\hline .640 & 384.0 & 129.0 & .610 & 366.0 & 196.0 \\
\hline .650 & 390.0 & 128.0 & .620 & 372.0 & 197.0 \\
\hline .700 & 420.0 & 133.0 & .630 & 378.0 & 198.0 \\
\hline .750 & 450.0 & 138.0 & .640 & 384.0 & 199.0 \\
\hline .800 & 480.0 & 143.0 & .650 & 390.0 & 200.0 \\
\hline .850 & 510.0 & 148.0 & .700 & 420.0 & 195.0 \\
\hline .880 & 528.0 & 151.0 & .750 & 450.0 & 190.0 \\
\hline .900 & 540.0 & 153.0 & .800 & 480.0 & 185.0 \\
\hline .920 & 552.0 & 155.0 & .850 & 510.0 & 180.0 \\
\hline .940 & 564.0 & 157.0 & .880 & 528.0 & 177.0 \\
\hline .960 & 576.0 & 159.0 & .900 & 540.0 & 175.0 \\
\hline .980 & 588.0 & 161.0 & .920 & 552.0 & 173.0 \\
\hline \multirow[t]{3}{*}{1.000} & 600.0 & 165.0 & .940 & 564.0 & 171.0 \\
\hline & & & .960 & 576.0 & 169.0 \\
\hline & & & .980 & 588.0 & 167.0 \\
\hline
\end{tabular}

$c=600.00 \mathrm{~mm}(23.622$ in. $)$ 
Table 4. Roughness Size and Location

\begin{tabular}{c|c|c|c|c|c|c}
\hline \hline \multicolumn{3}{c}{ Upper Surface } & \multicolumn{3}{c}{ Lower Surface } \\
\cline { 2 - 7 } $\begin{array}{c}\text { Reynolds } \\
\text { Number }\end{array}$ & $\begin{array}{c}\text { Grit } \\
\text { Number }\end{array}$ & $\begin{array}{c}\text { Nominal } \\
\text { Size, mm/in. }\end{array}$ & $\mathrm{x} / \mathrm{c}$ & $\begin{array}{c}\text { Grit } \\
\text { Number }\end{array}$ & $\begin{array}{c}\text { Nominal } \\
\text { Size, mm/in. }\end{array}$ & $\mathrm{x} / \mathrm{c}$ \\
\hline \hline $1.0 \times 10^{6}$ & 80 & $0.211 / 0.0083$ & 0.02 & 46 & $0.419 / 0.0165$ & 0.05 \\
\hline $1.5 \times 10^{6}$ & 120 & $.124 / .0049$ & .02 & 70 & $.249 / .0098$ & .05 \\
\hline $2.0 \times 10^{6}$ & 120 & $.124 / .0049$ & .02 & 70 & $.249 / .0098$ & .05 \\
\hline $2.5 \times 10^{6}$ & 120 & $.124 / .0049$ & .02 & 70 & $.249 / .0098$ & .05 \\
\hline $3.0 \times 10^{6}$ & 120 & $.124 / .0049$ & .02 & 70 & $.249 / .0098$ & .05 \\
\hline \hline
\end{tabular}




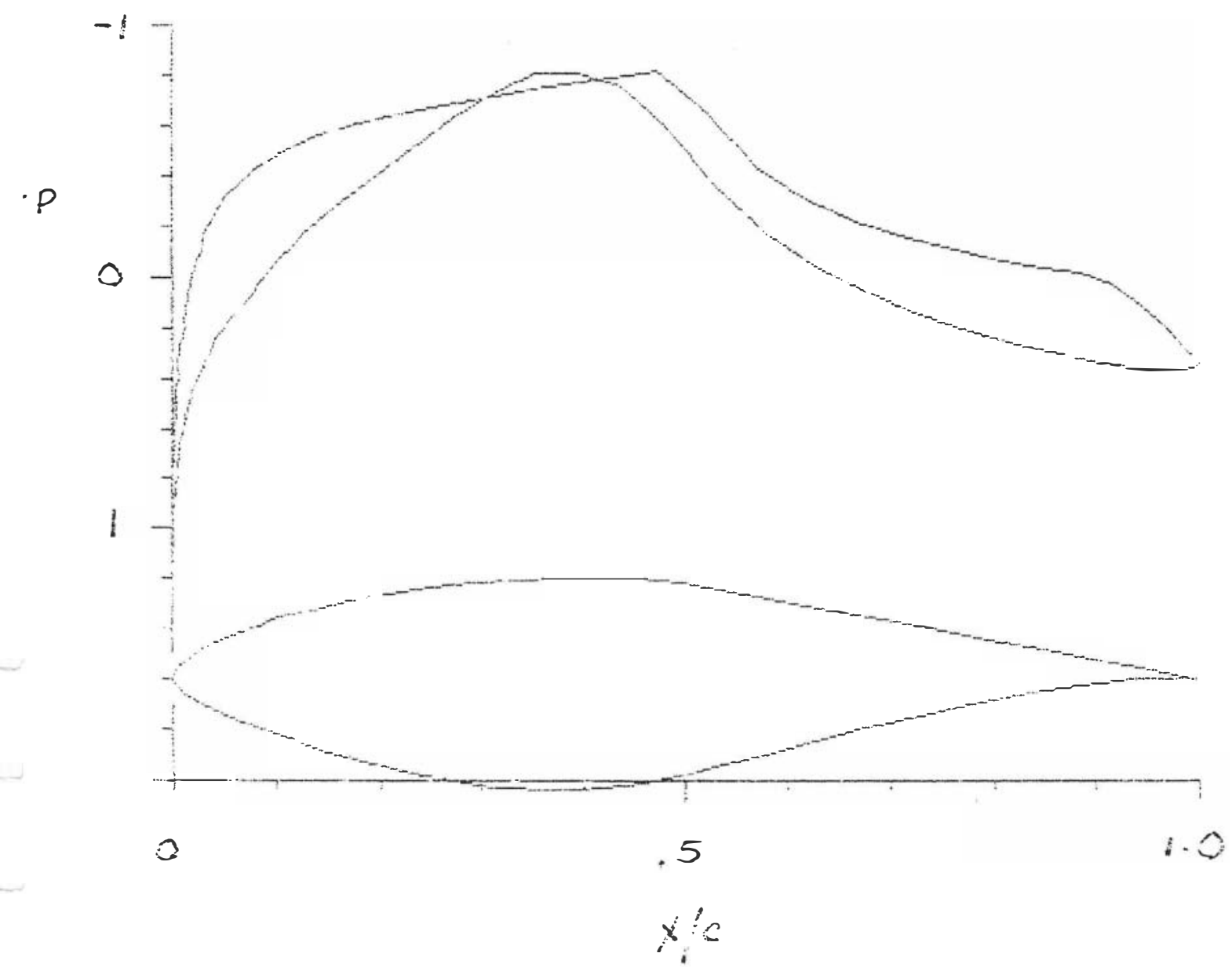

(a) $c_{2}=0.2$.

Figure 1. - Inviscid pressure distributions. 


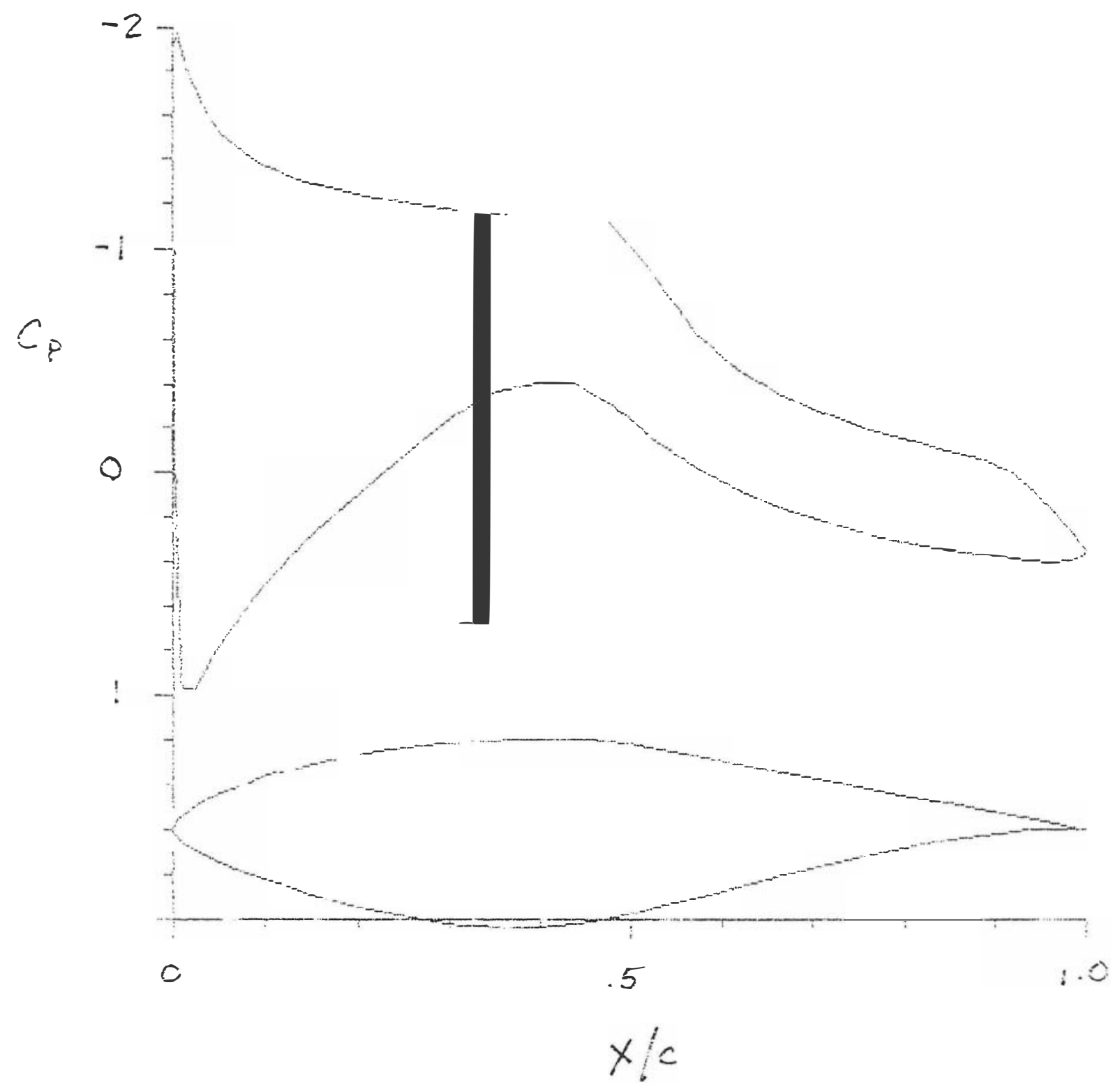

(b) $c_{2}=0.8$

Figure 1.- Concluded. 


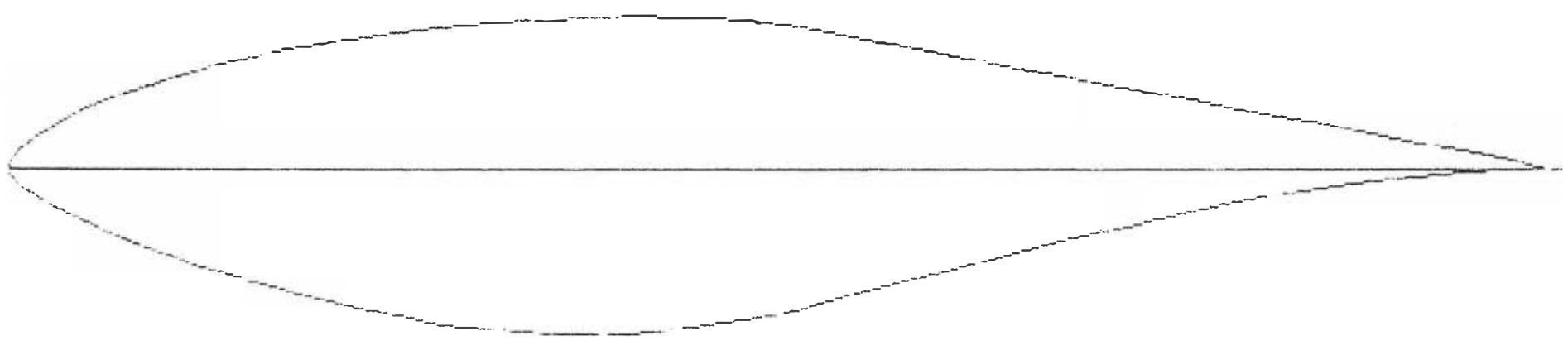

Eigure 2.-5809 airfoil shape. 


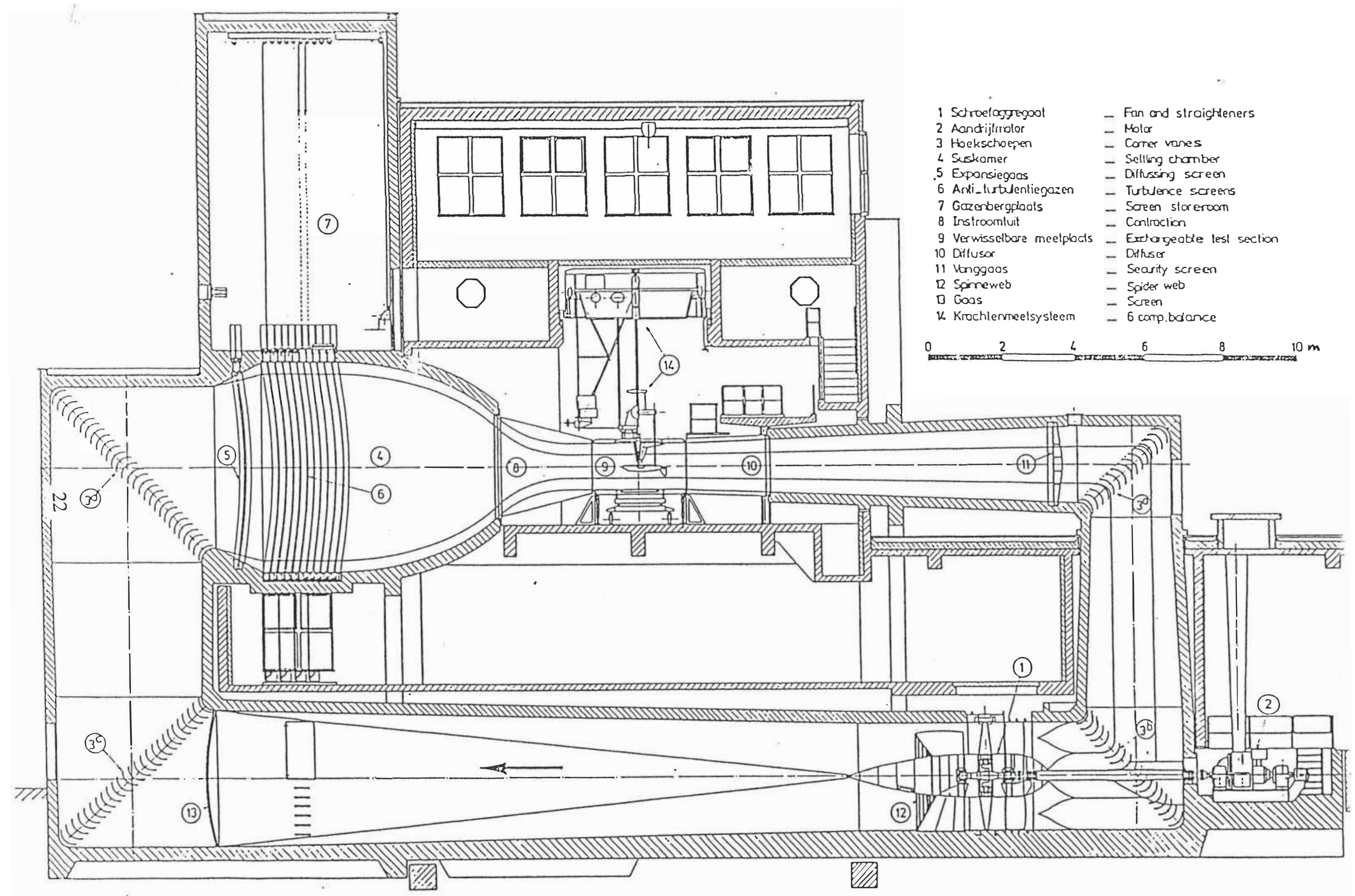

Figure 3. - Delft University of Technology $1.80-81.25$-m low-speed wind tunnel. 

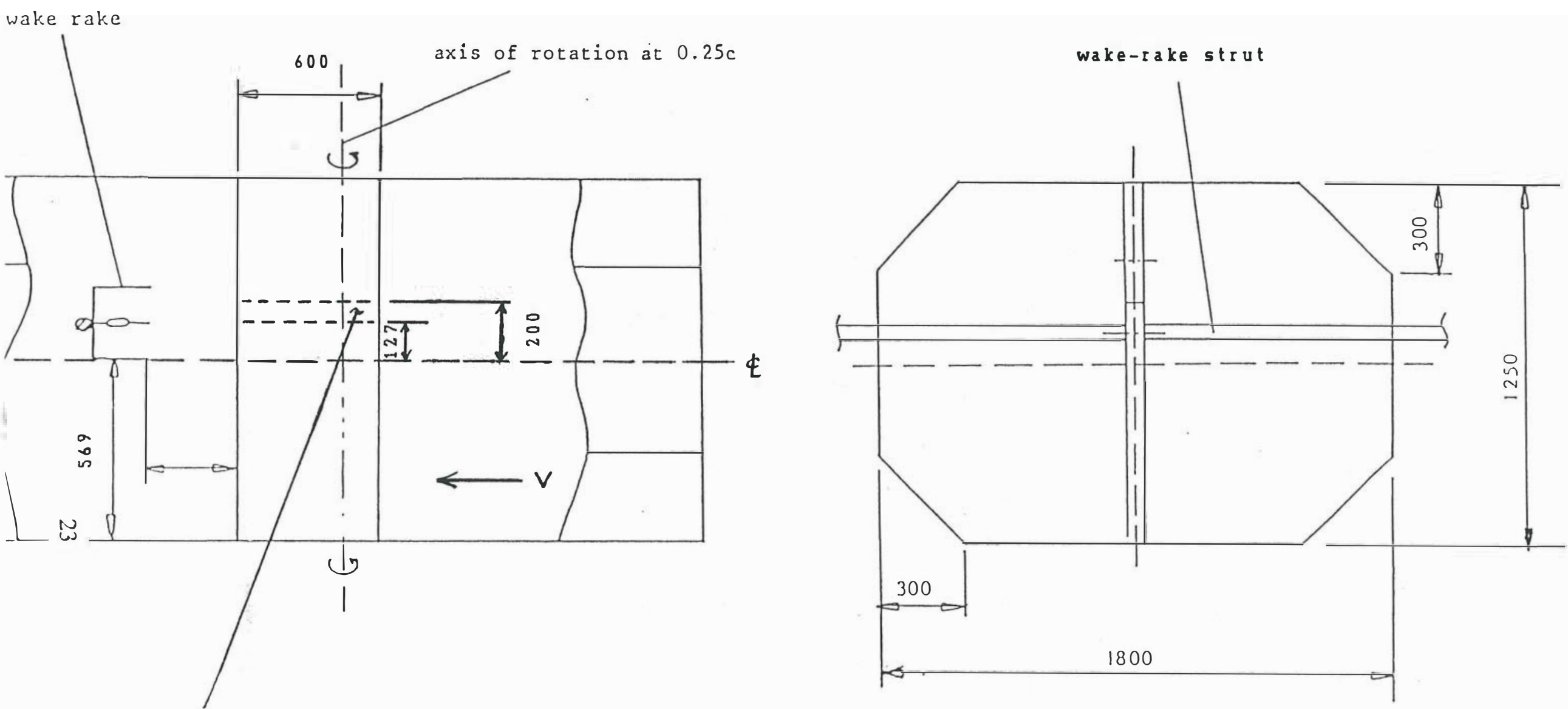

region of pressure orifices

Figure 4.- Model and wake rakes mounted in test section. All dimensions are in $\mathrm{mm}$. 


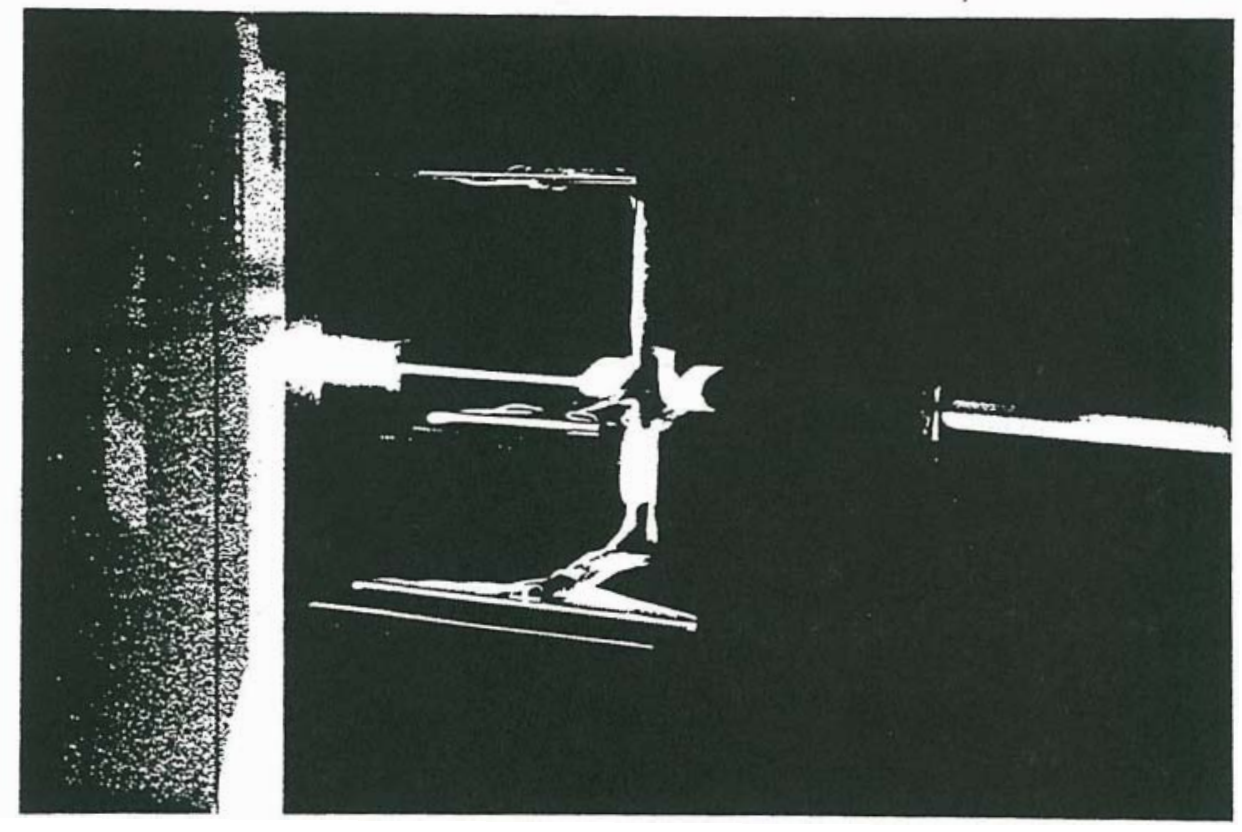

Eigure 5. - Photograph of wake rakes mounted on strut. 


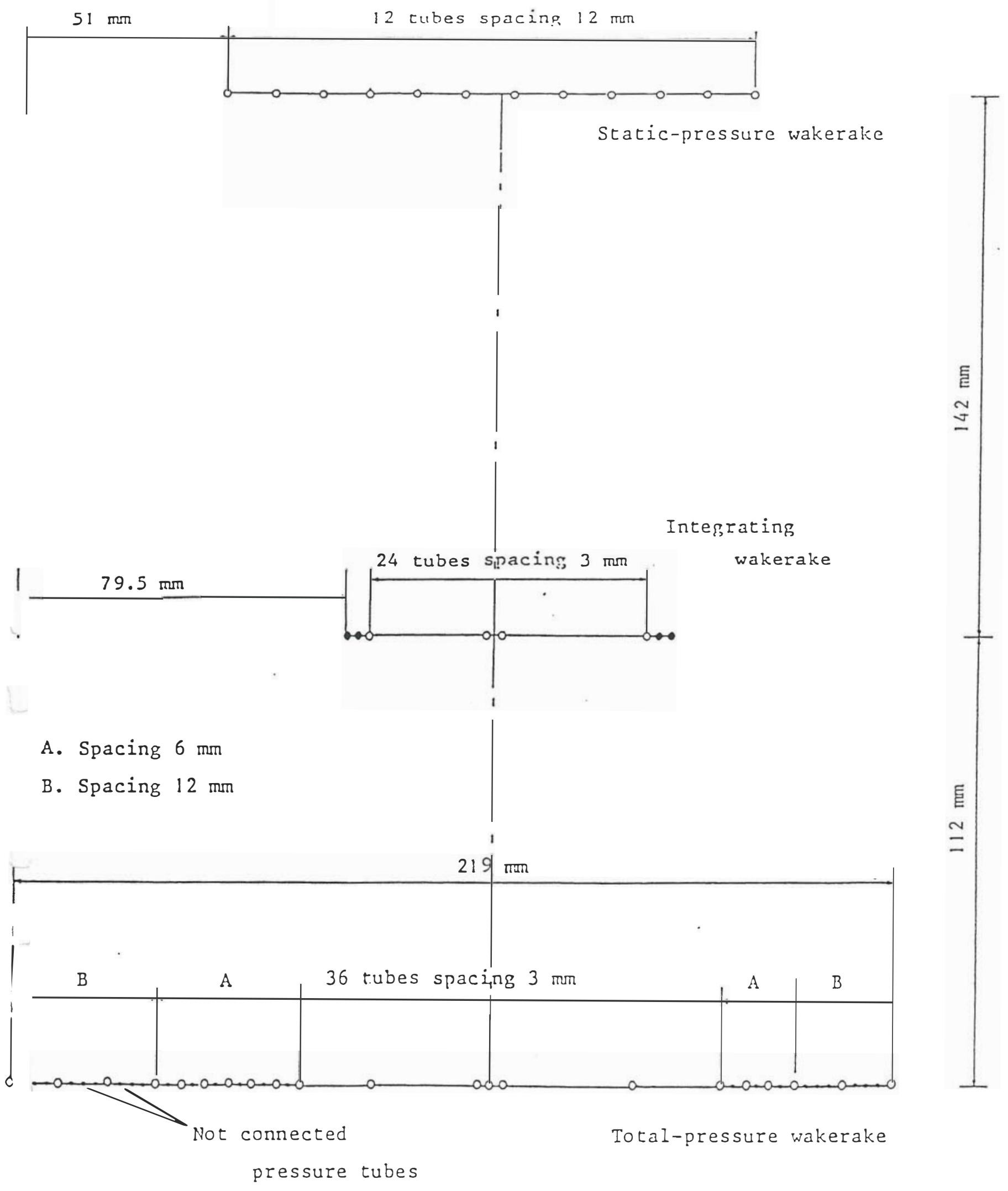

Figure 6.- Wake rakes. 


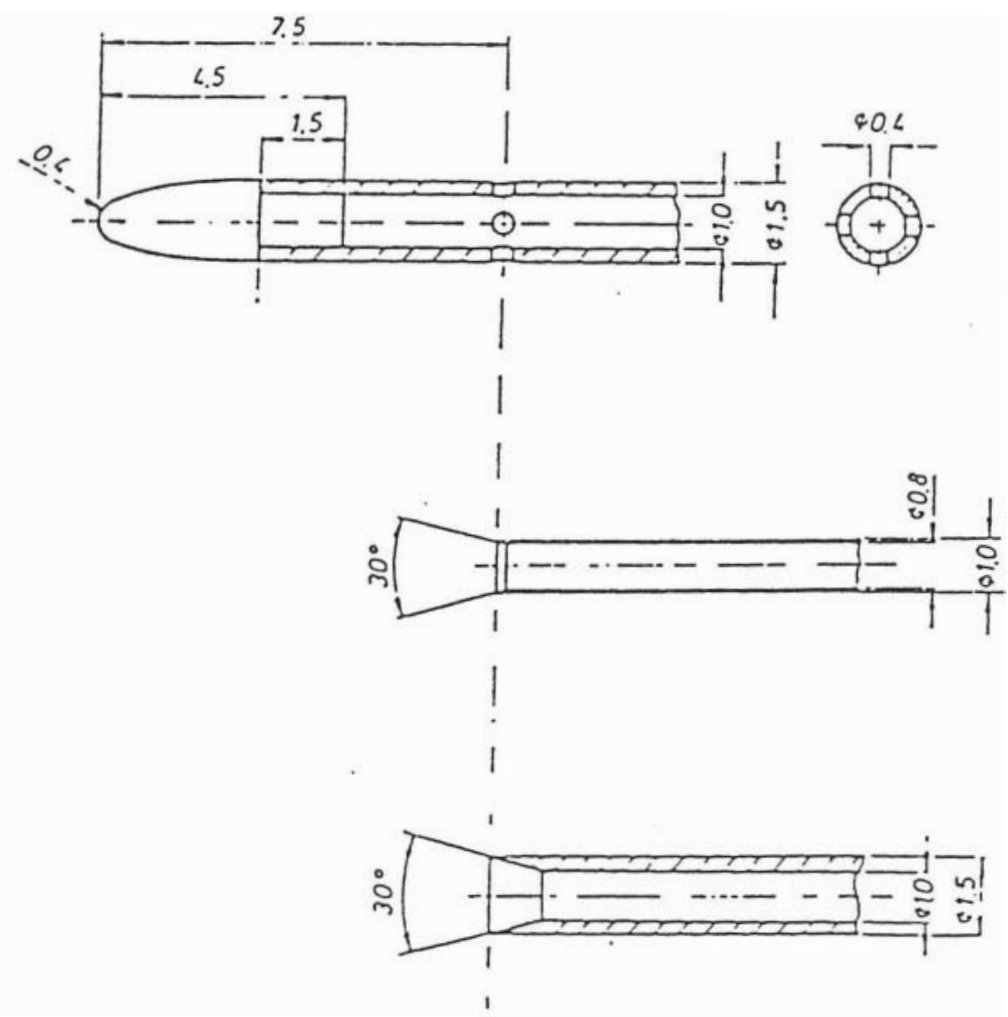

Figure 7. - Static-pressure, integrating, and total-pressure wake-rake tubes. All dimensions are in mm. 


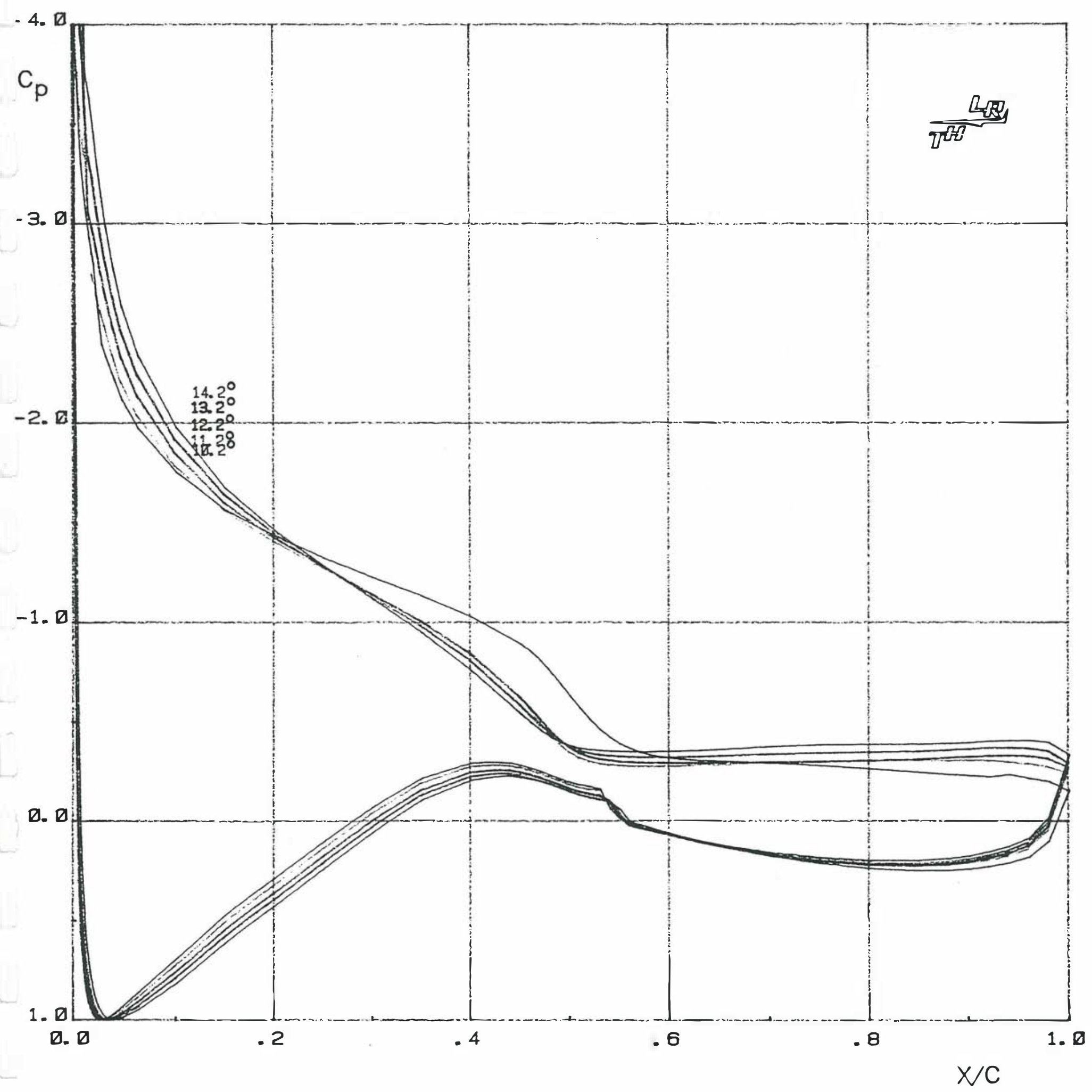

(a) $\alpha=10.21,11.21,12.22,13.24$, and 14.24 degrees.

Figure 8. - Continued 


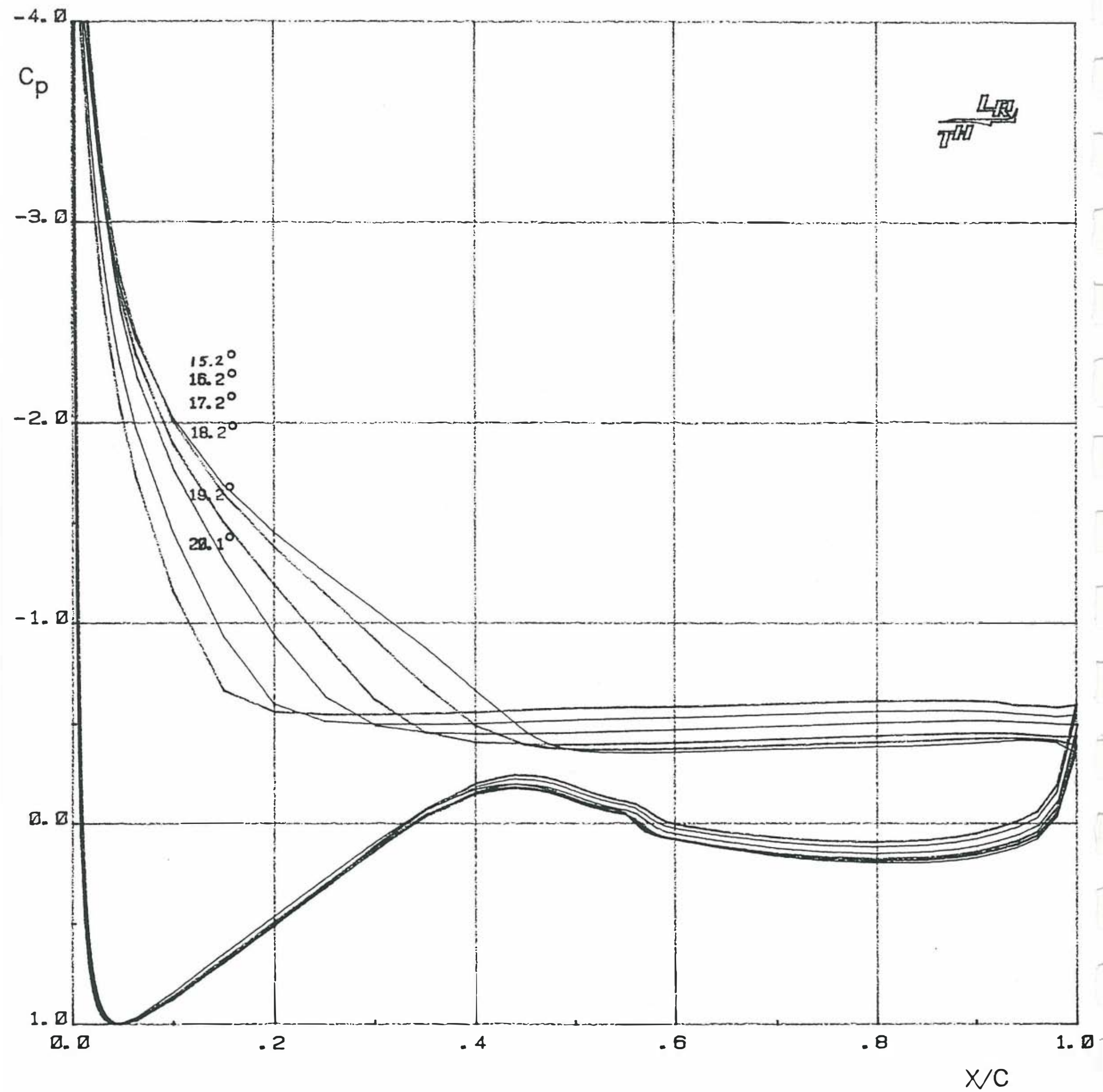

(d) $\alpha=15.24,16.24,17.23,18.20,19.17$, and 20.15 degrees.

Figure 8. - Continued 


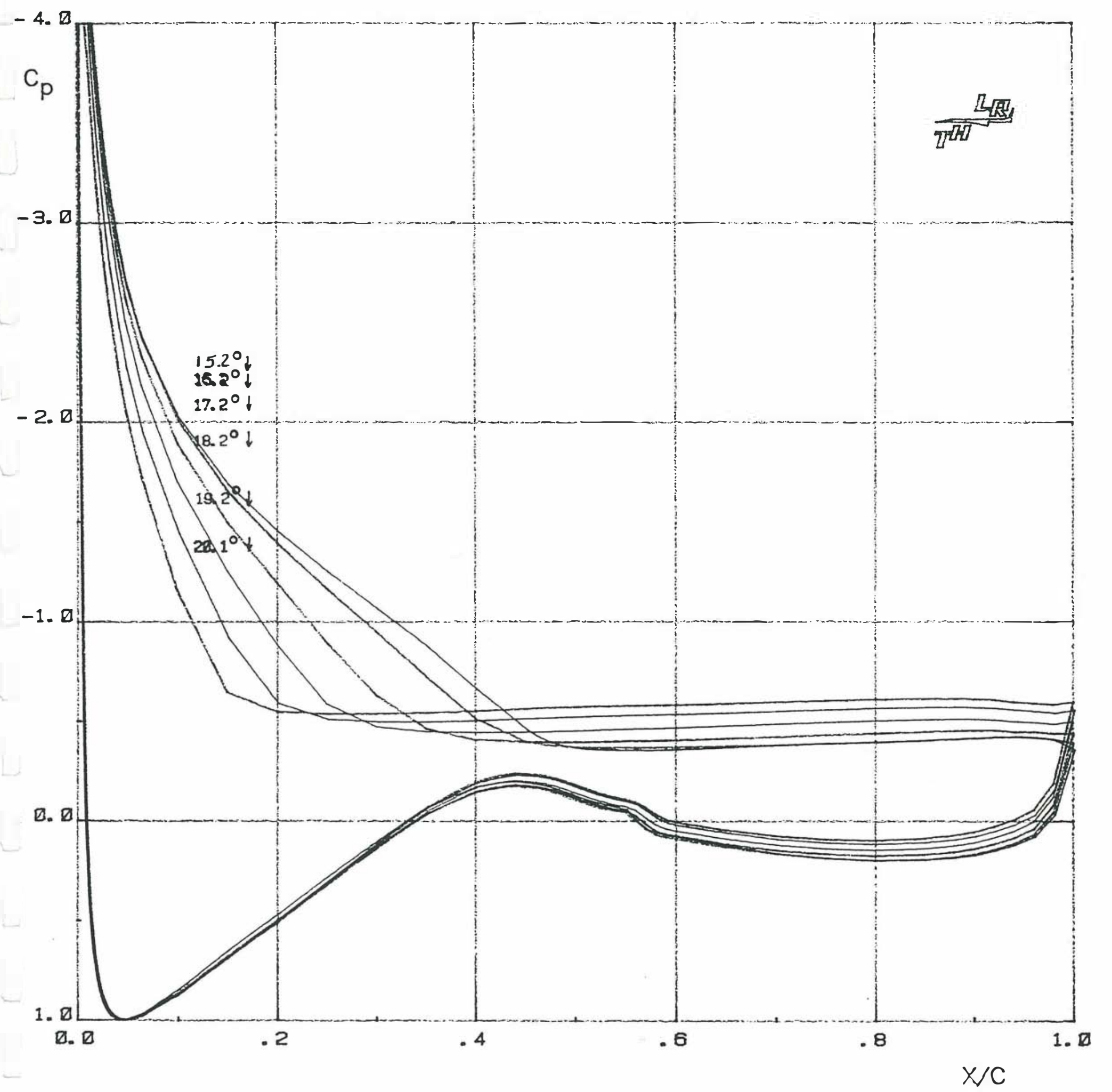

(e) $\alpha=20.14 \downarrow, 19.16 \downarrow, 18.19 \downarrow, 17.22 \downarrow, 16.24 \downarrow$, and $15.24 \downarrow$ degrees.

Figure 8. - Continued. 


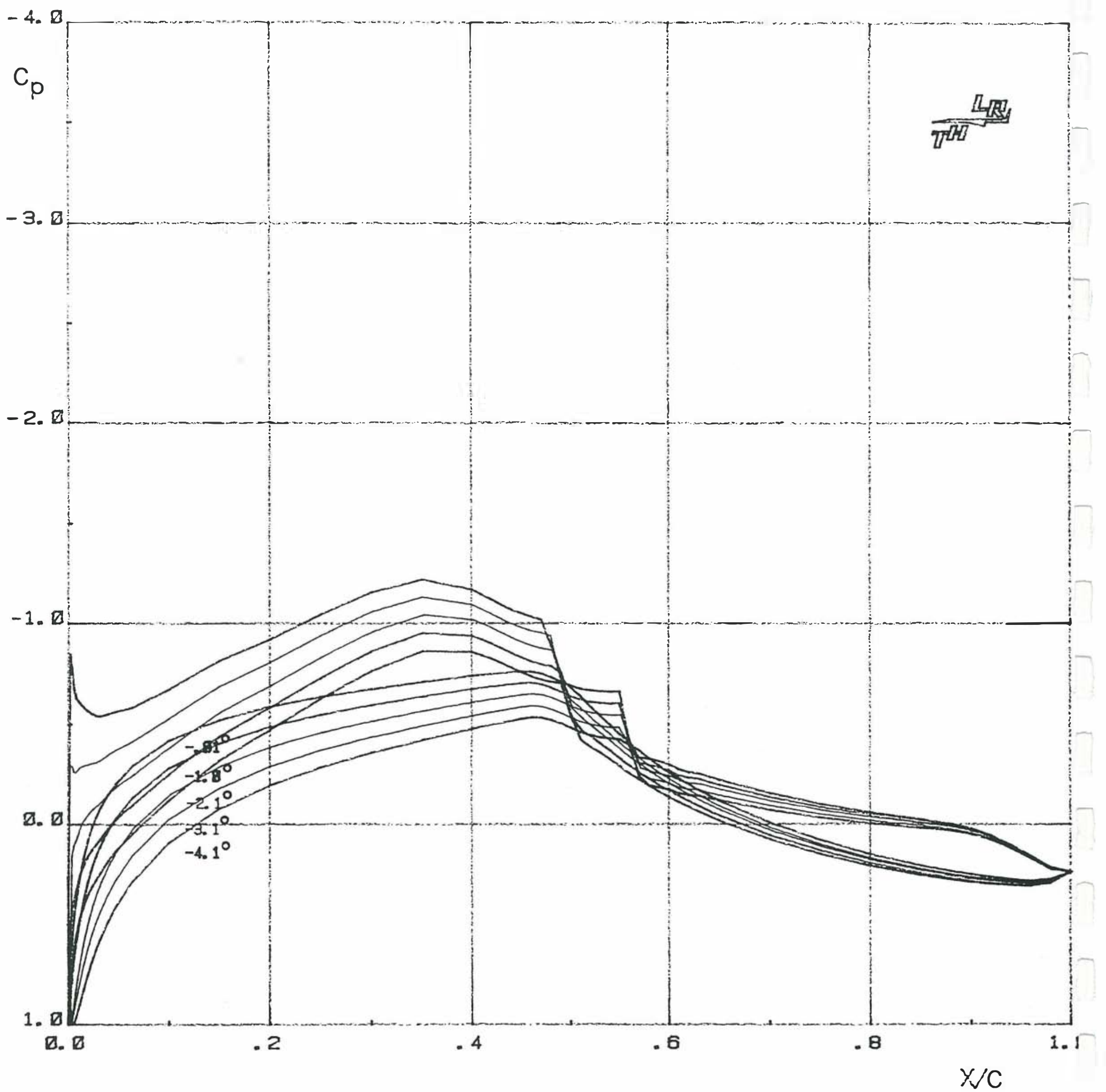

(f) $\alpha=-0.01,-1.04,-2.06,-3.09$, and -4.12 degrees.

Figure 8. - Continued. 


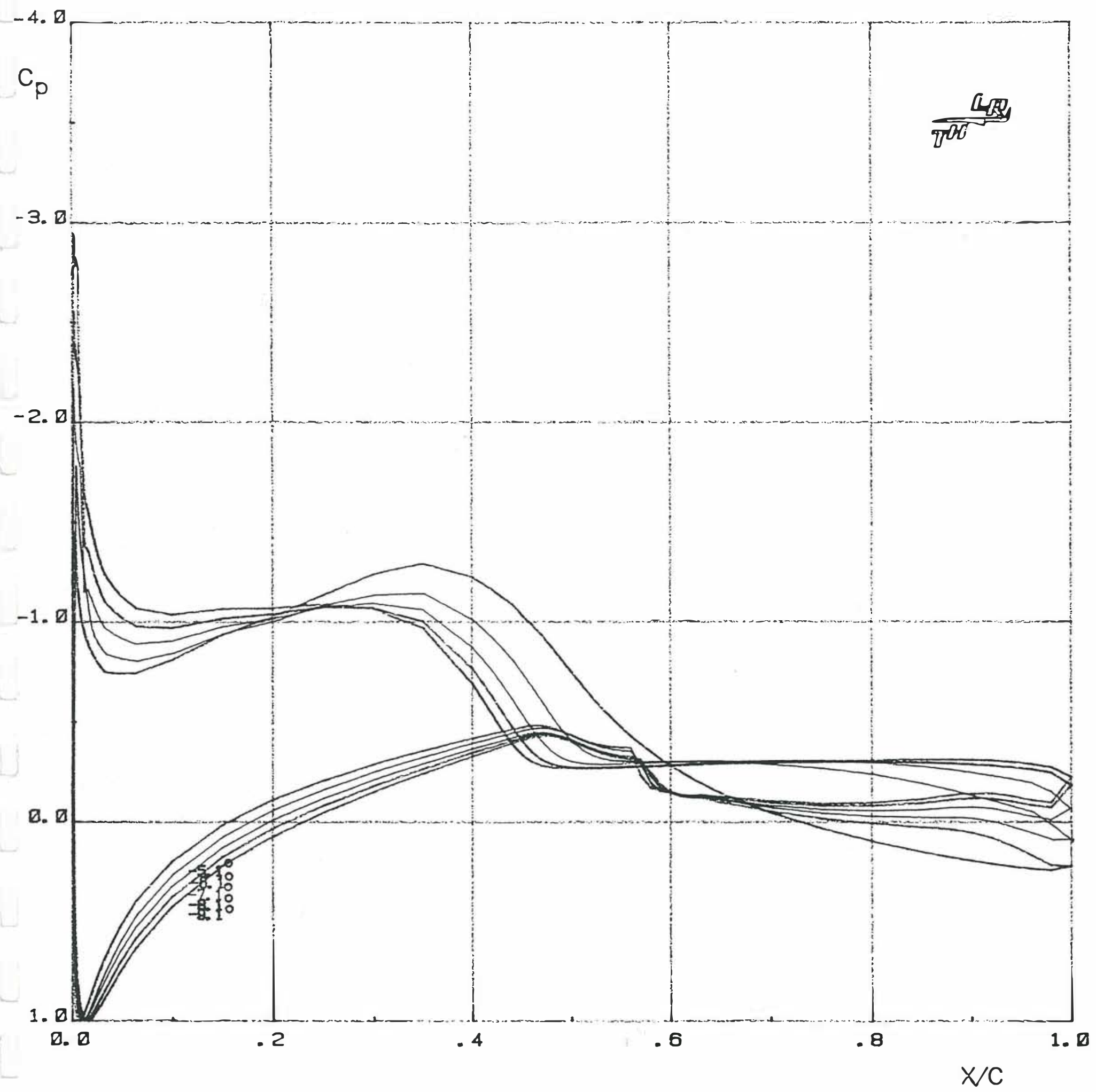

(g) $\alpha=-5.14,-6.12,-7.13,-8.14$, and -9.15 degrees.

Figure 8.- Continued. 


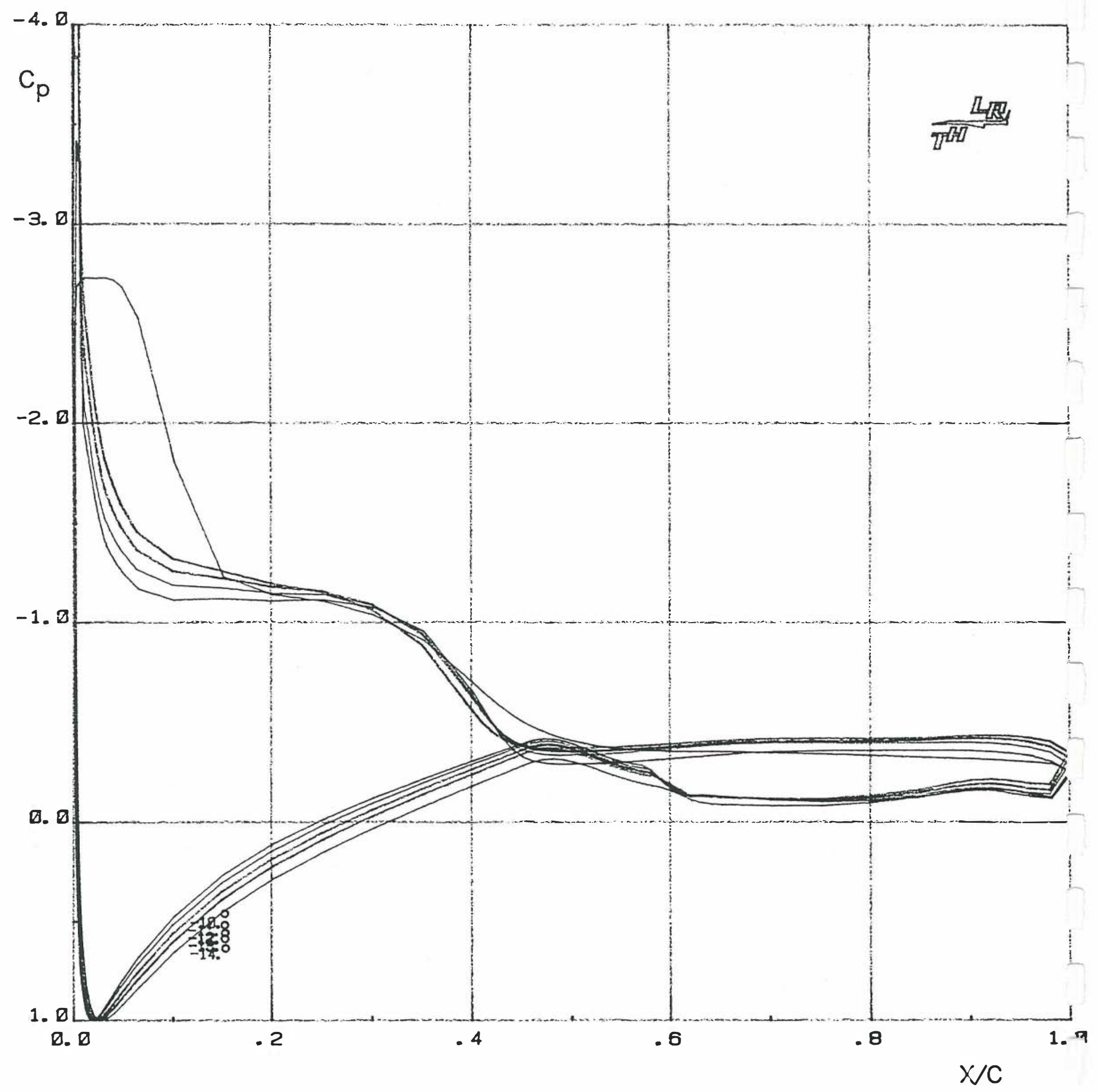

(h) $\alpha=-10.16,-11.17,-12.18,13.19$, and -14.23 degrees.

Figure 8.- Continued 


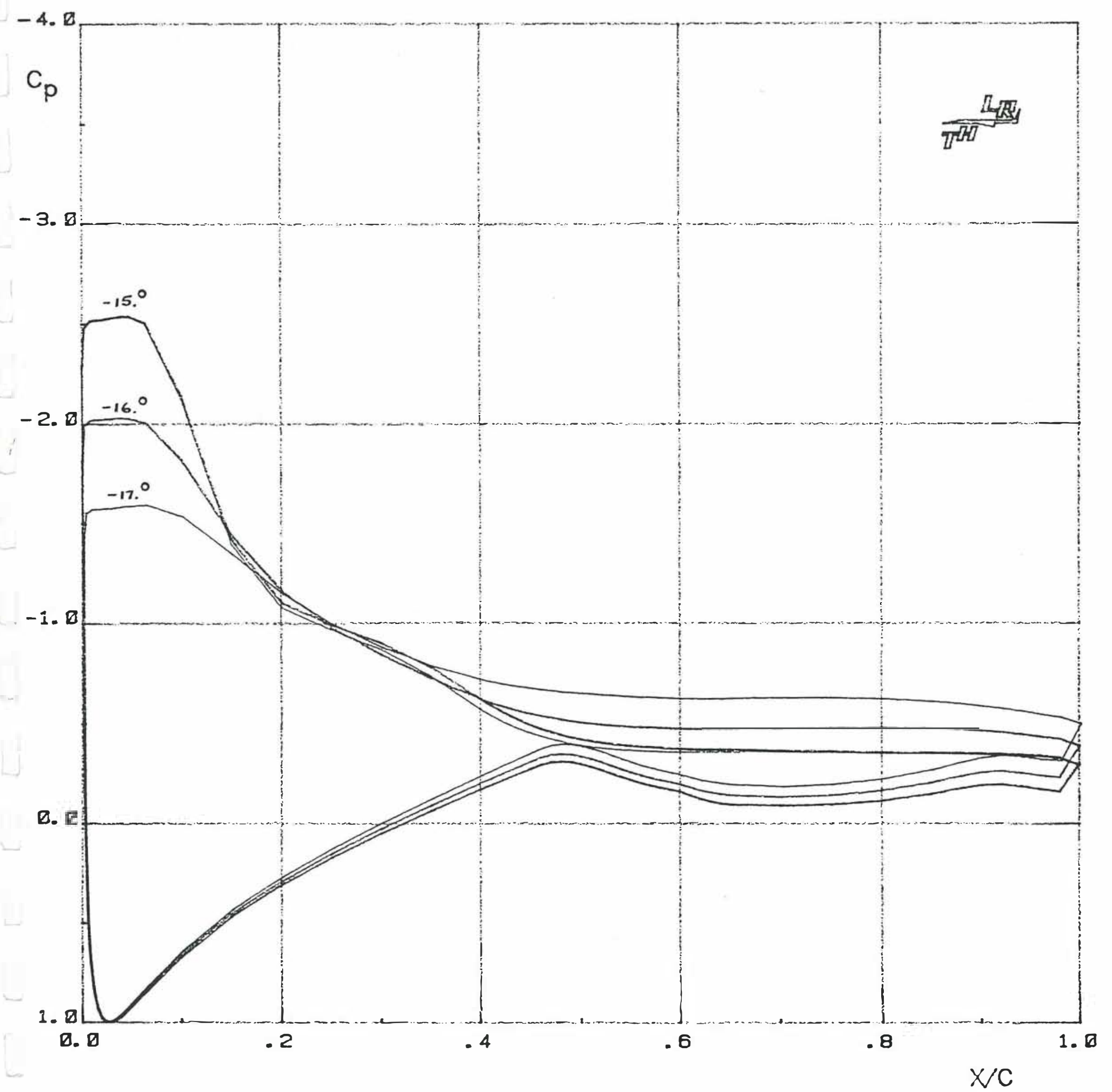

(i) $\alpha=-15.23,-15.23,-16.20$, and -17.17 degrees.

Figure 8.- Continued. 


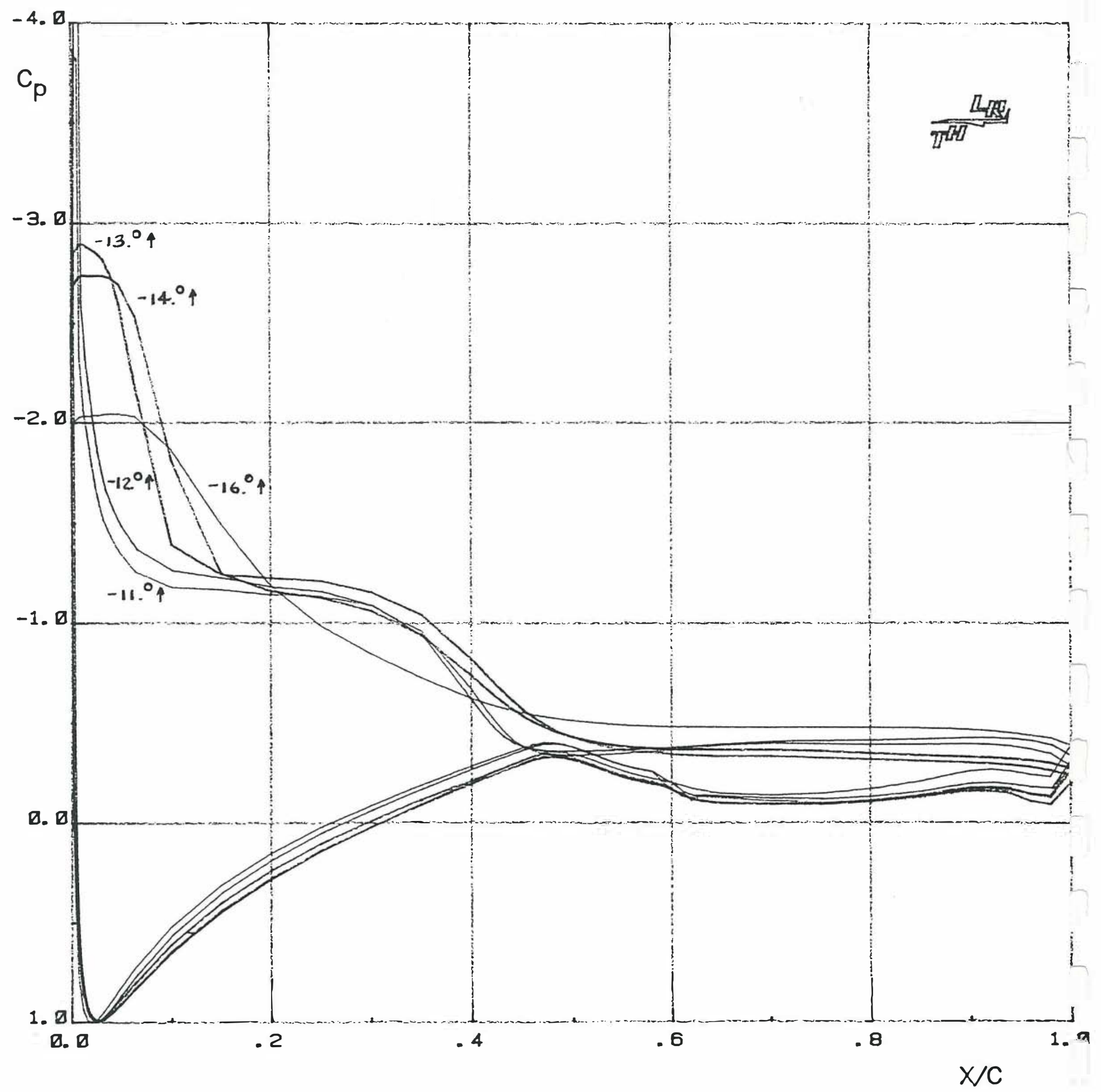

(j) $\alpha=-16.20 \uparrow,-14.23 \uparrow,-13.23 \uparrow,-12.17 \uparrow$, and $-11.17 \uparrow$ degrees.

Eigure 8. - Concluded. 


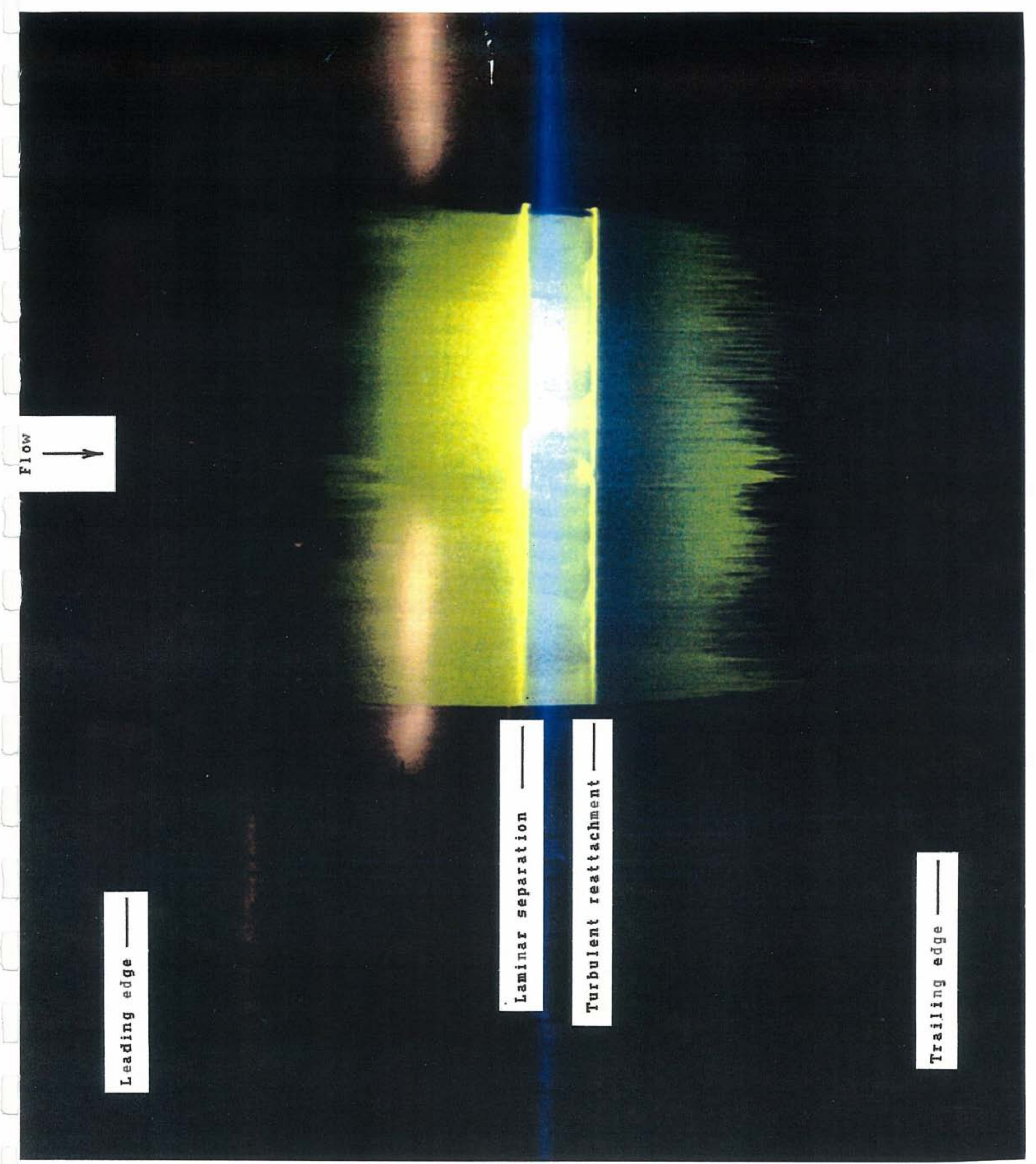

(a) $\alpha=0.0$ degrees.

Figure 9.- Oil-flow photographs of upper surface for $R=1,000,000$. 


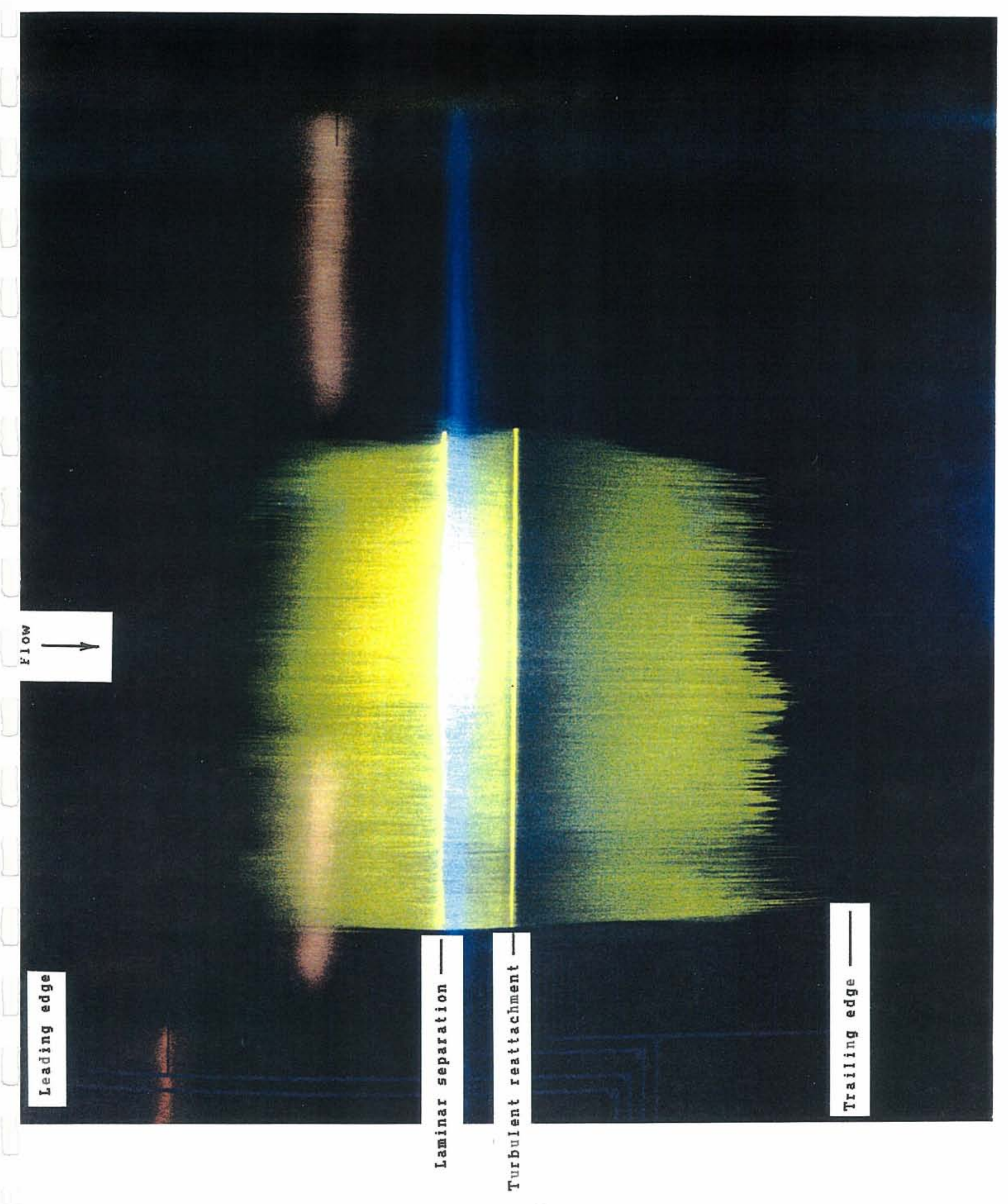

(b) $\alpha=2.1$ degrees.

Figure 9. - Continued. 


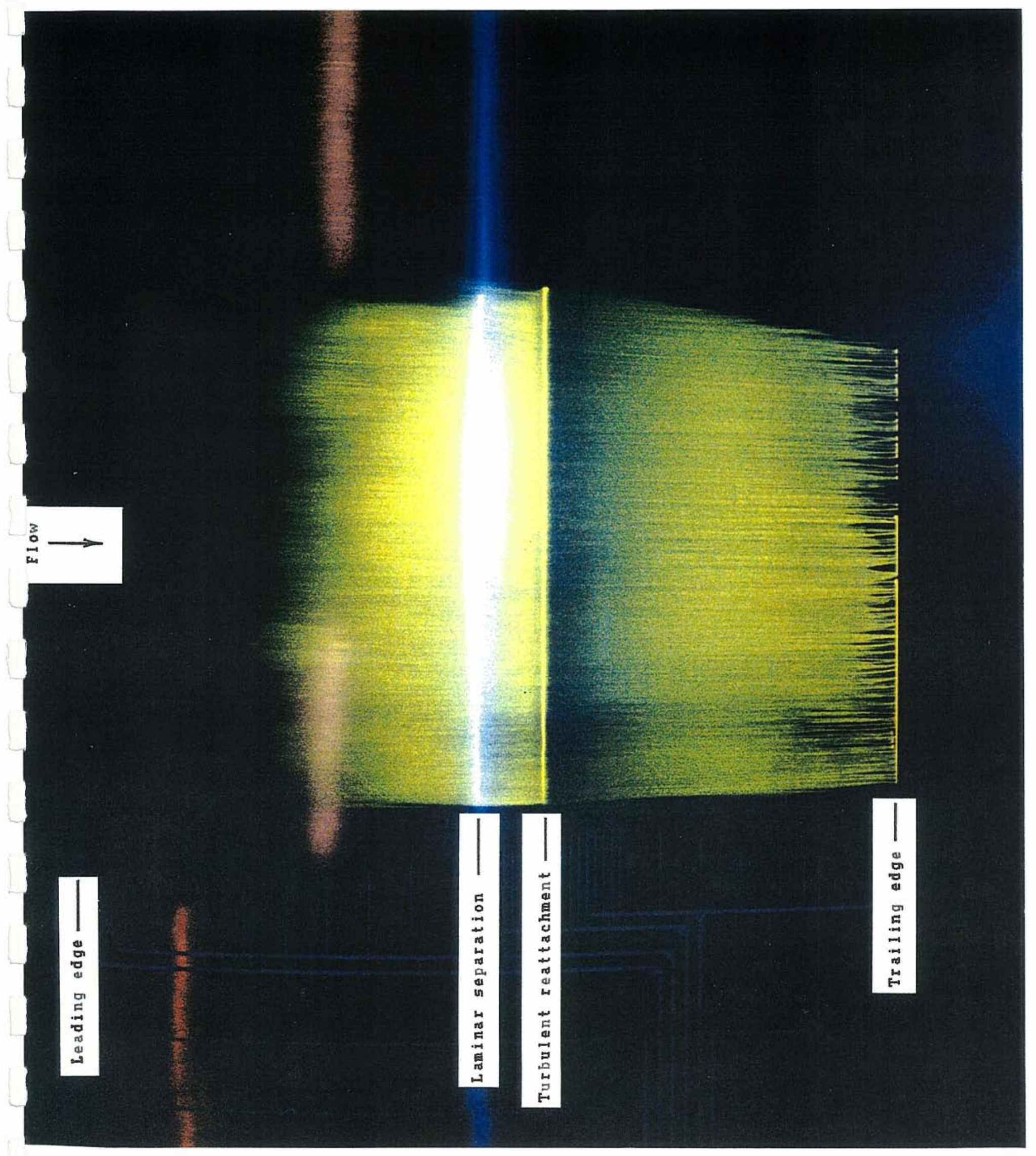

(c) $\alpha=4.1$ degrees.

Figure 9. - Continued. 
Leading edge -

Laminar separation

Turbulent reattachment

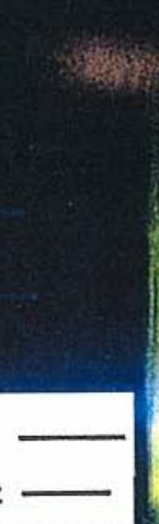

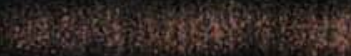

Trailing edge
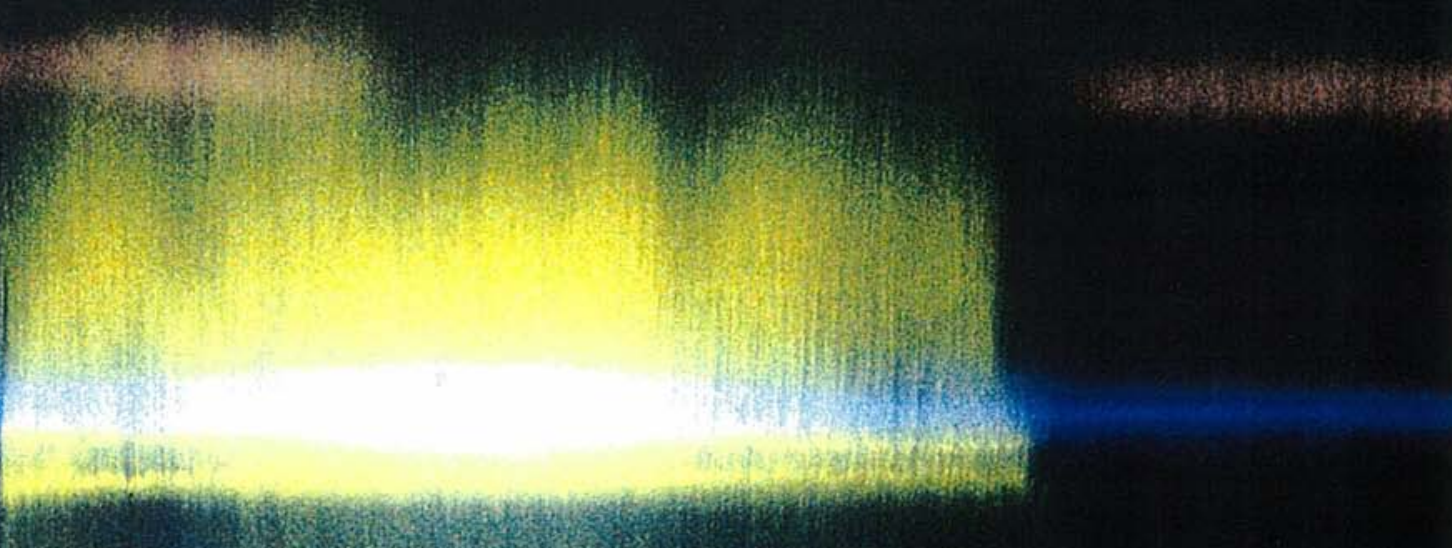

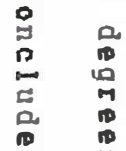

总 


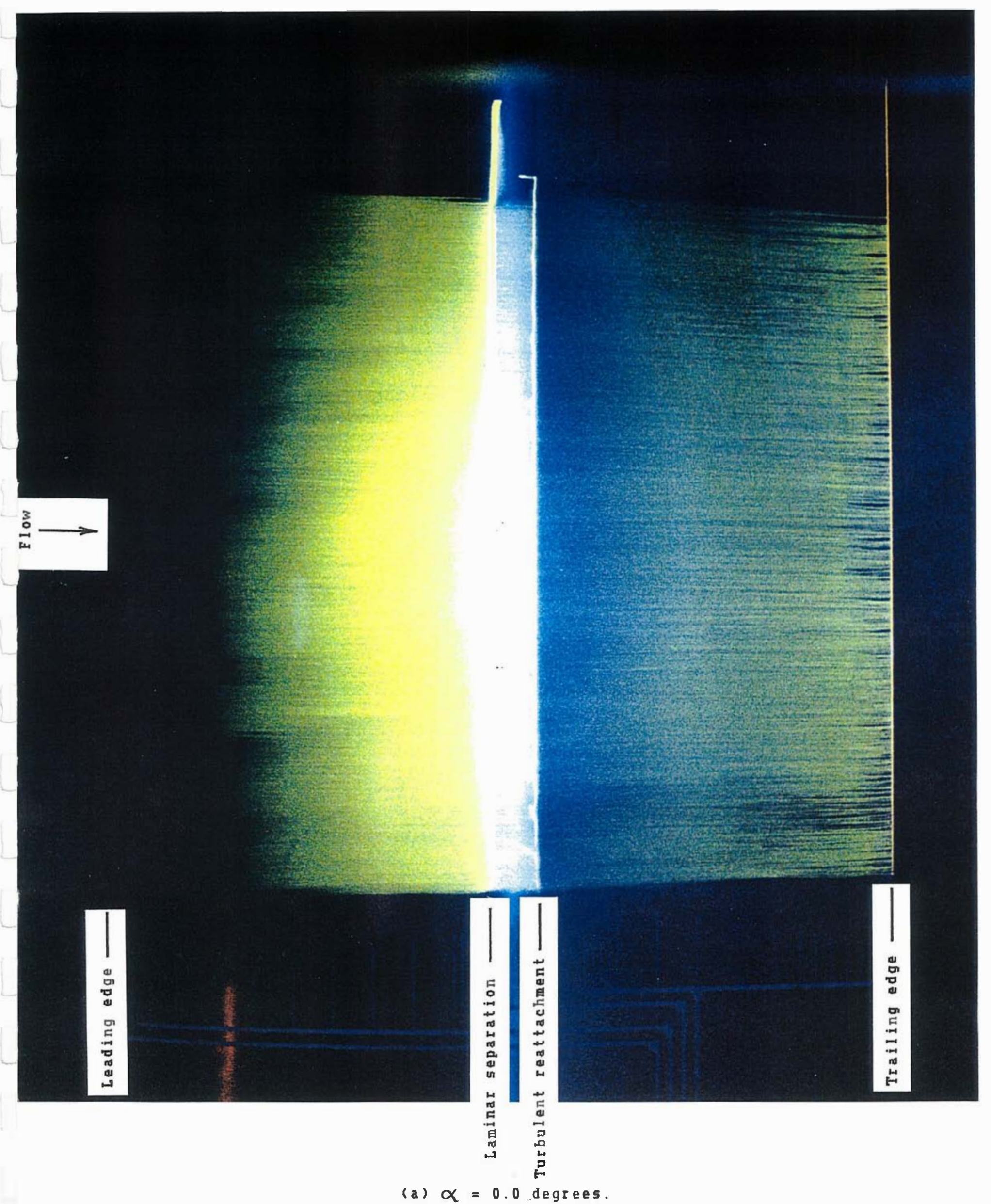

Figure 10.- Oil-flow photograghs of upper surface for $R=2,000,000$. 


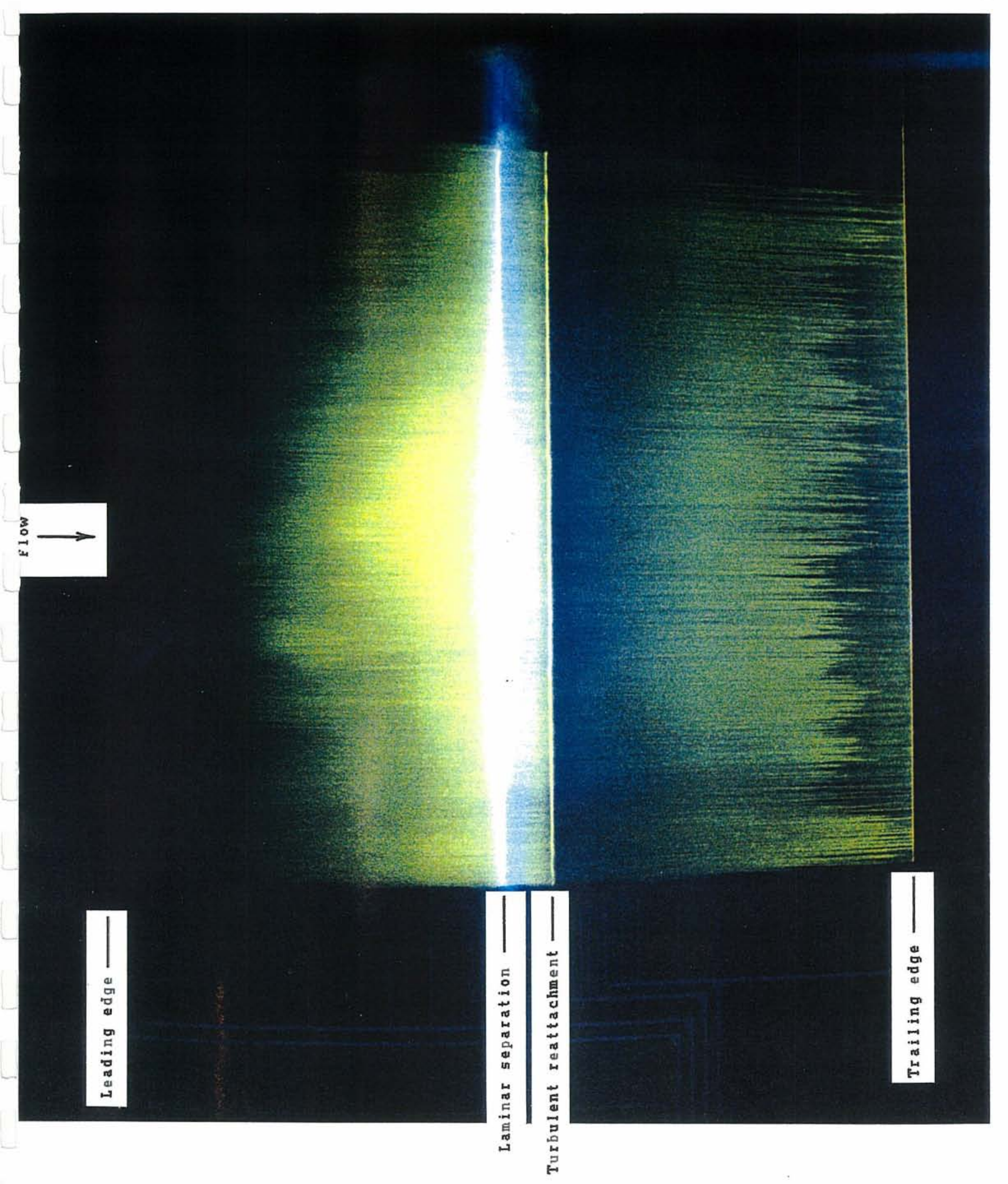

(b) $\alpha=2.1$ degrees.

Figure 10. - Continued. 


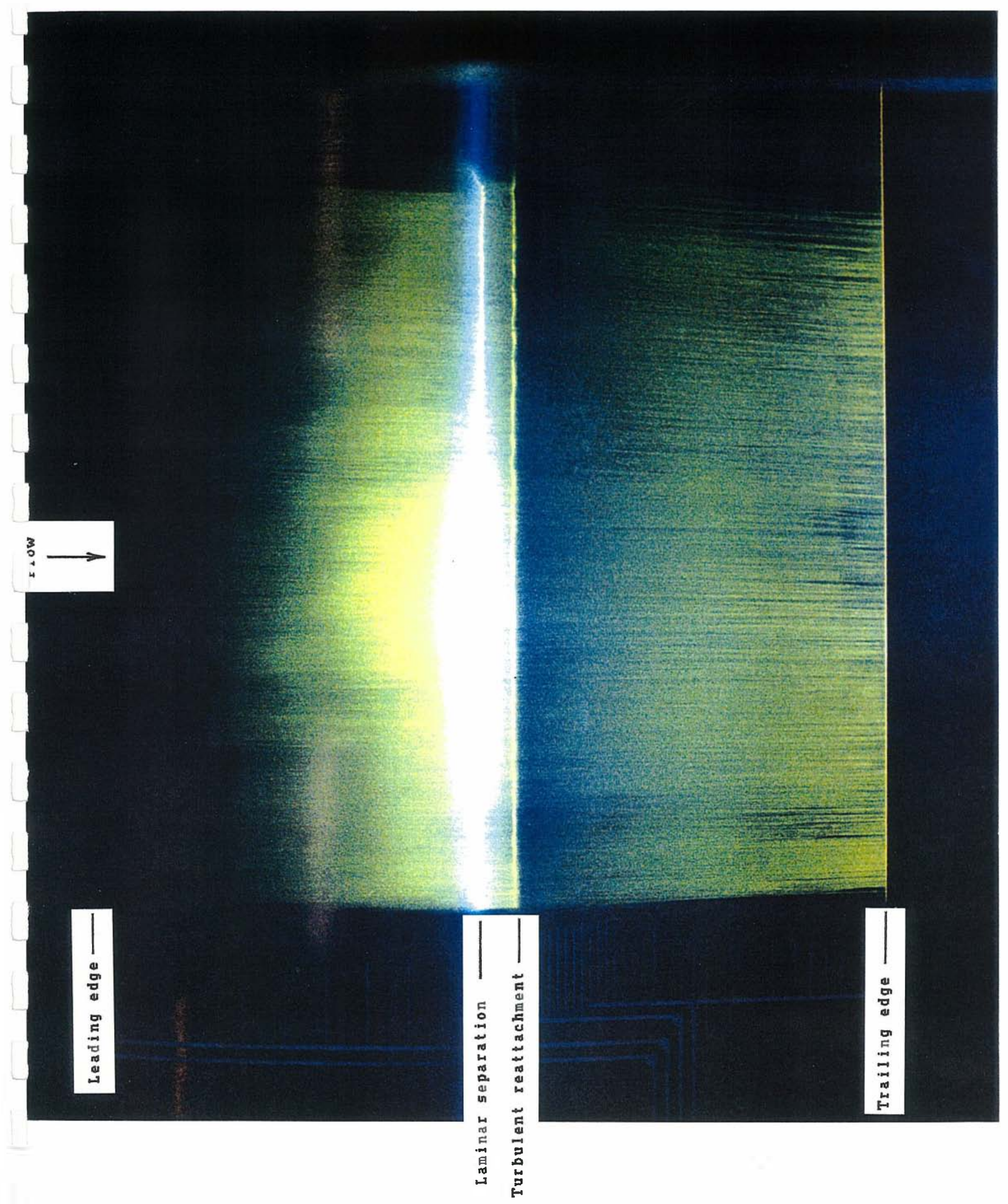

(c) $\alpha=4.1$ degrees.

Figure 10. - Continued. 


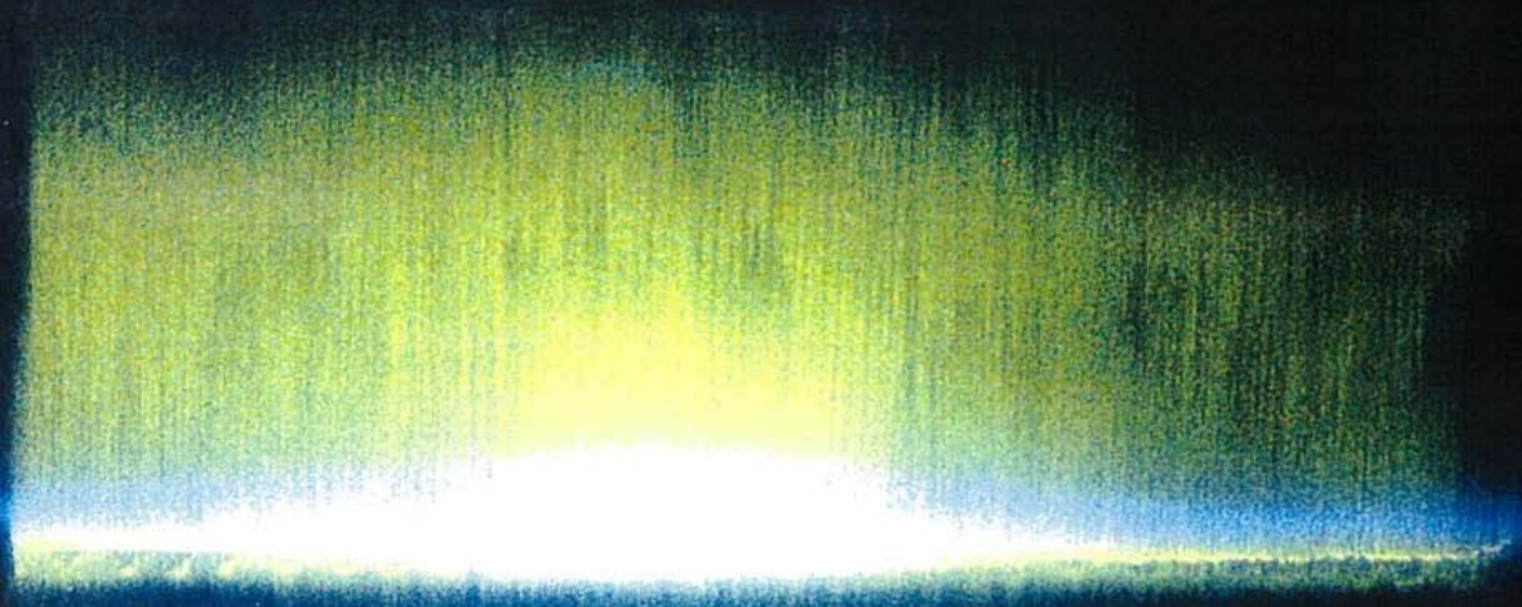

Trailing edge 


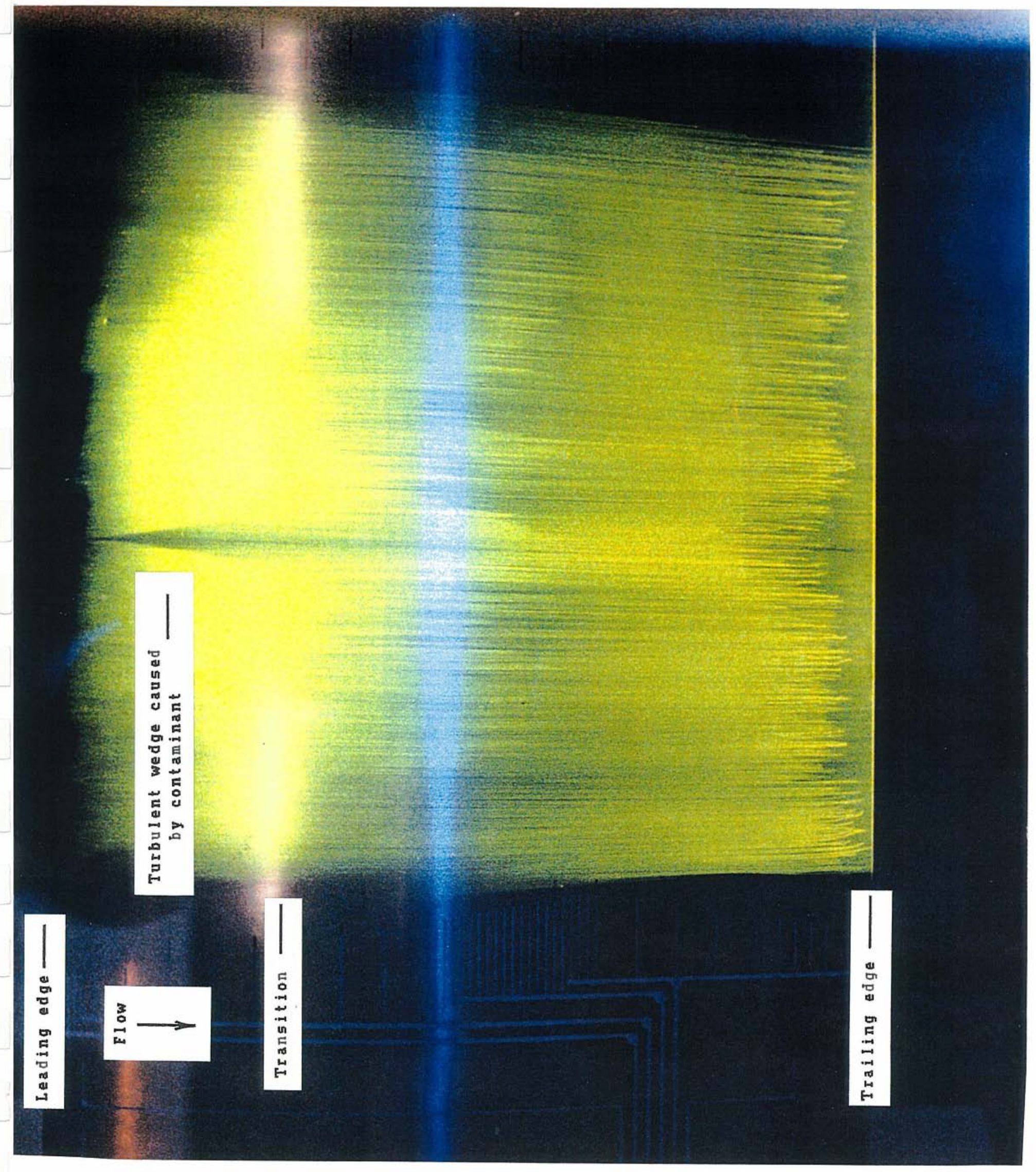

(e) $\alpha=6.2$ degrees.

Figure 10.- Continued. 


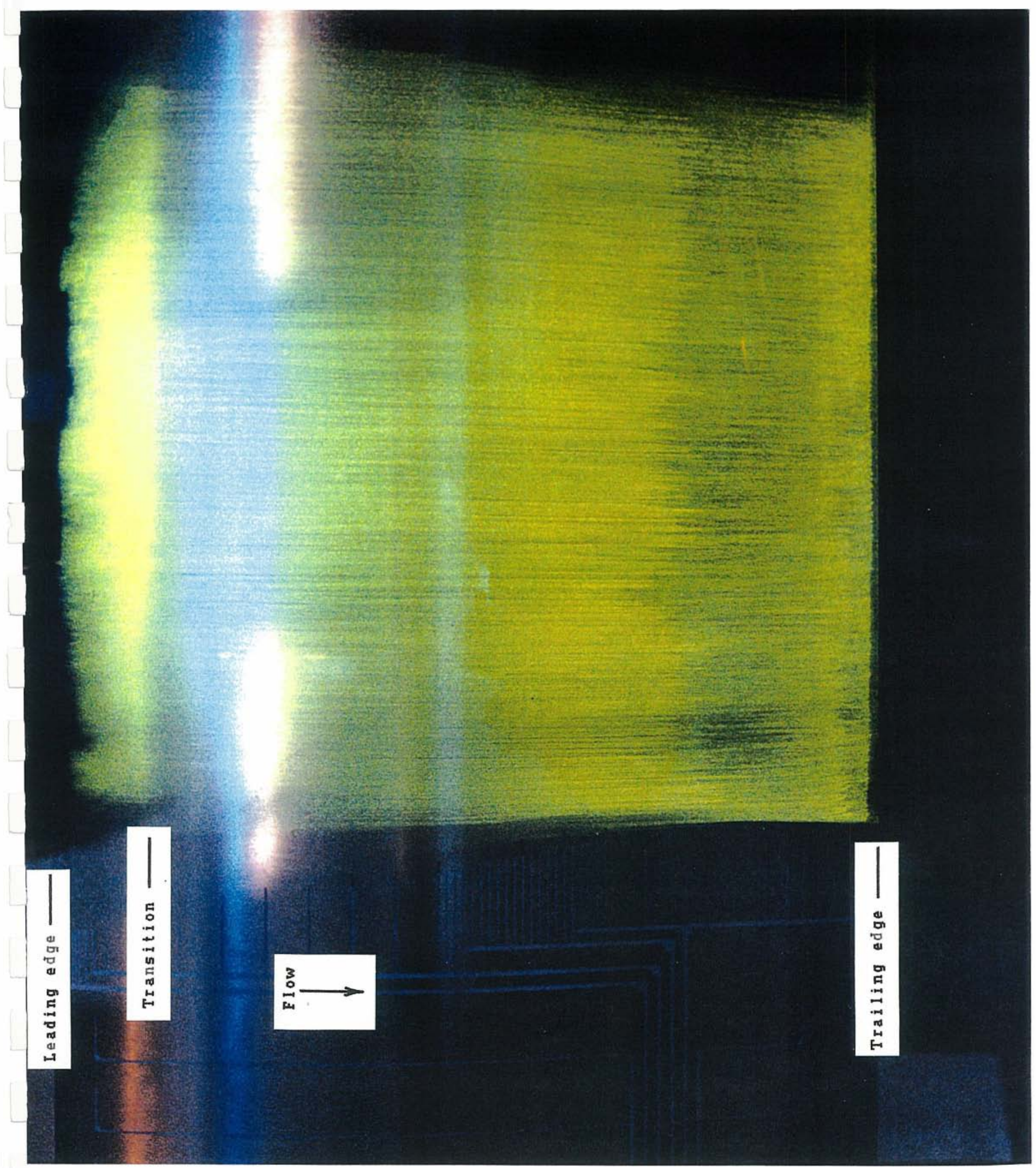

(f) $\alpha=7.2$ degrees.

Figure 10.- Continued. 


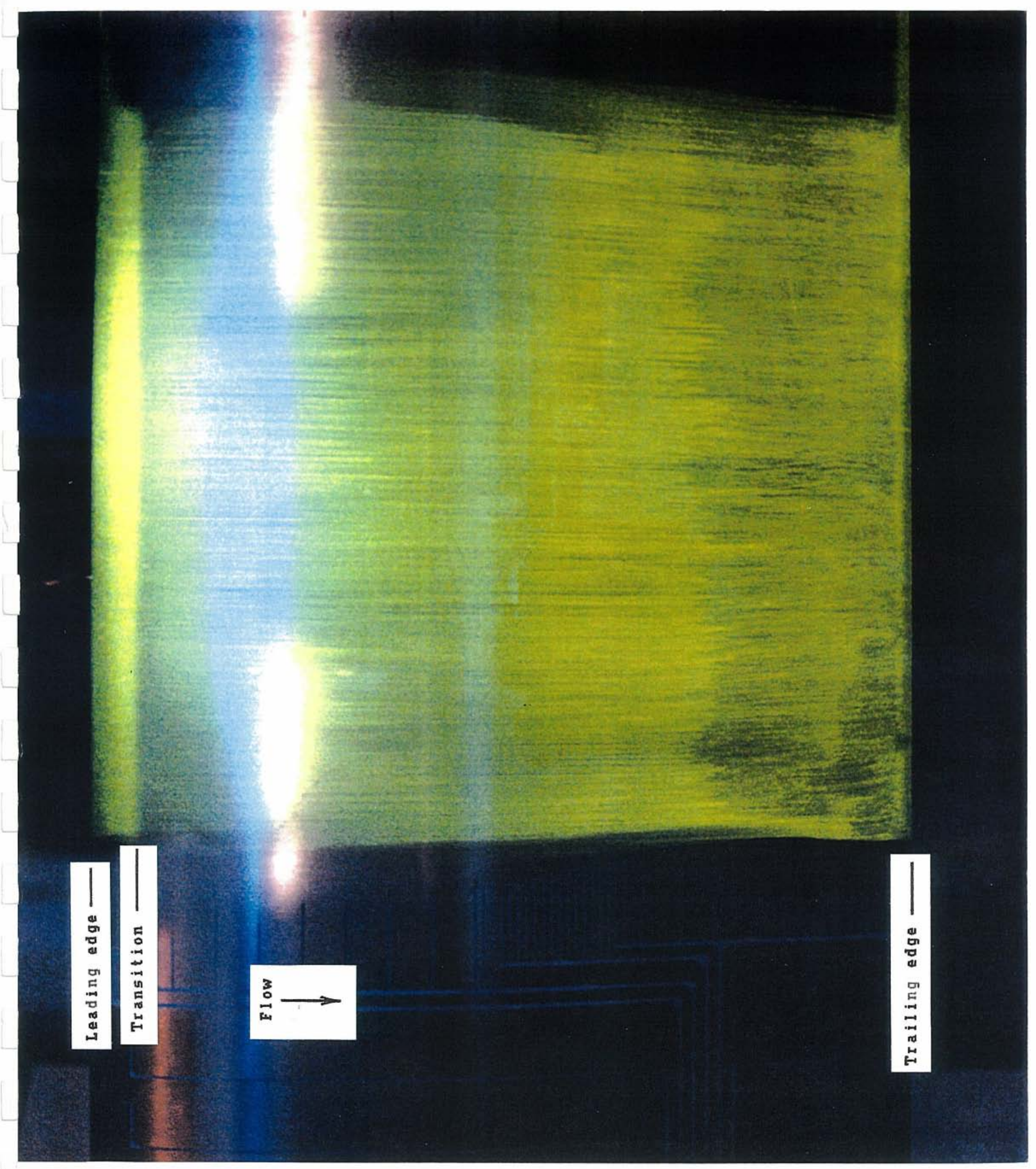

(g) $\alpha=8.2$ degrees.

Figure 10. - Continued. 


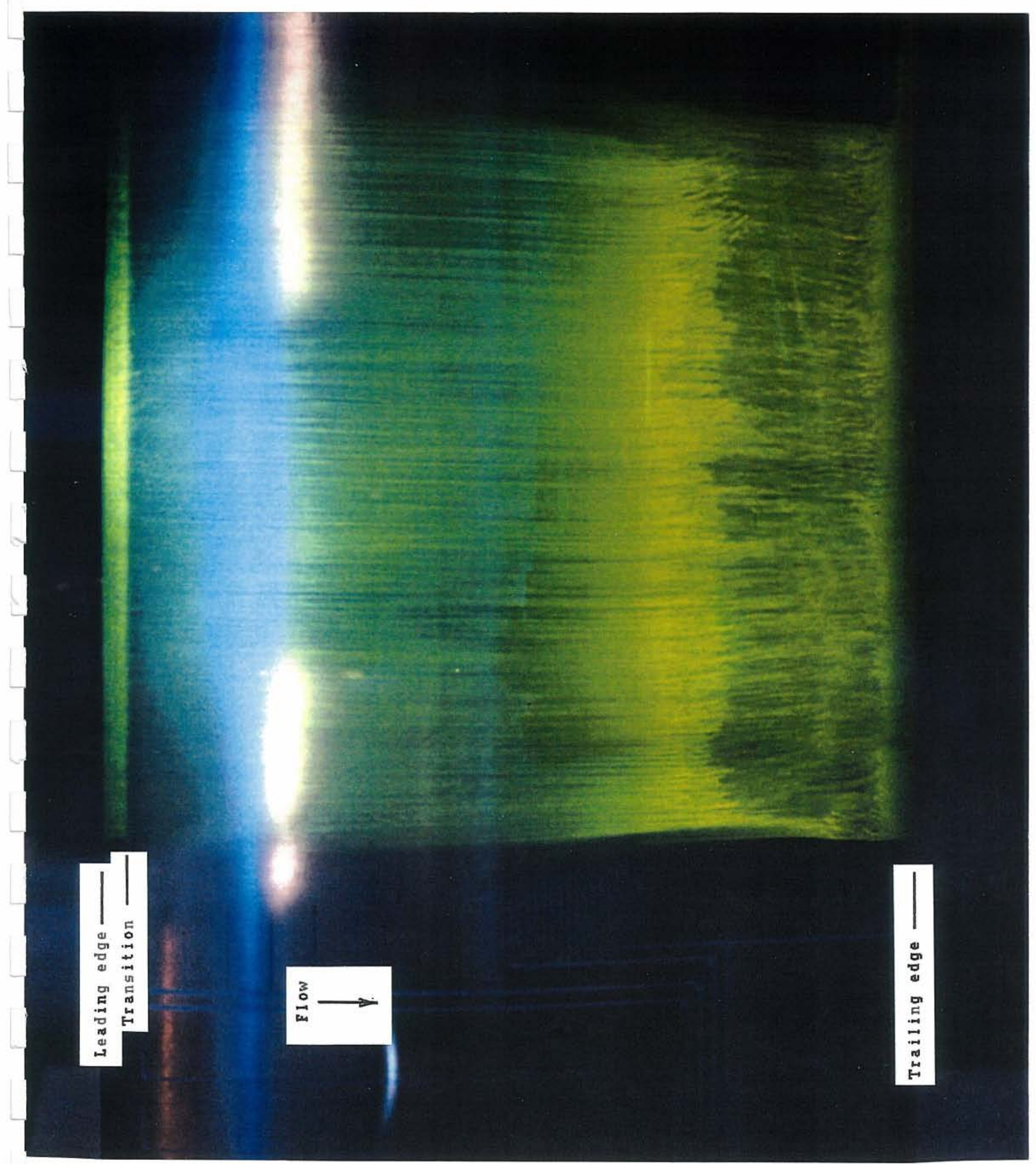

(h) $\alpha=9.2$ degrees.

Figure 10.- Concluded. 

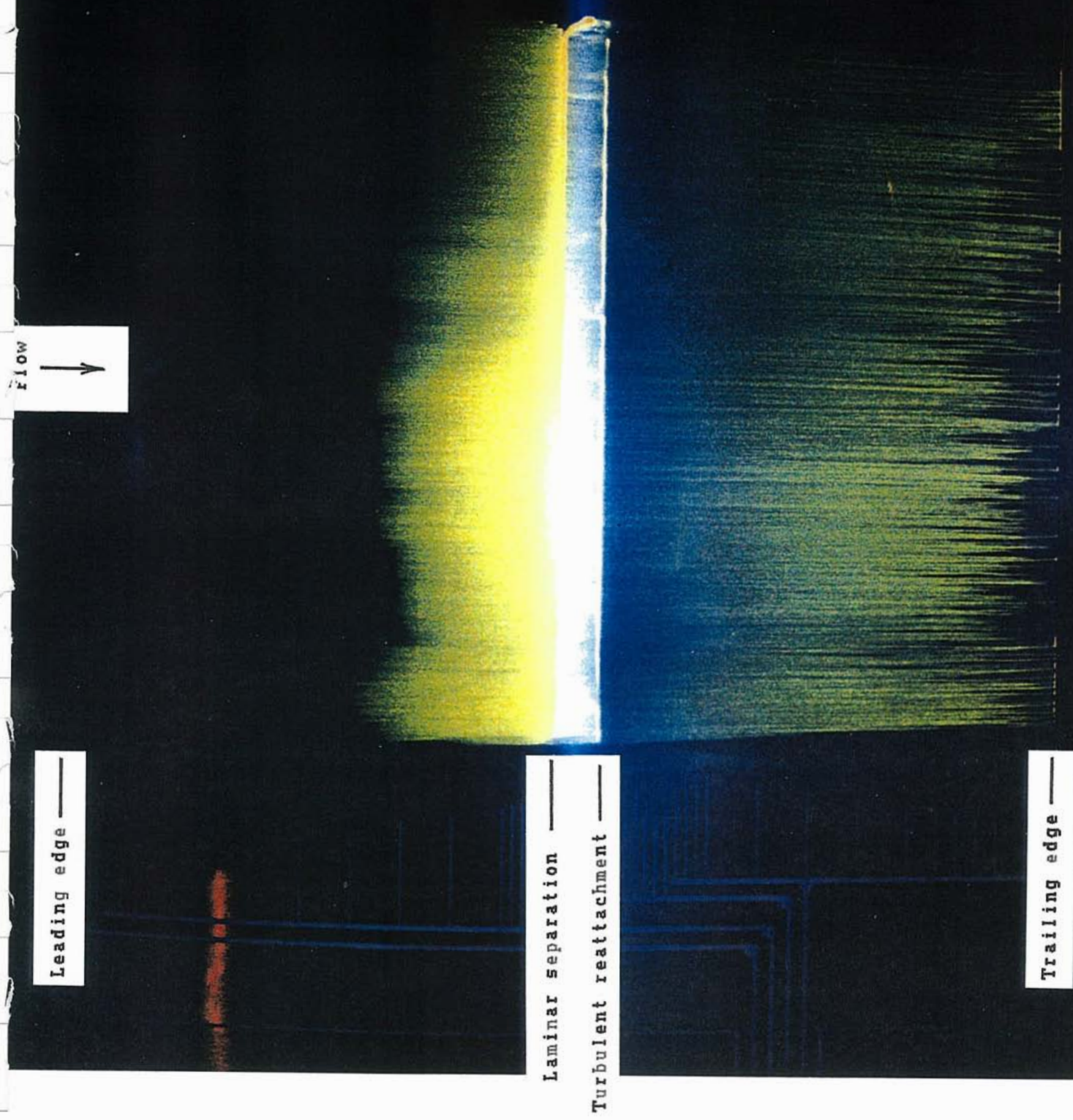

(a) $\alpha=0.0$ degrees.

Figure 11.- Oil-f low photographs of upper surface for $R=3,000,000$. 


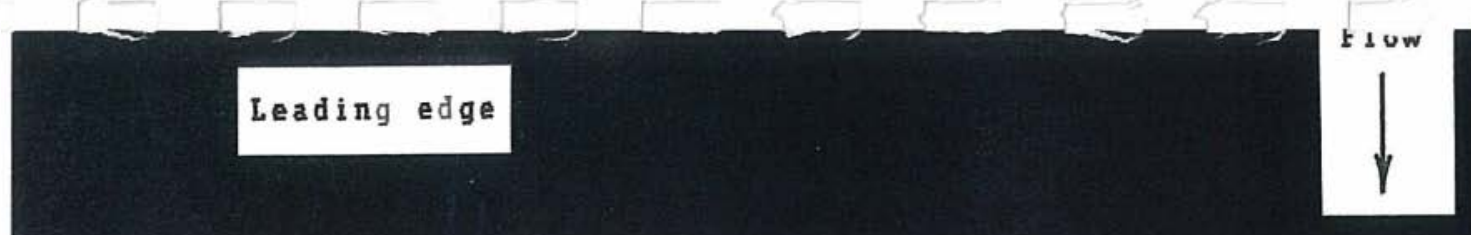

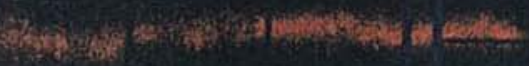

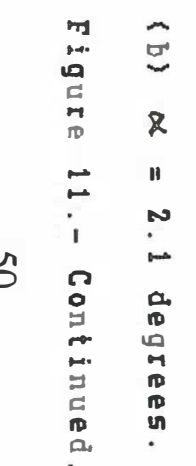

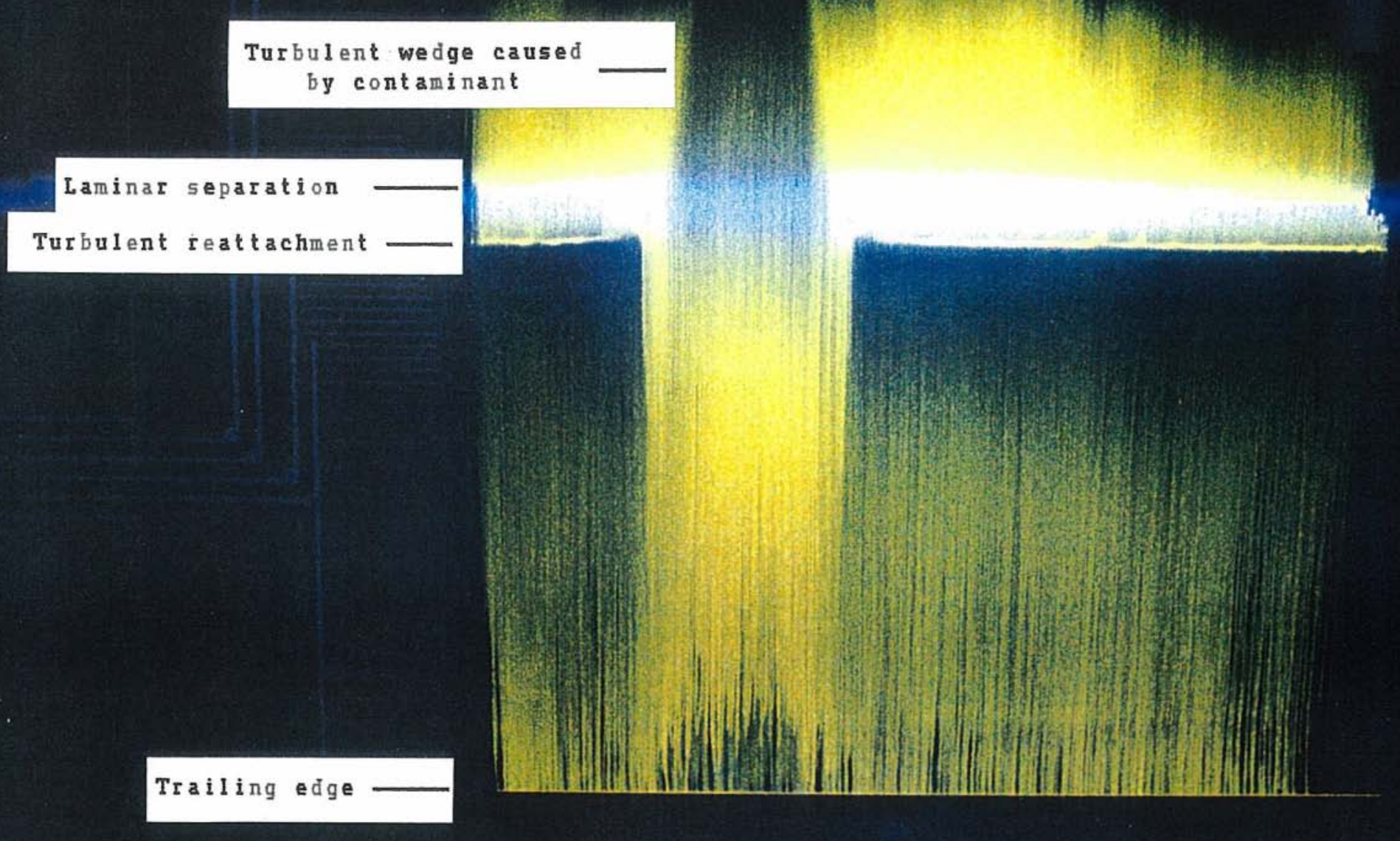




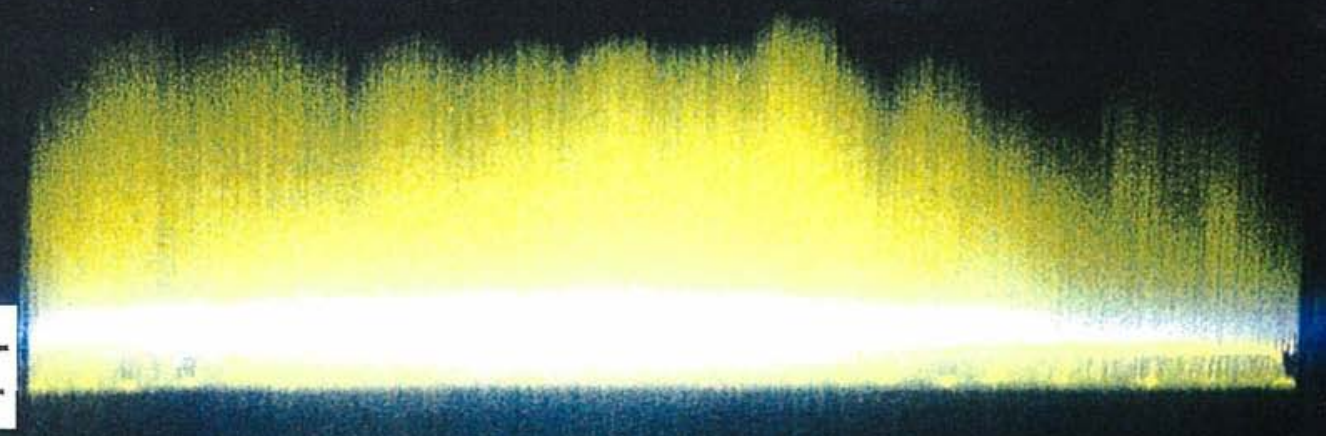




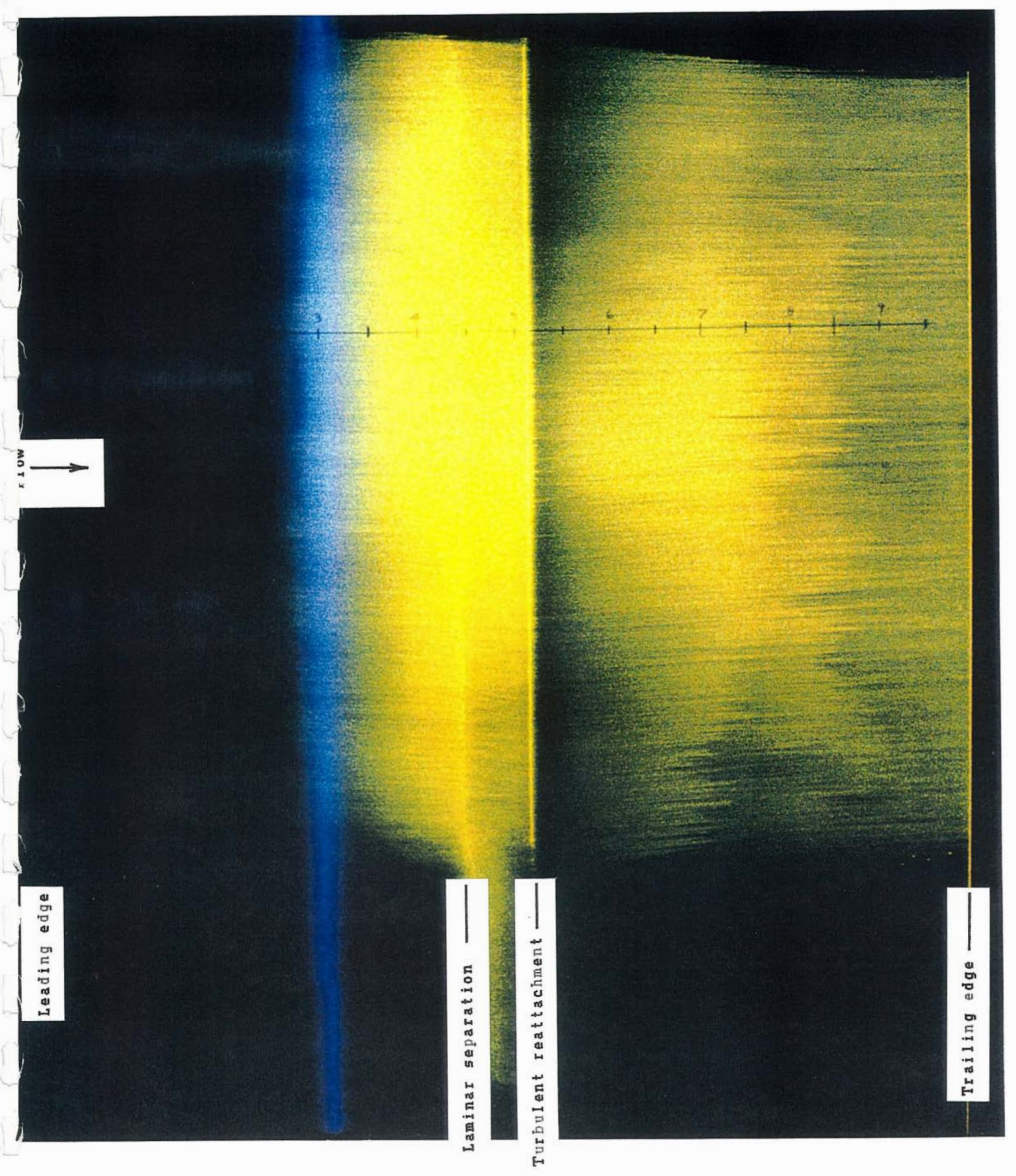

(a) $\alpha=0.0$ degrees.

Figure 12.- 0il-flow photographs of lower surface for $R=1,000,000$. 


\section{Leading edge}
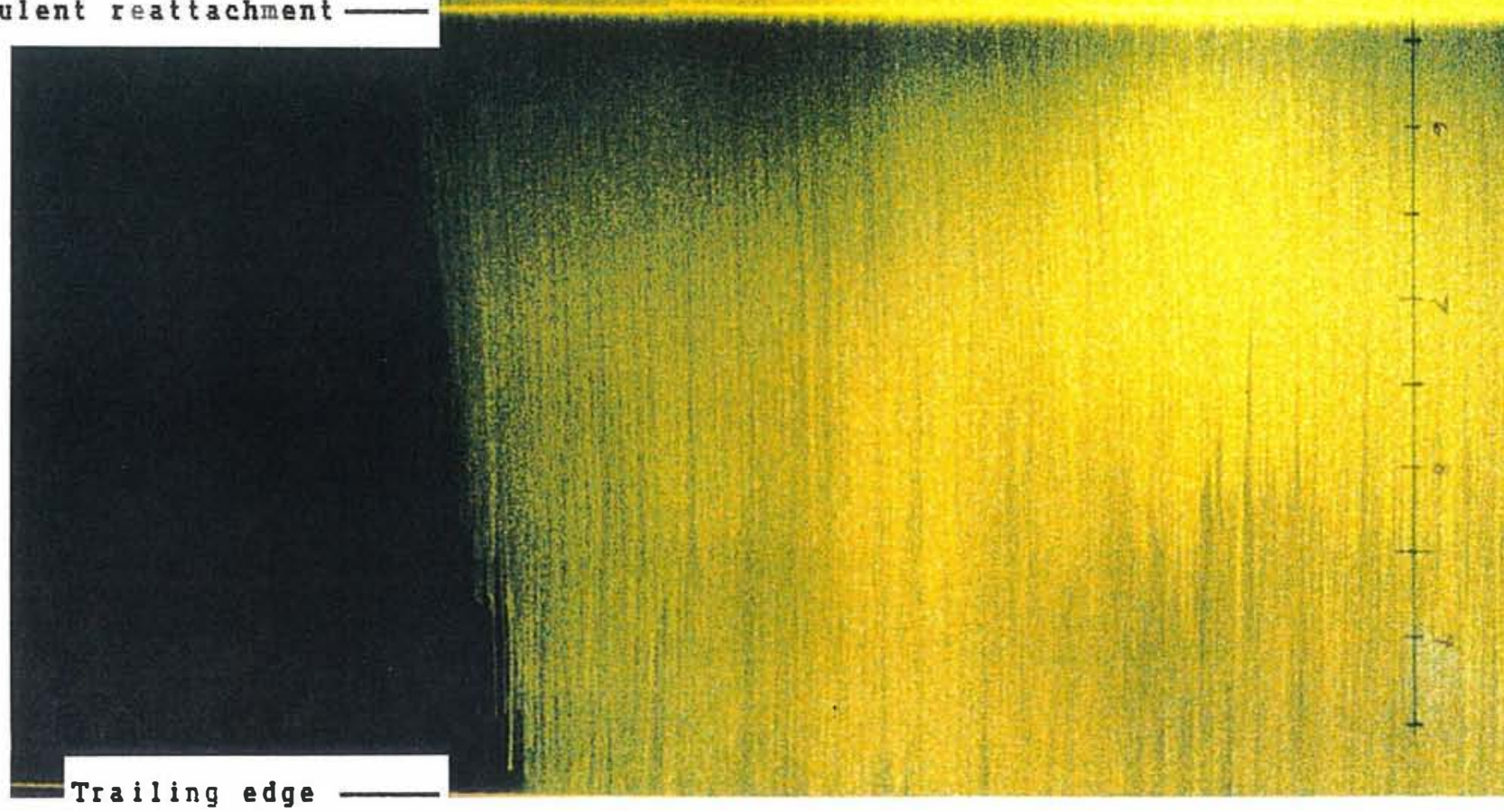


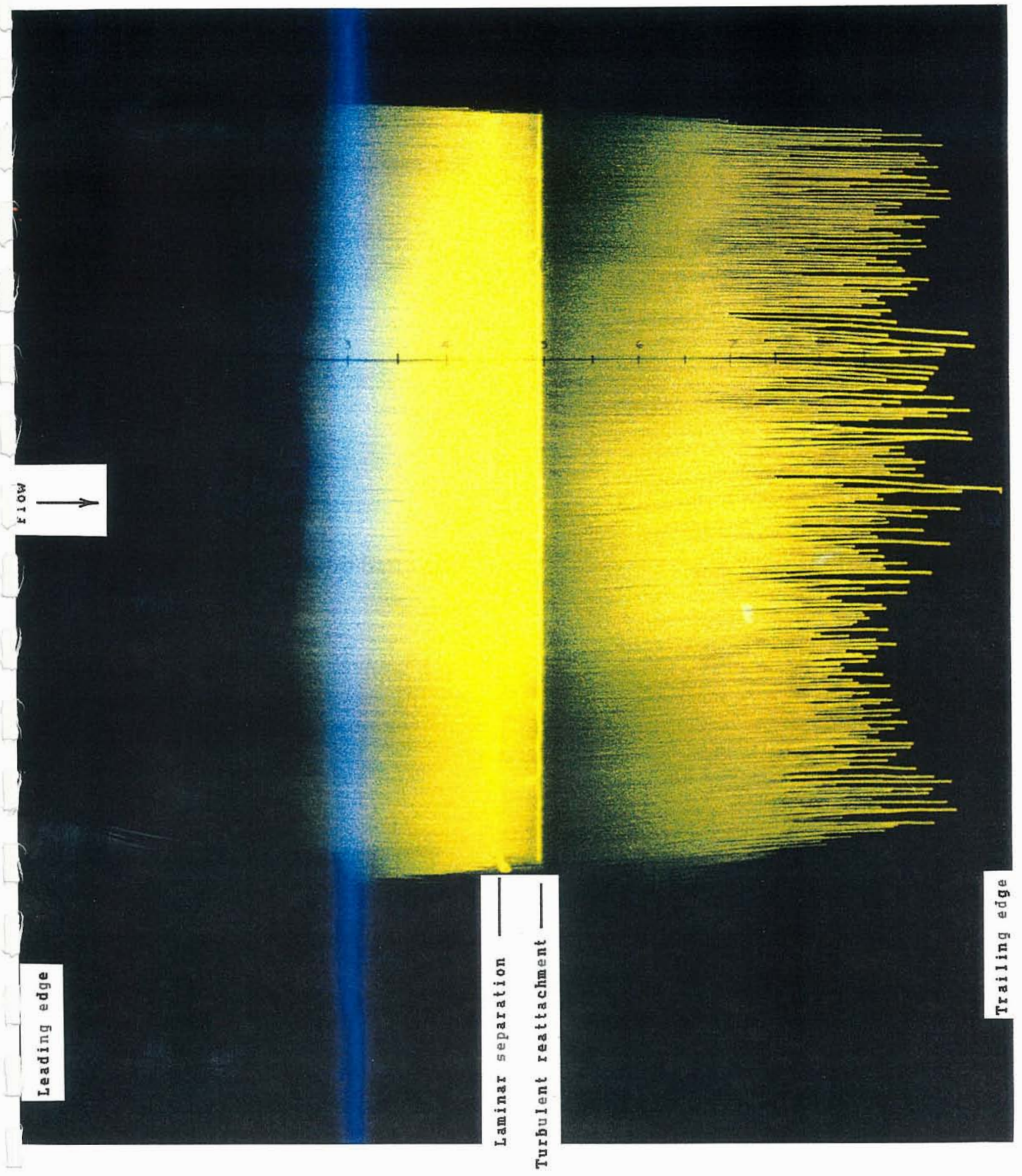

(a) $\alpha=0.0$ degrees.

Figure 13.- 0il-f low photographs of lower surface for $R=2,000,000$. 

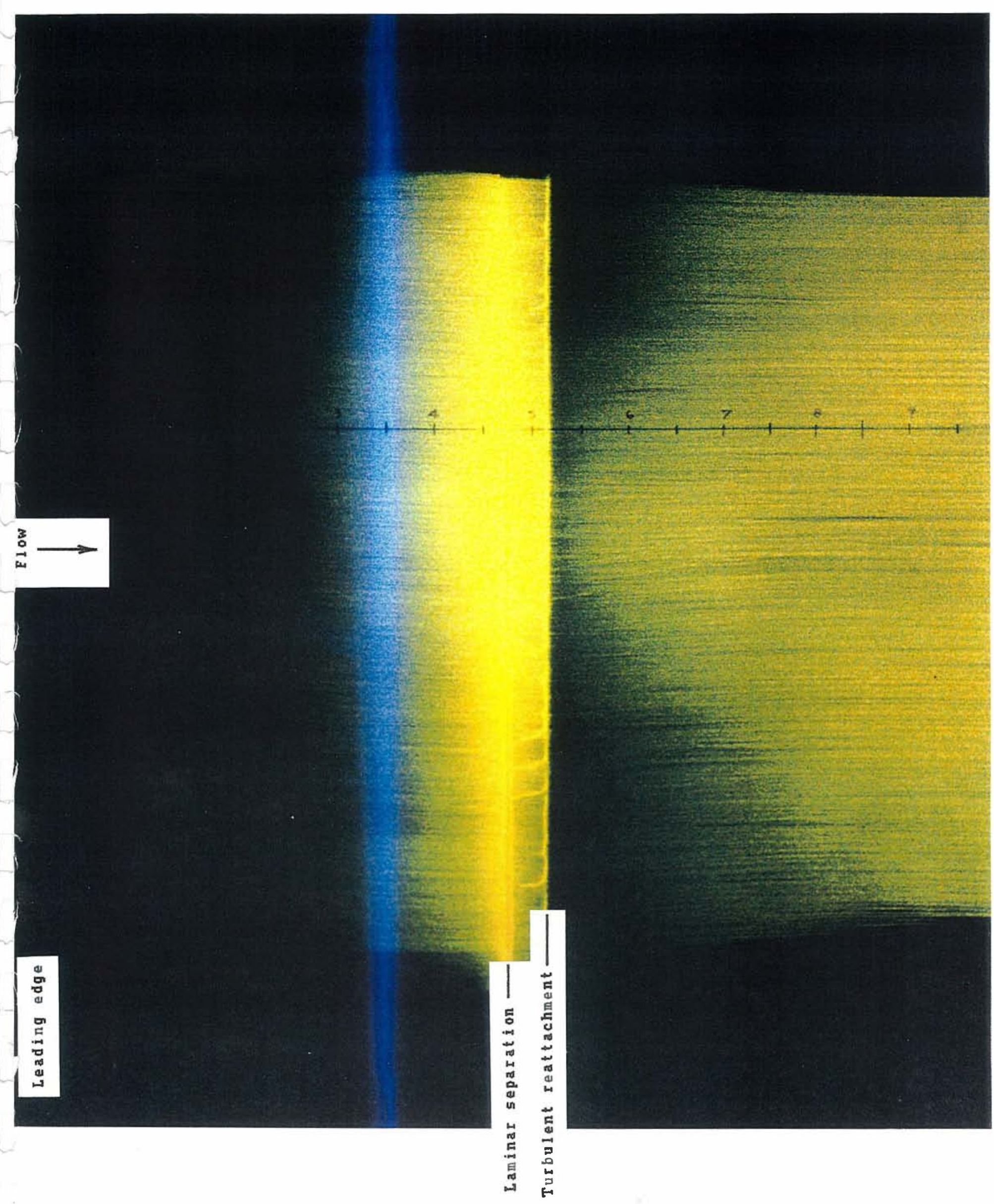

(b) $\alpha=5.4$ degrees.

Figure 13. - Concluded. 


$$
\text { Leading edge }
$$

by contaminant . 


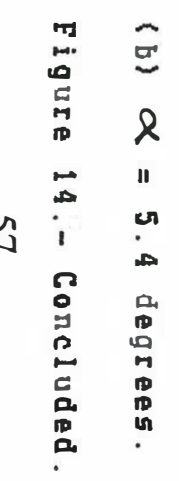

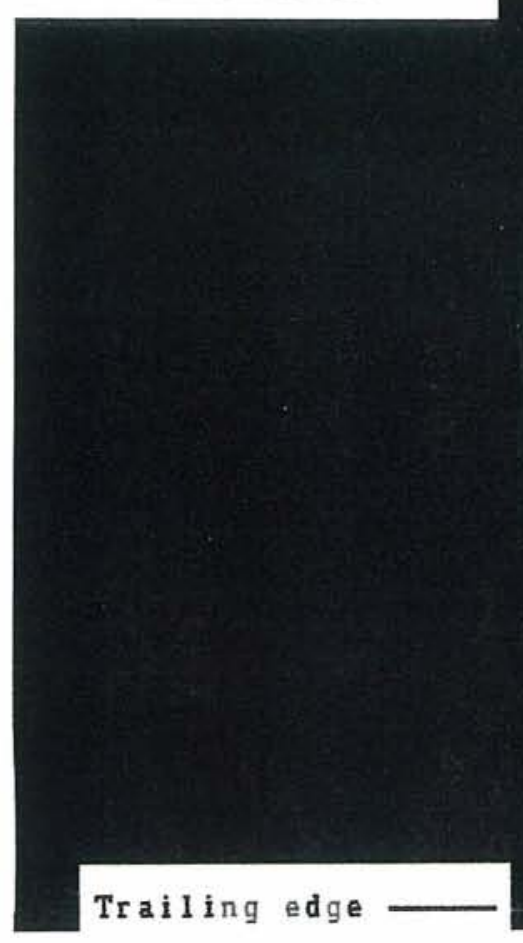




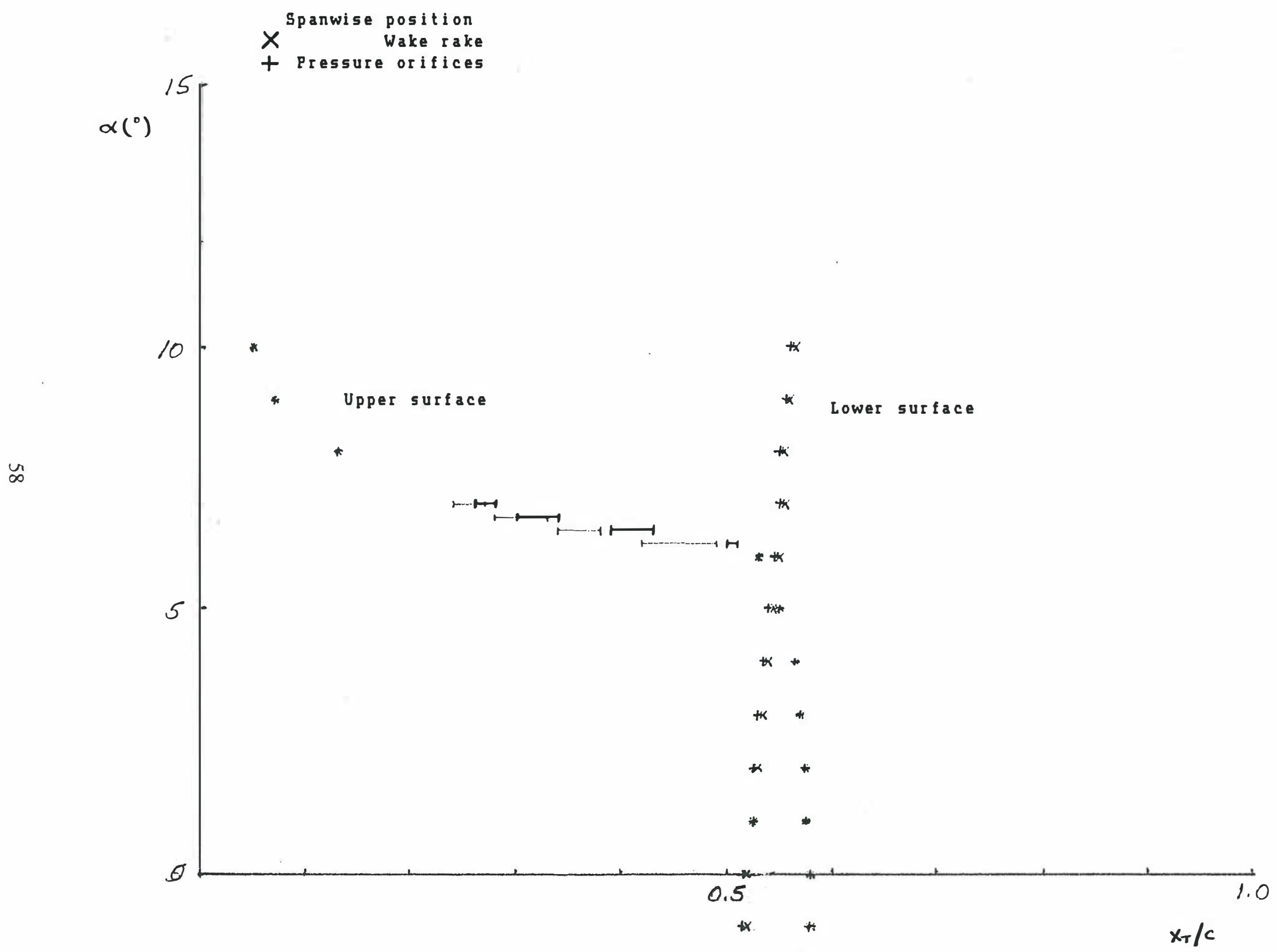

(a) $R=1,000,000$.

Figure 15. - Transition location. Bars extend from beginning to end of transition. 


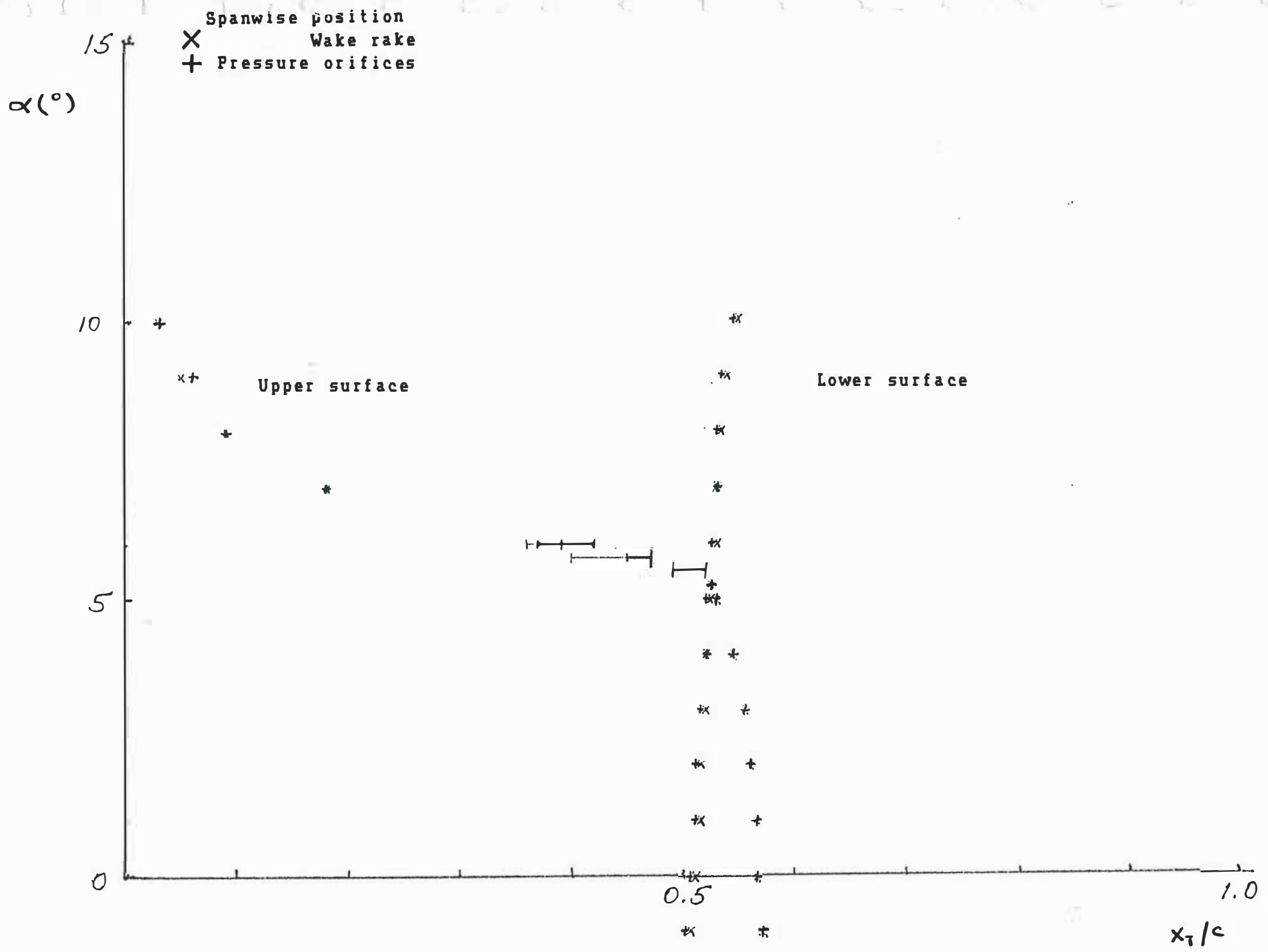

(b) $R=1,500,000$

Figure 15. - Continued. 

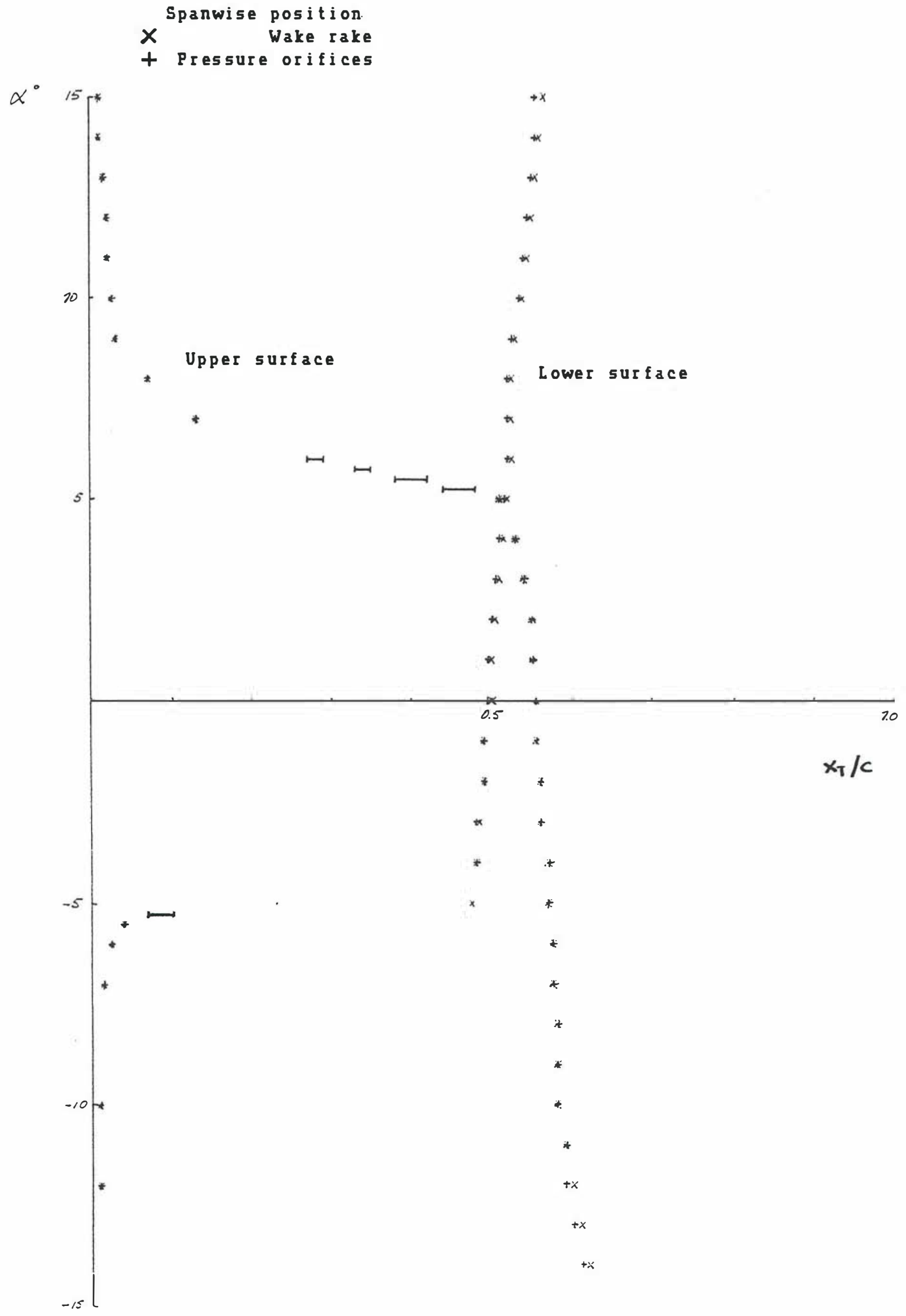

(c) $R=2,000,000$.

F igure 15. - Continued. 

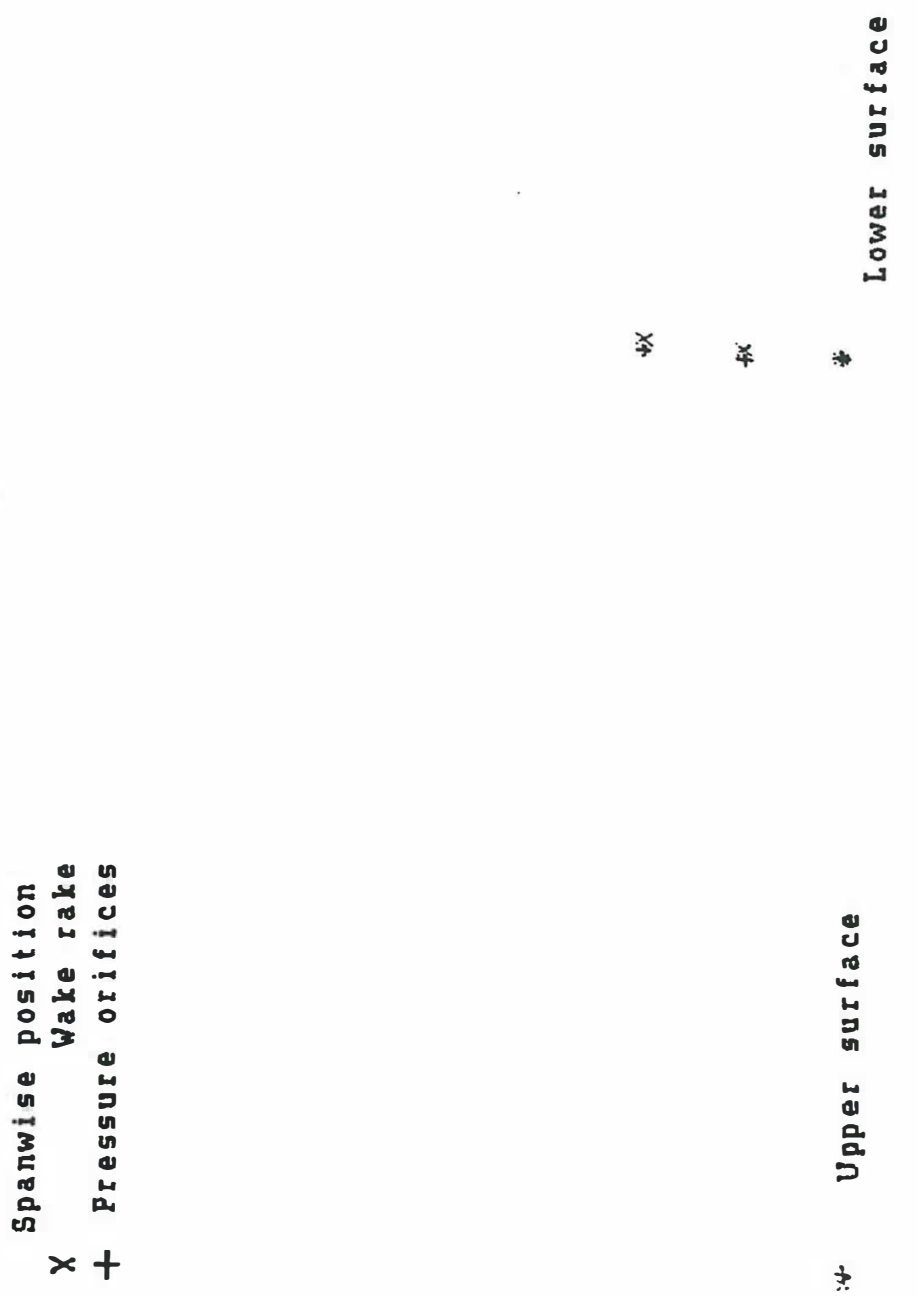

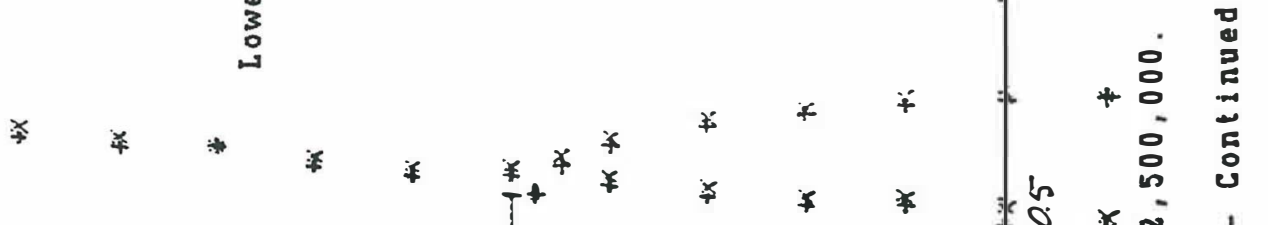

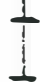

"1

ช

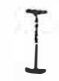

I

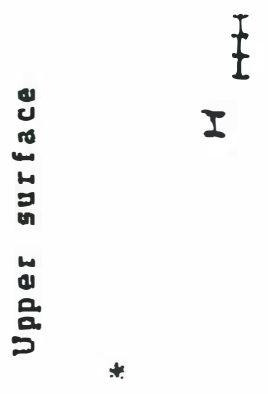

$\pm$

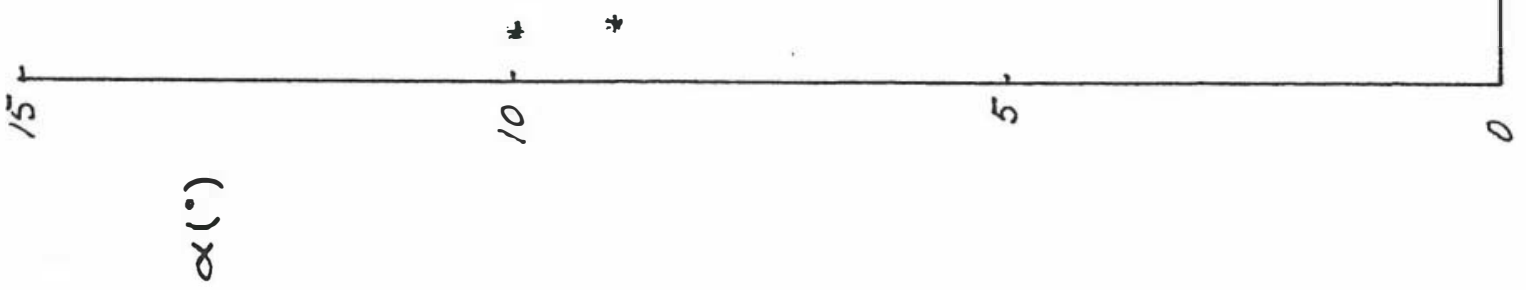




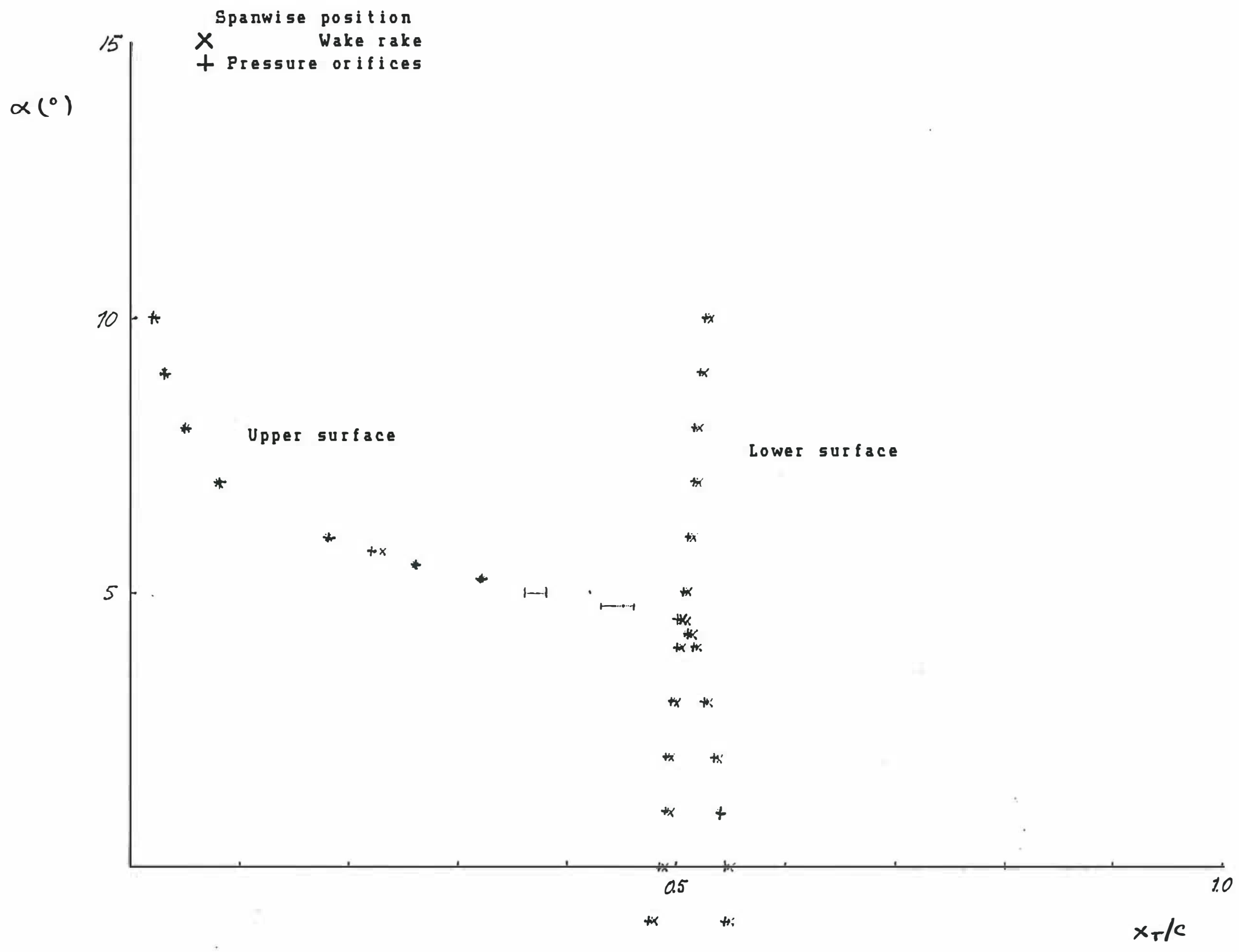

(e) $R=3,000,000$.

Figure 15. - Concluded. 


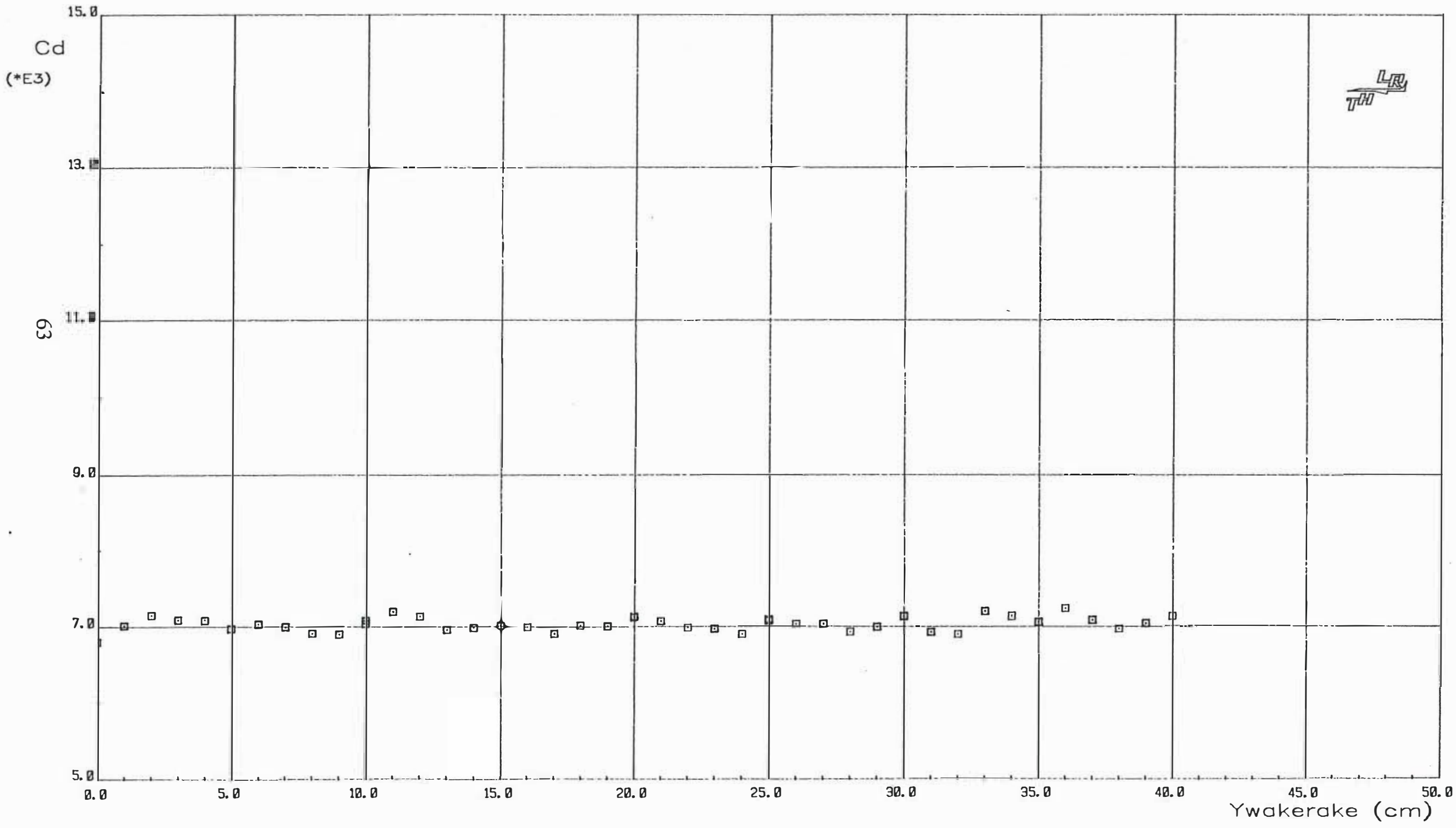

(a) $\alpha=0.0$ degrees.

Figure 16. - Spanwise drag coefficients for $R=2,000,000$. 


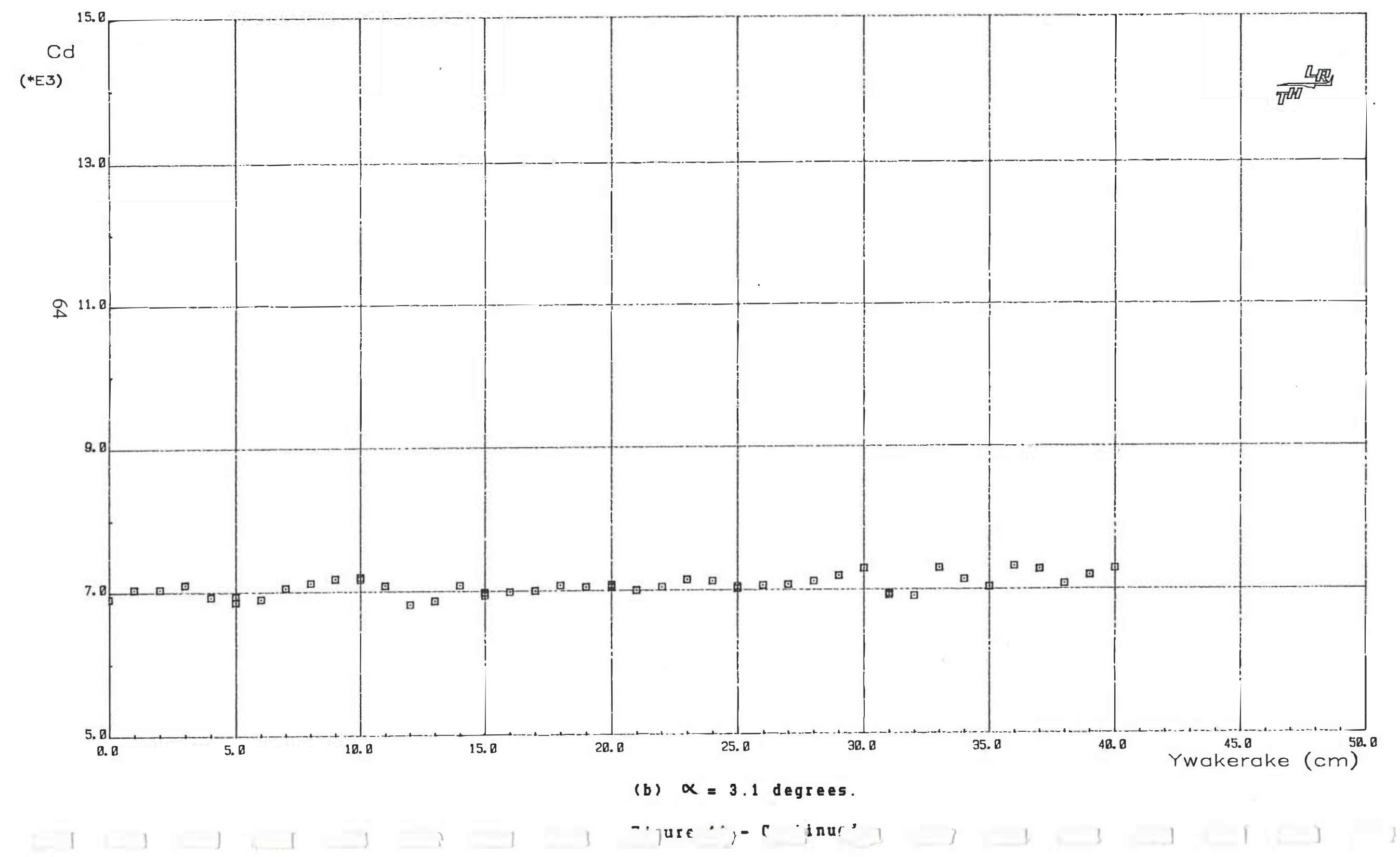




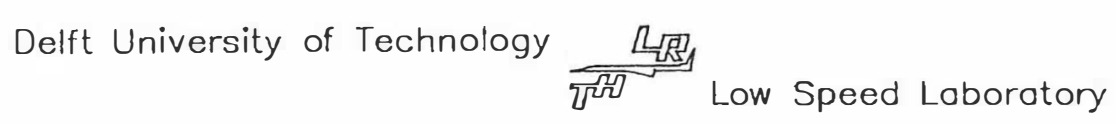
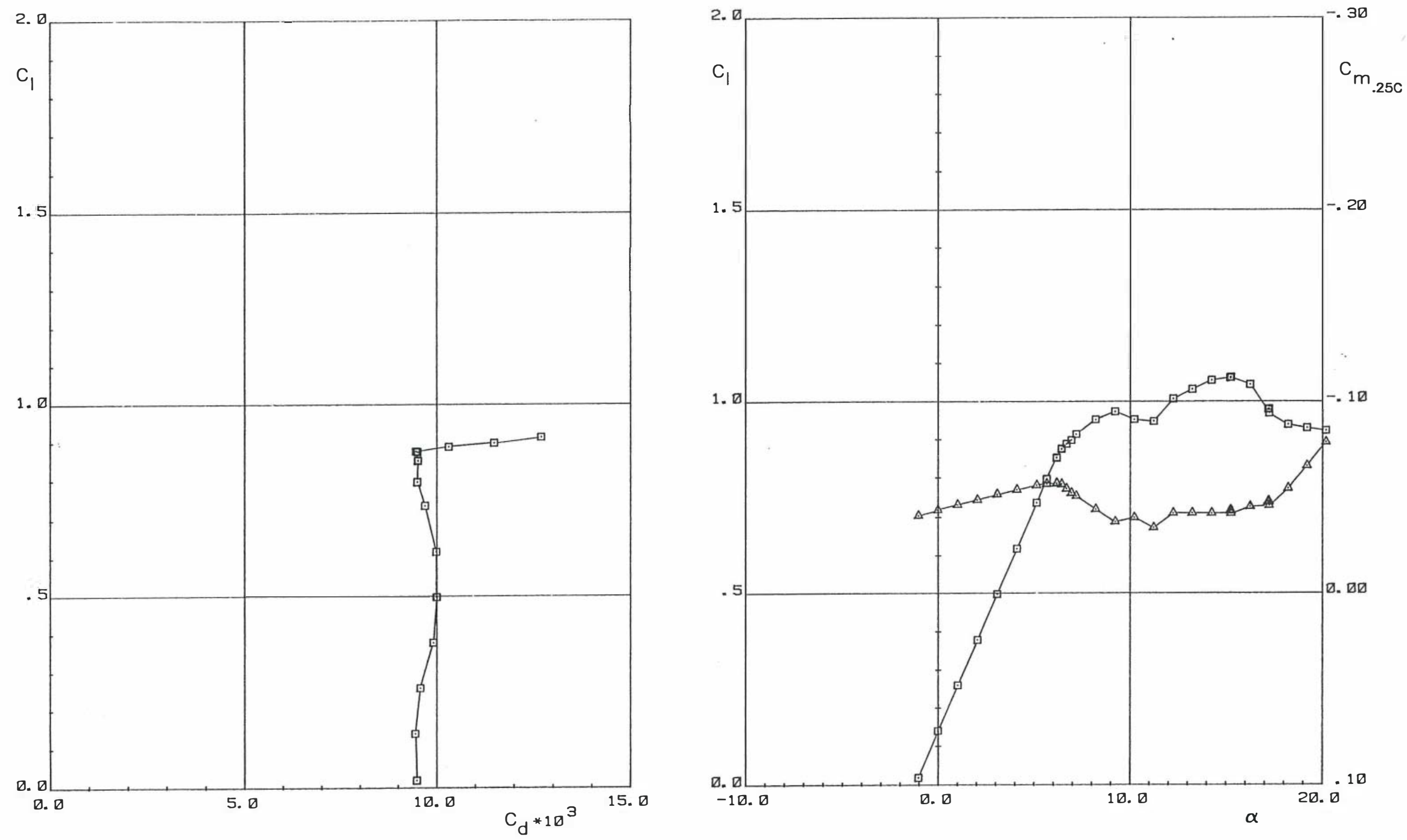

(a) $R=1,000,000$. 


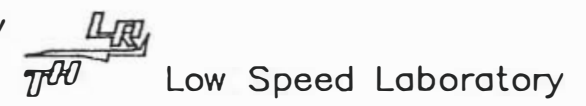
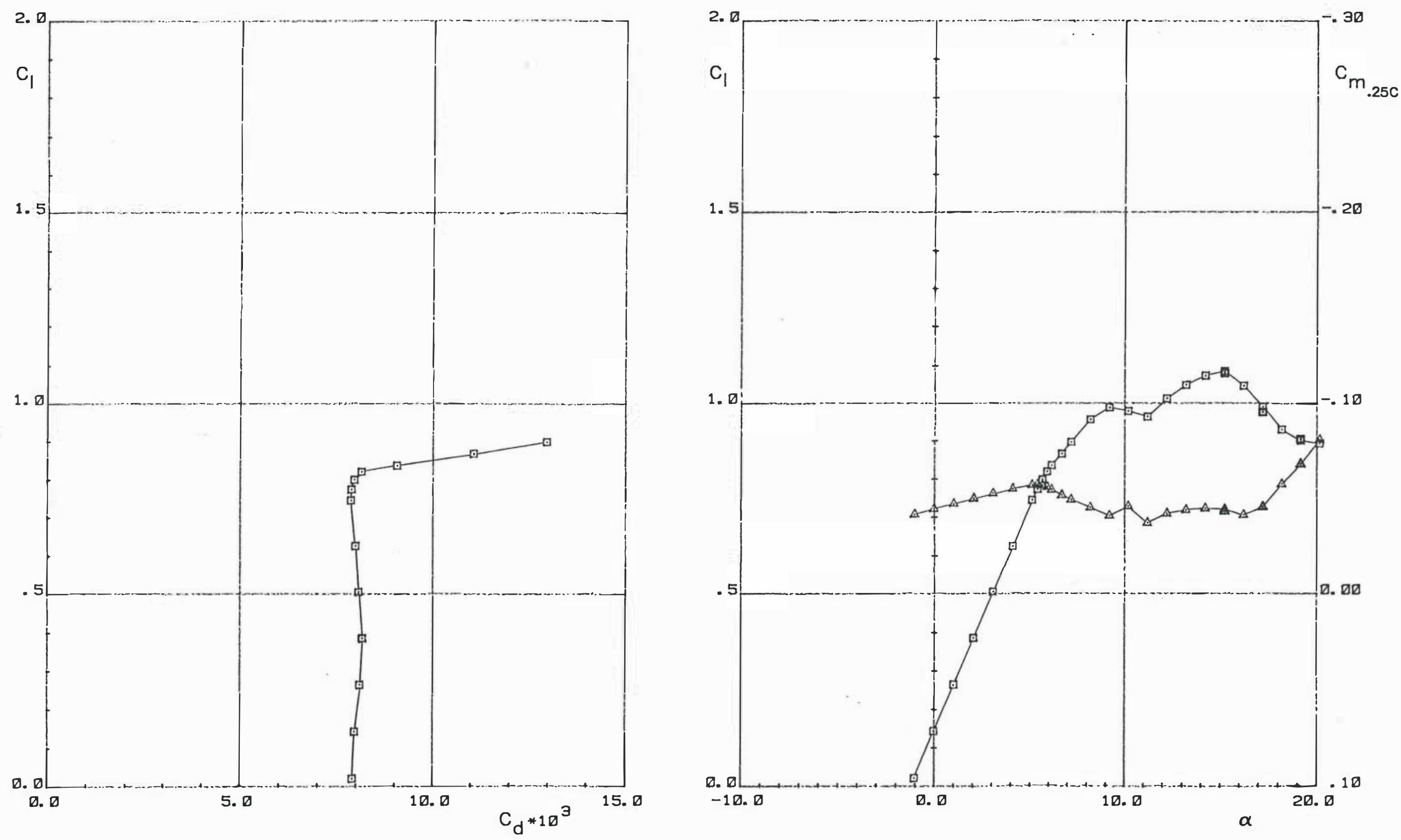

(b) $R=1,500,000$.

Figure 17. - Continued. 
Delft University of Technology

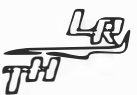

Low Speed Laboratory
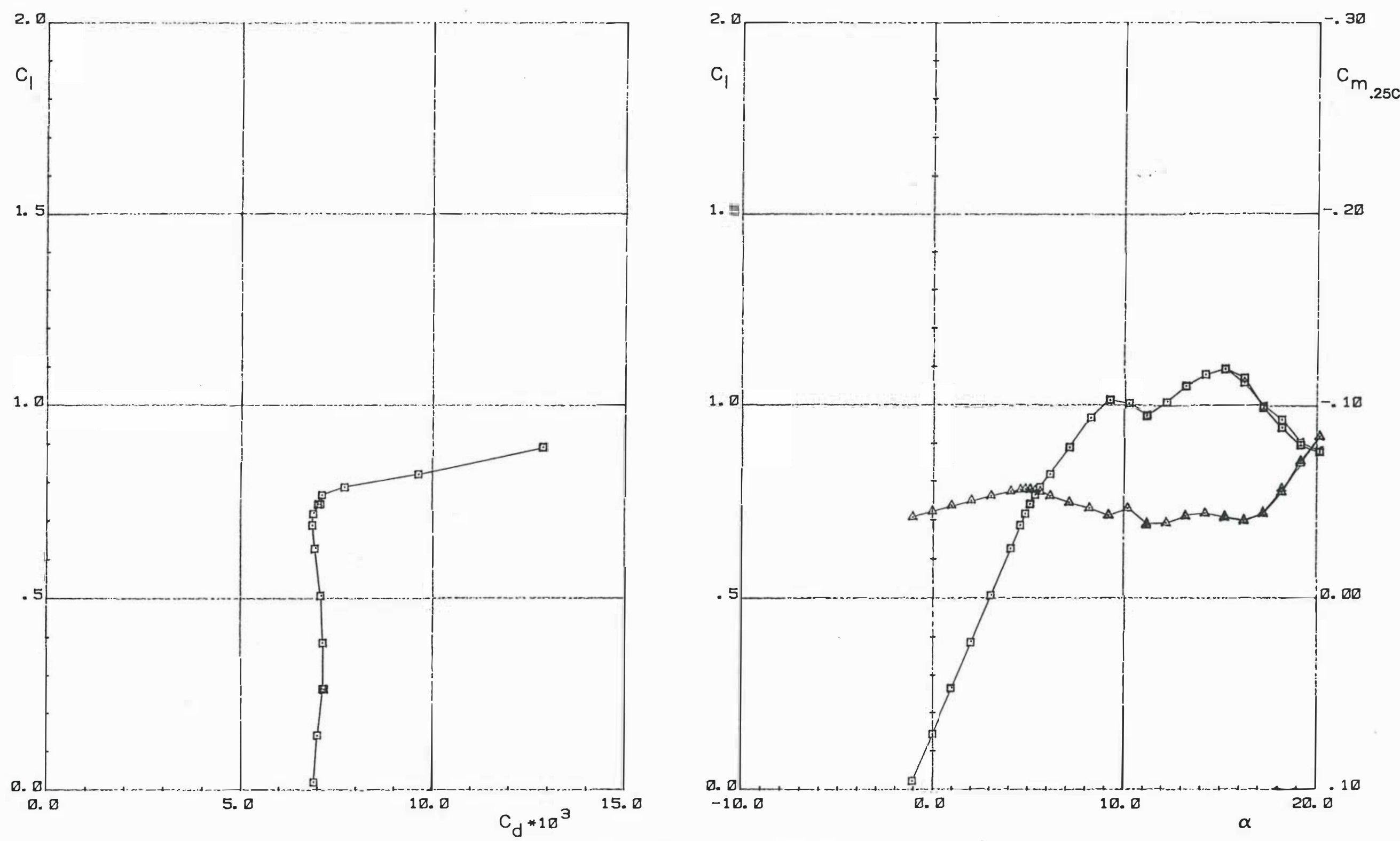

(i) Positive lift coefficients. 
Delft University of Technology

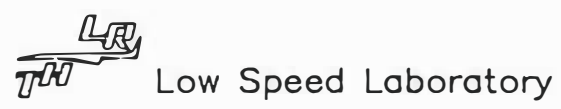
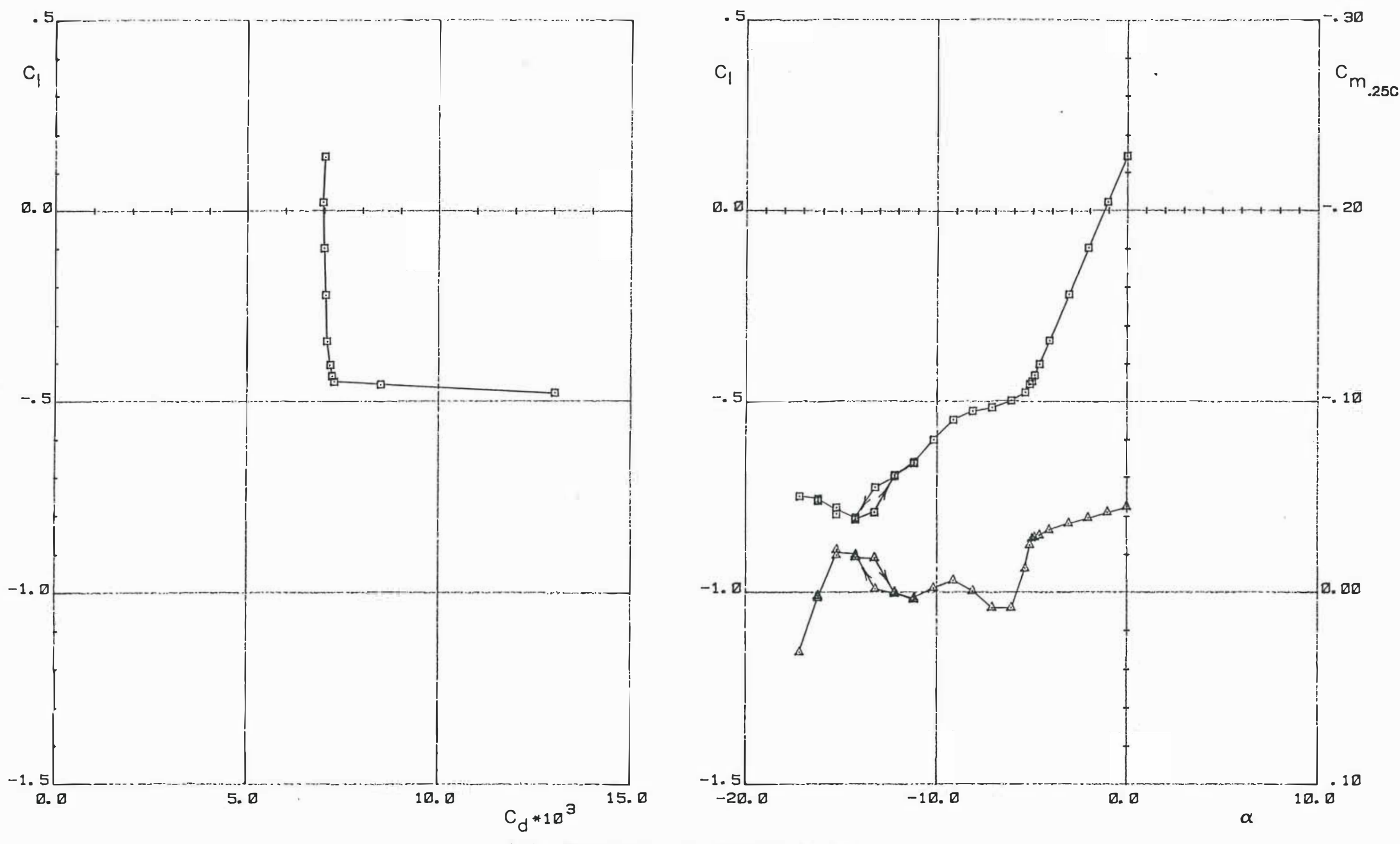

(ii) Negative Iift coefficients.

(c) $R=2,000,000$.

Flaure 17. - Continued. 


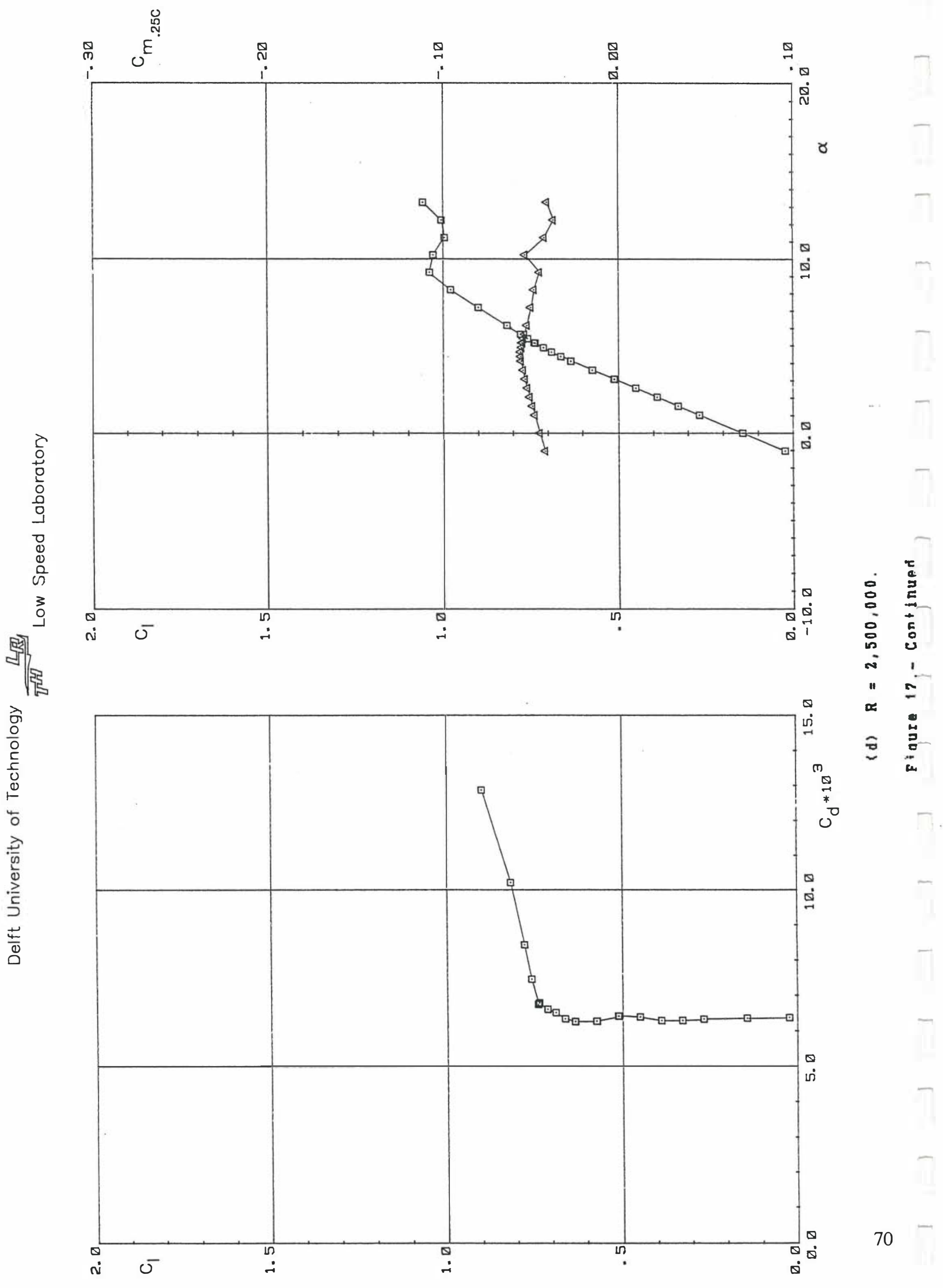


Delft University of Technology त्यु

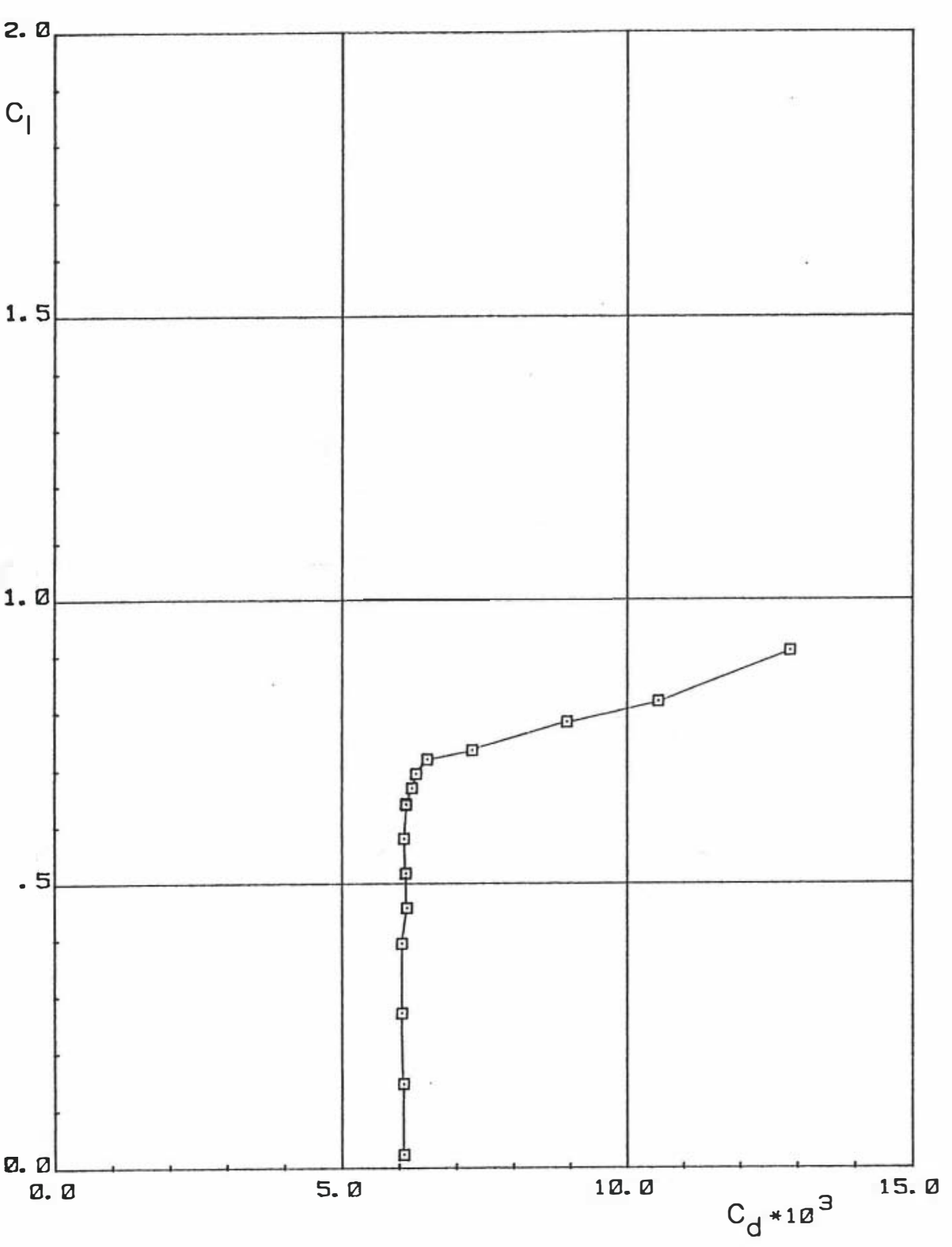

Low Speed Laboratory

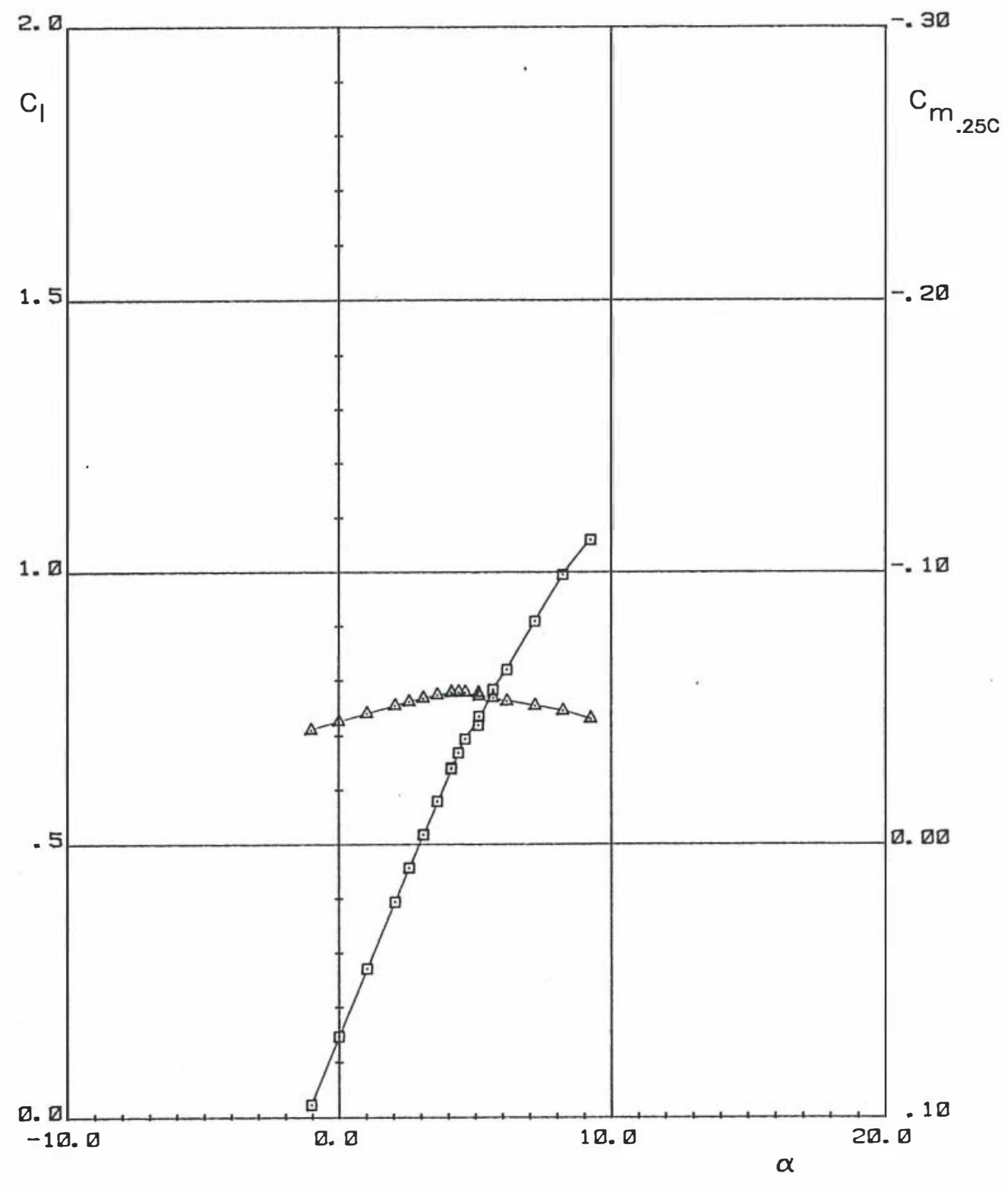

(e) $R=3,000,000$.

Figure 17.- Concluded. 


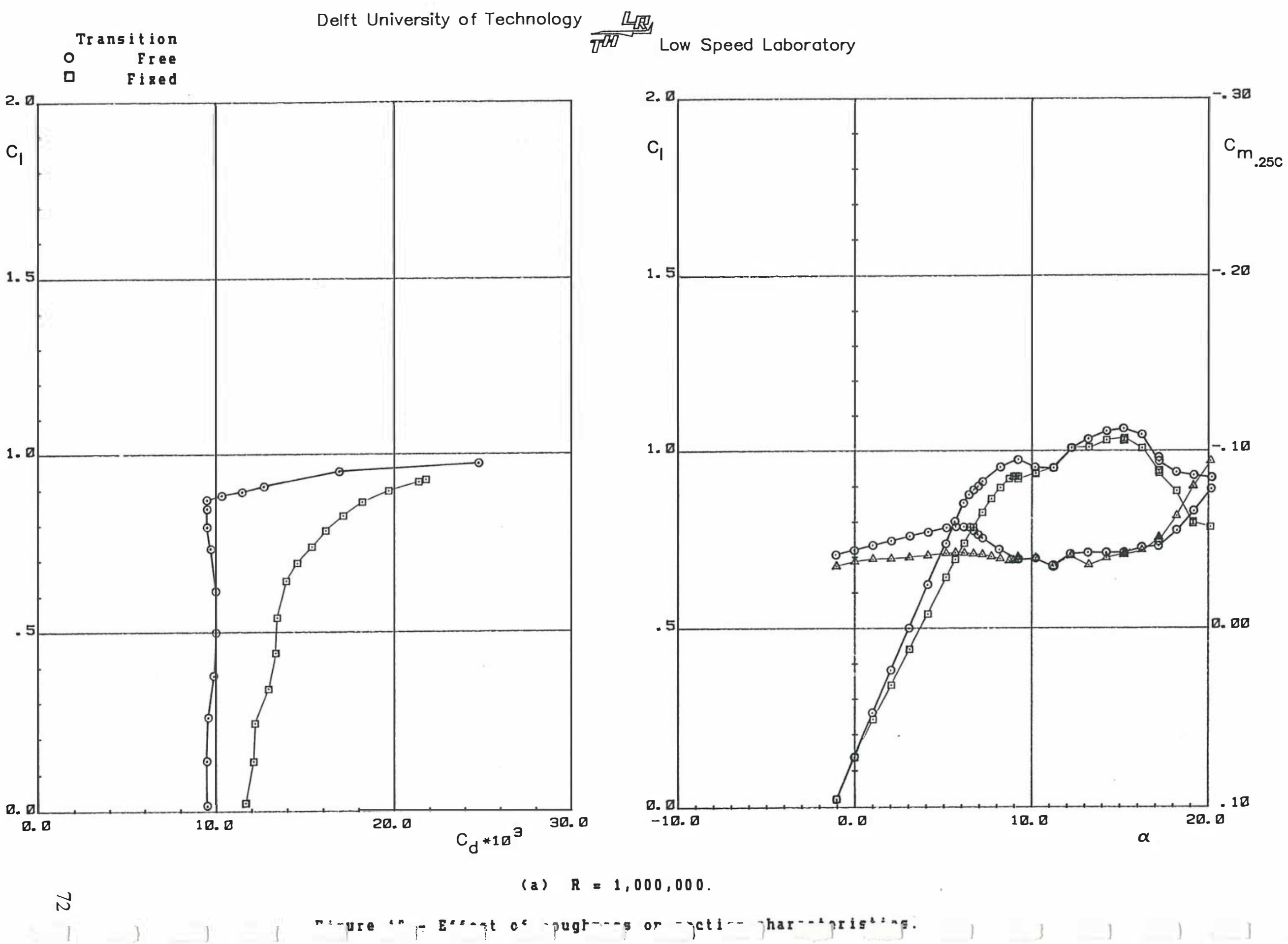




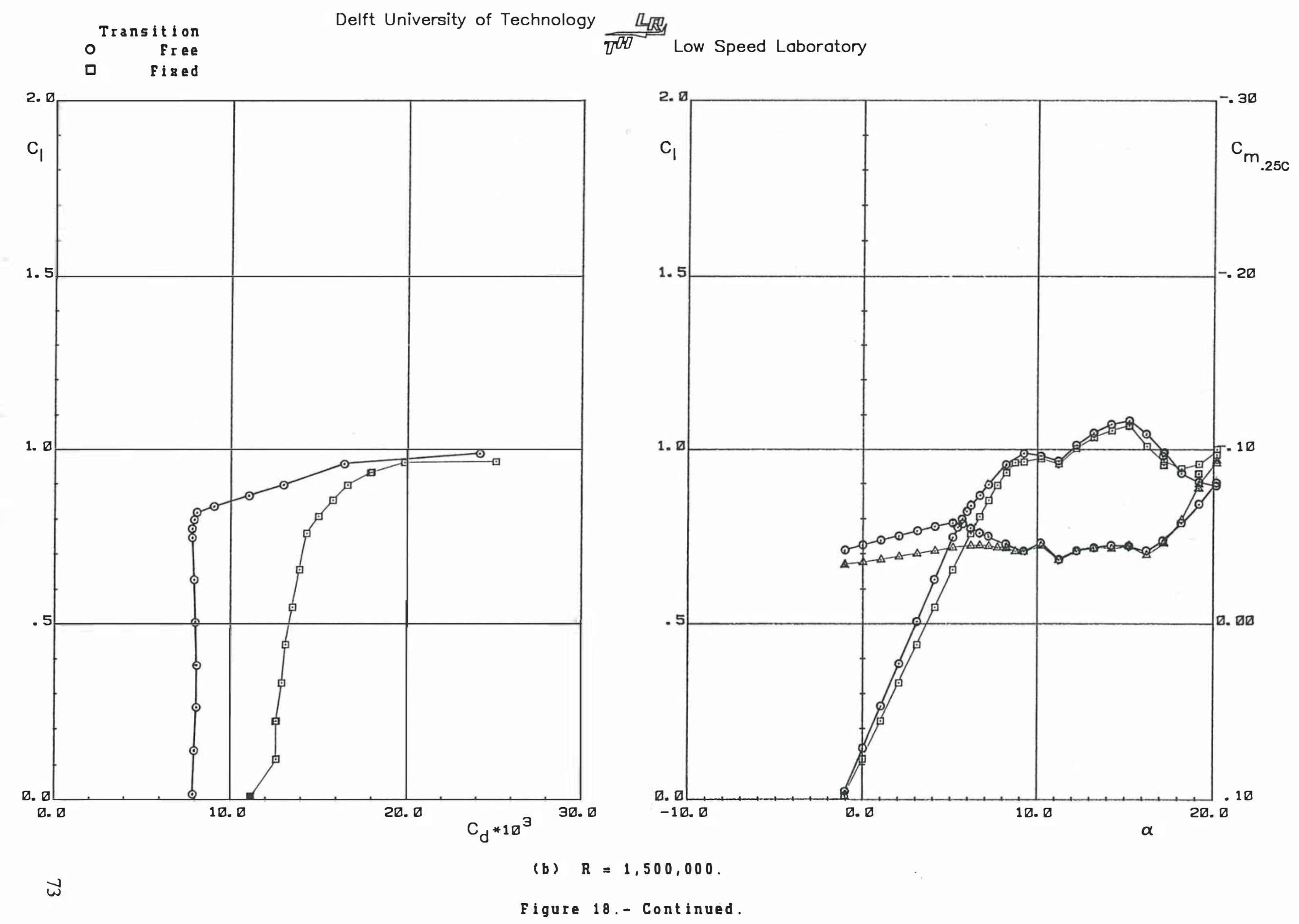




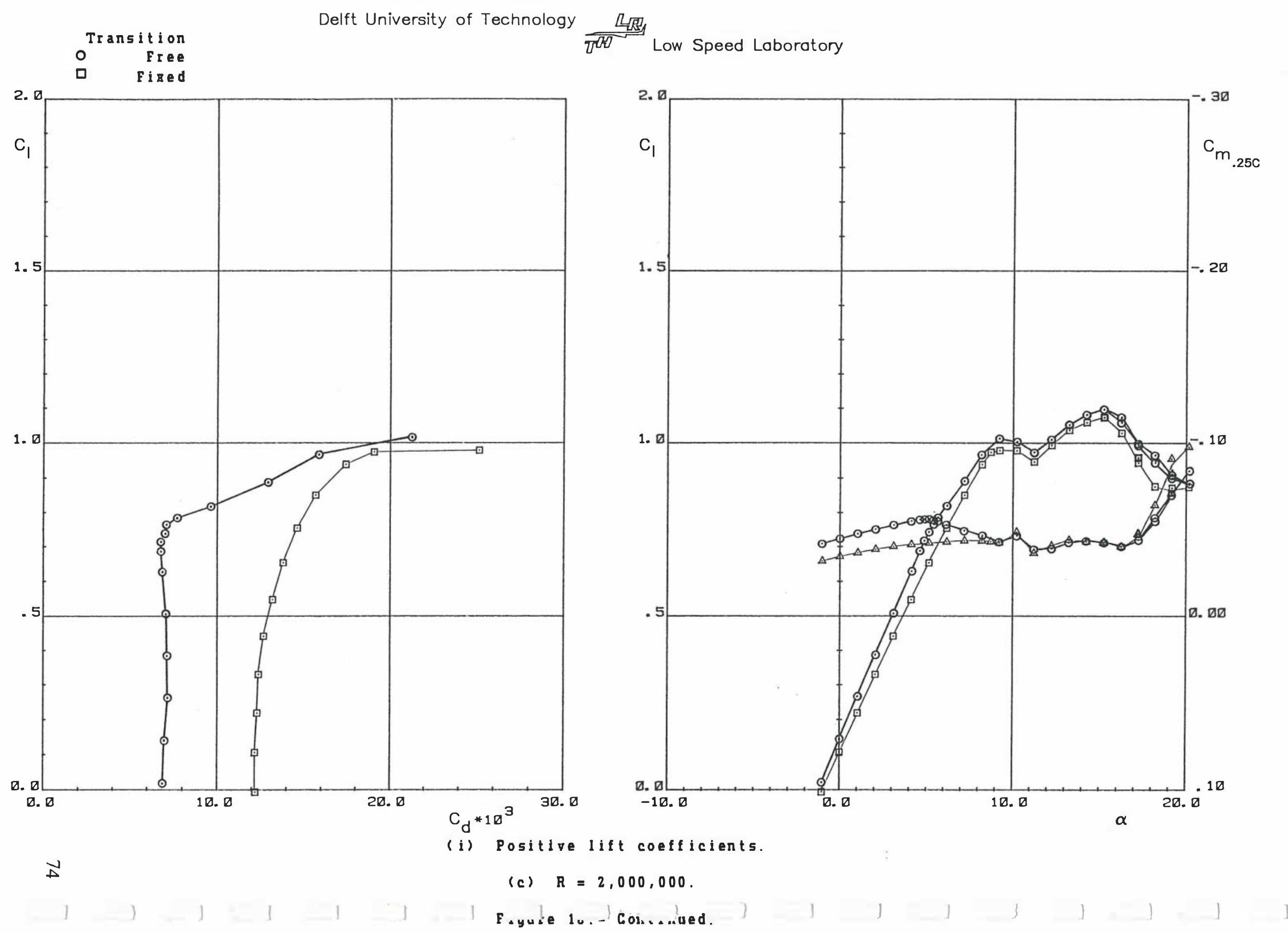




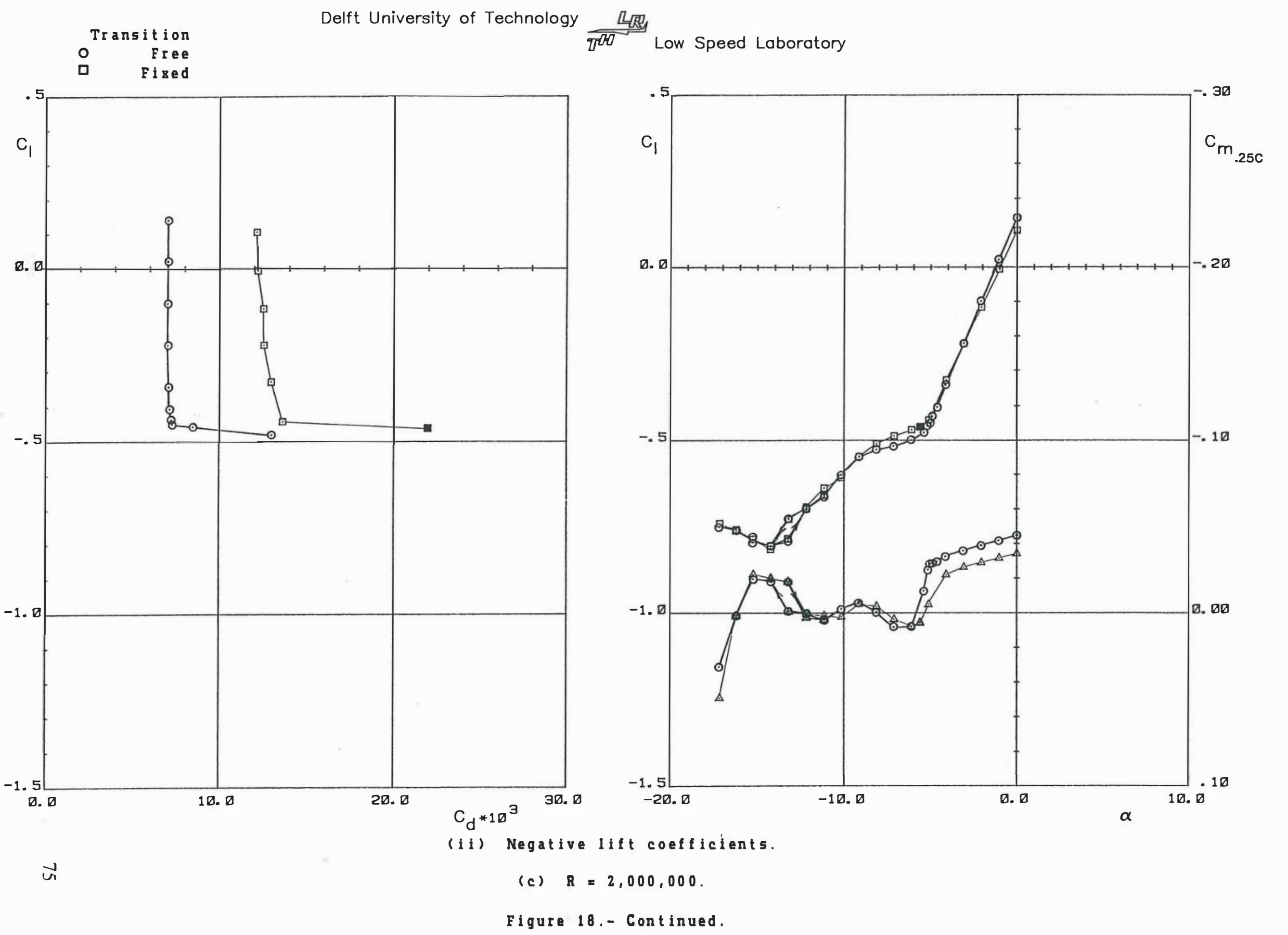




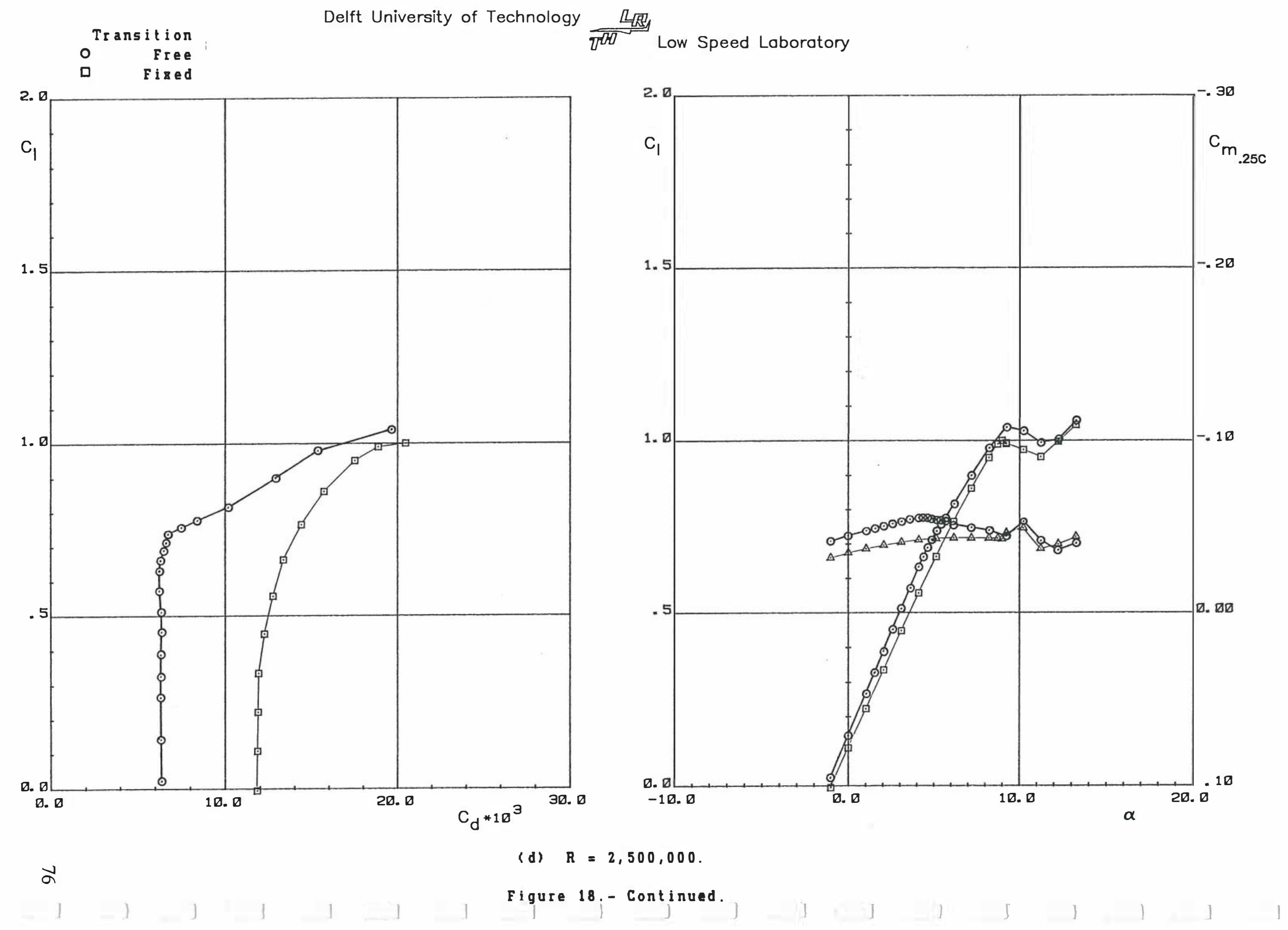




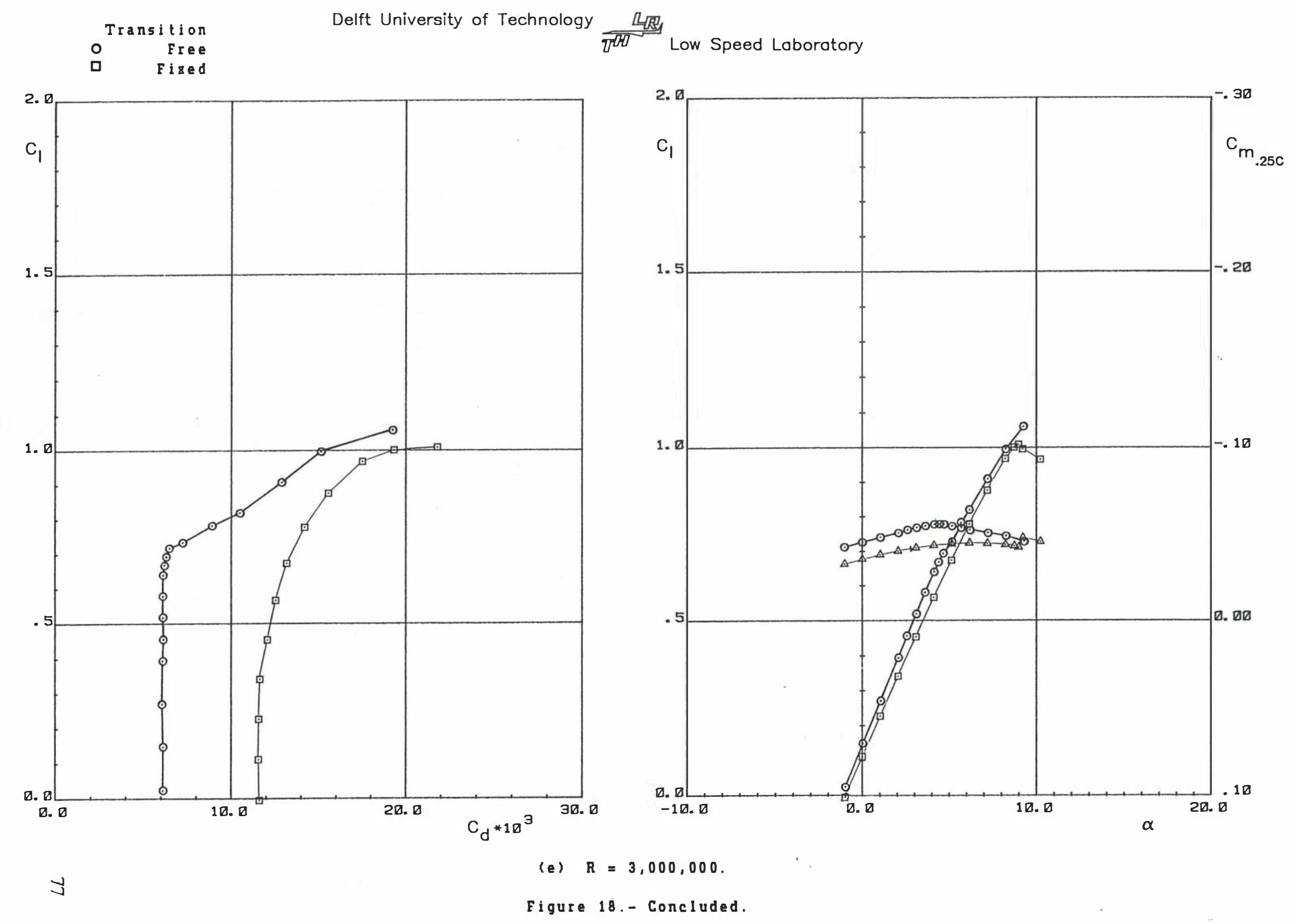




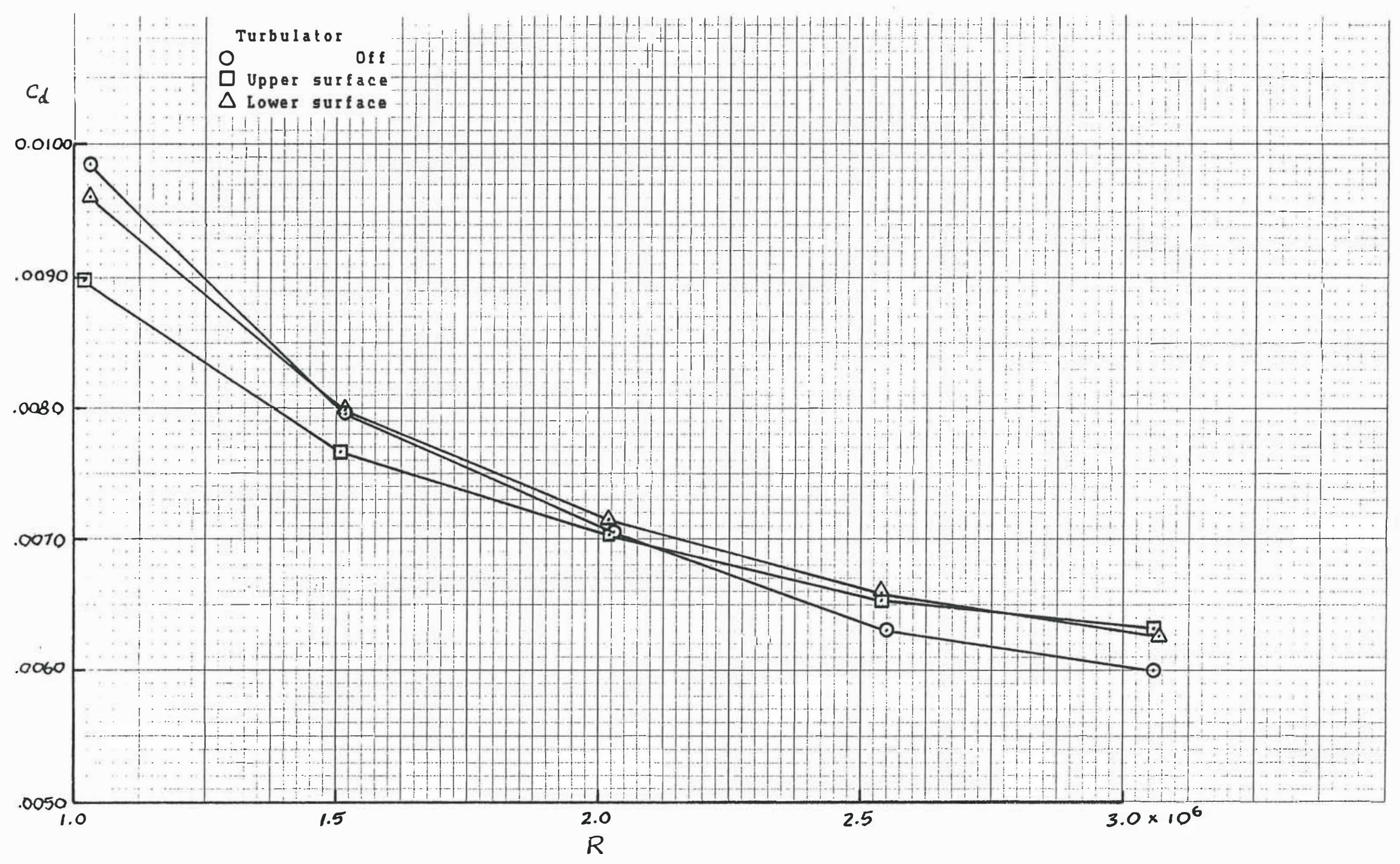

(a) $c_{2}=0.5$. 


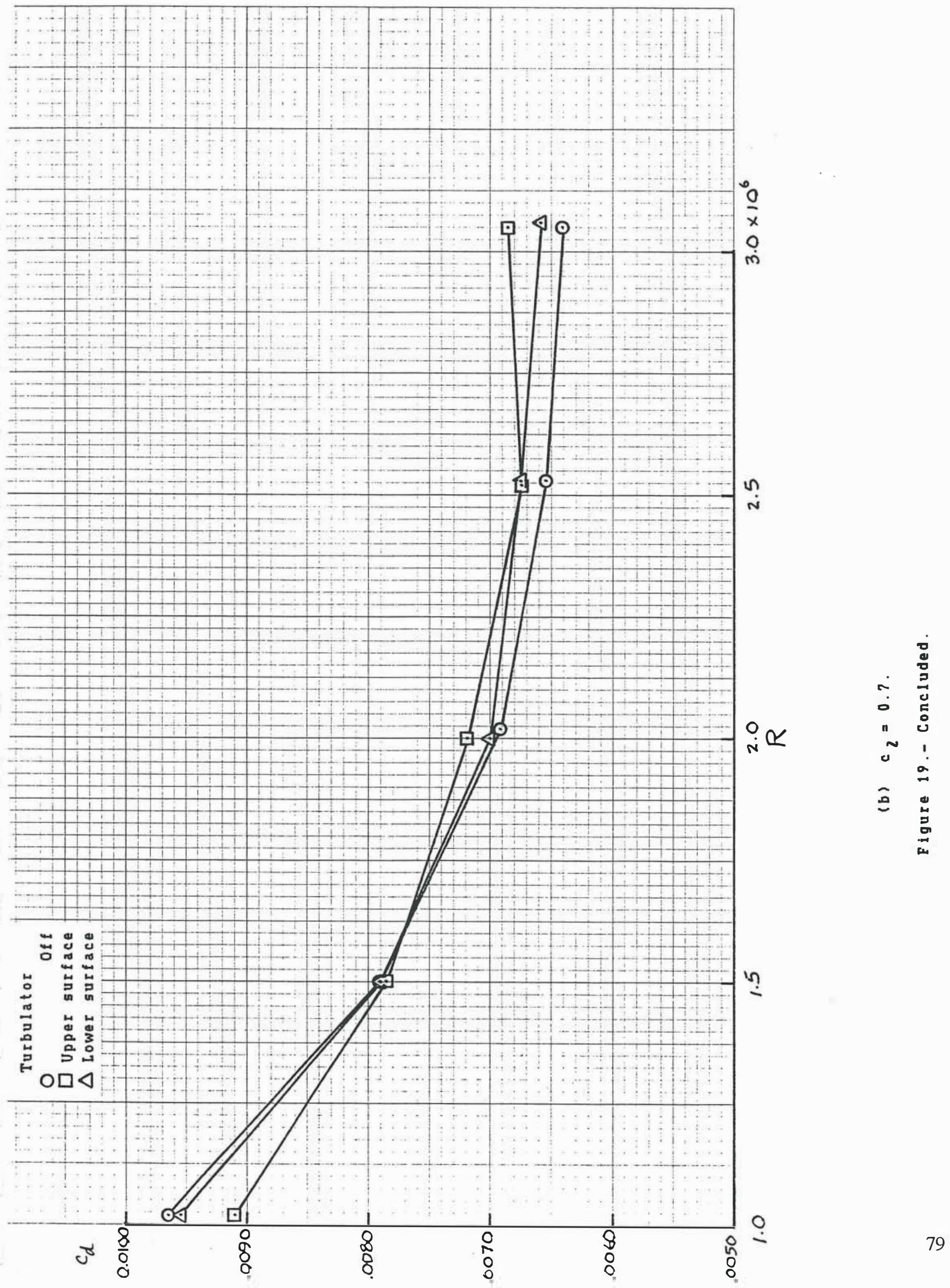




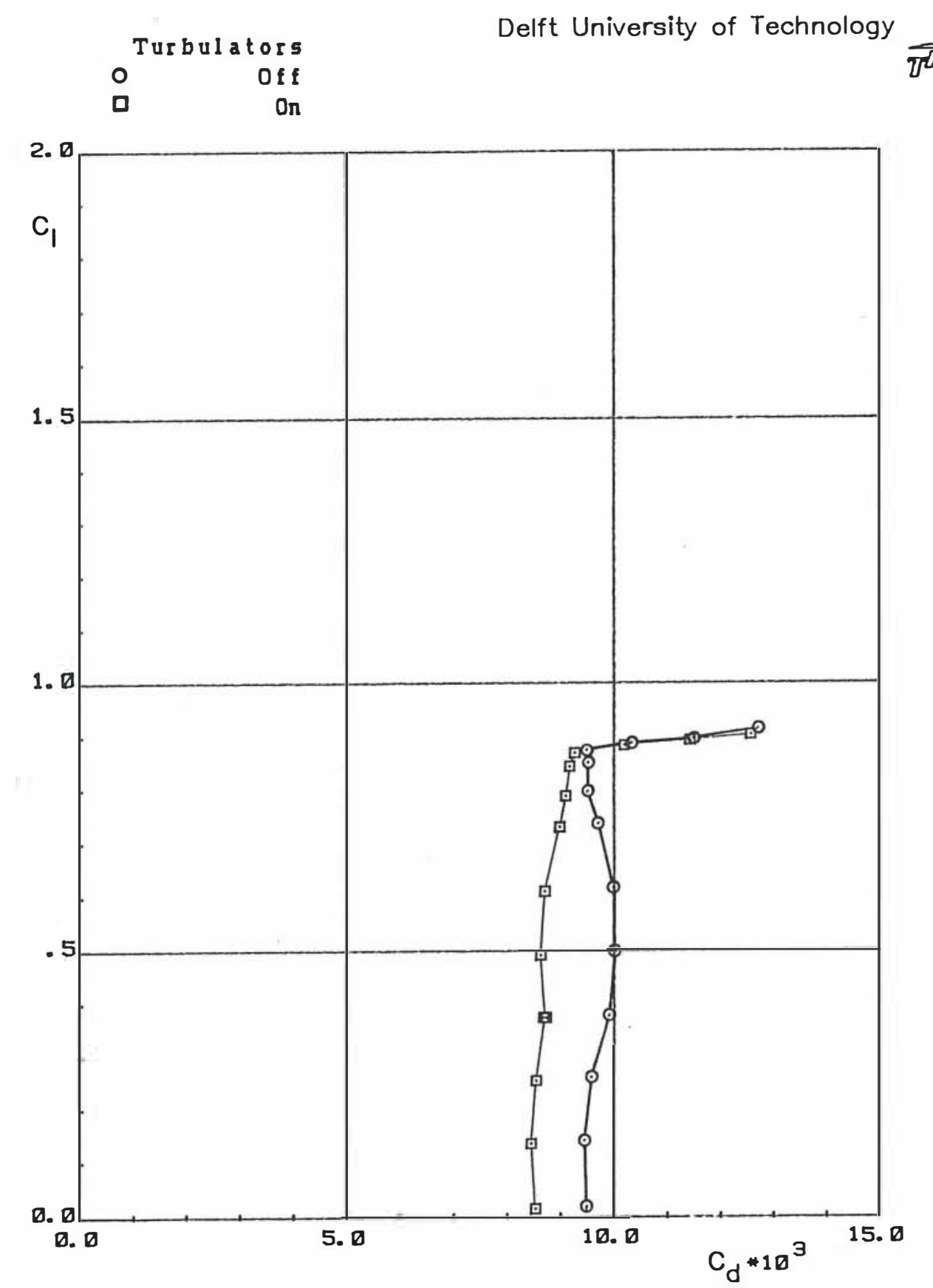

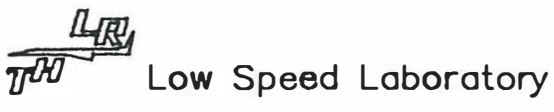

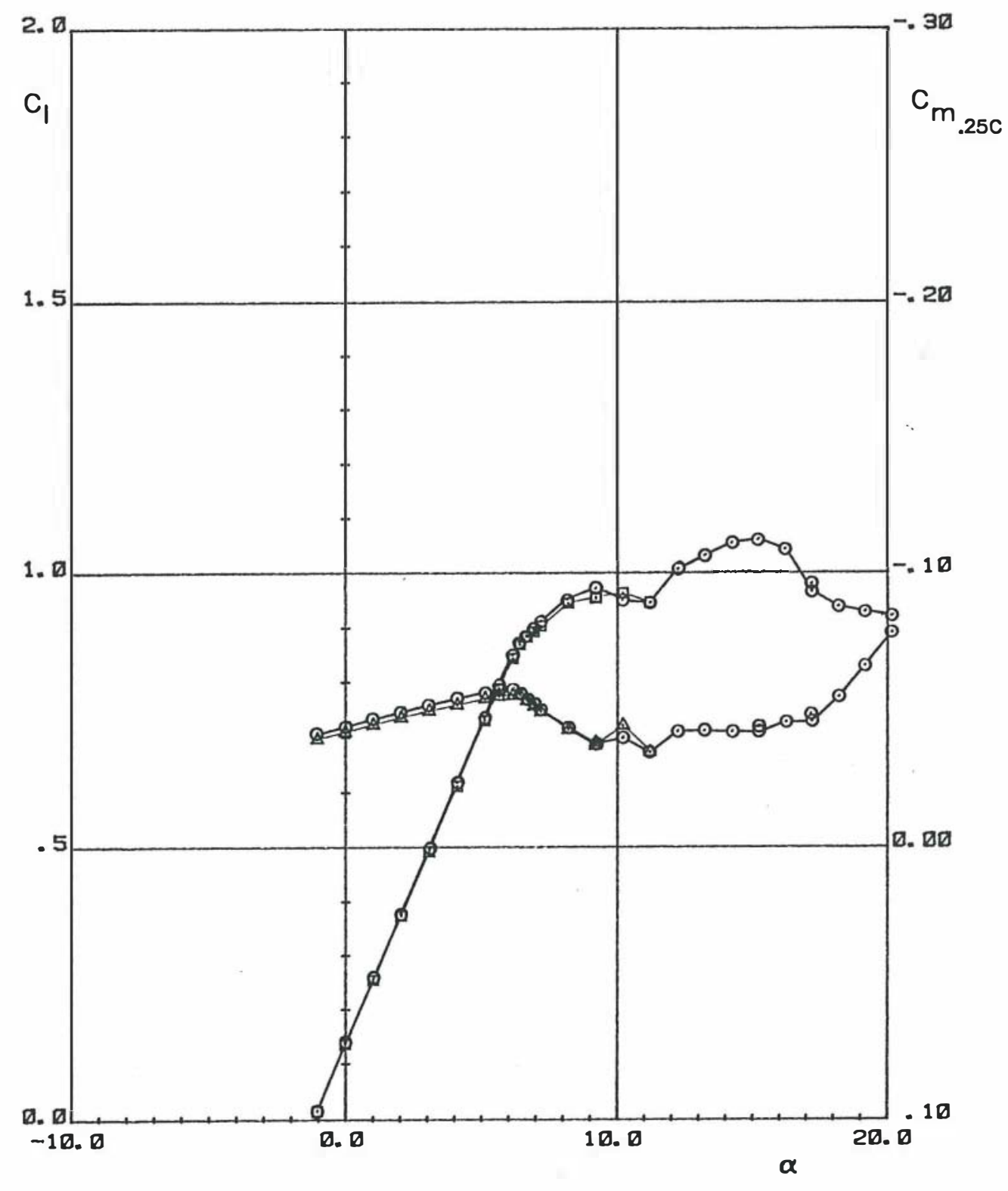

Figure 20.- Effect of turbulators on section characteristics for $R=1,000,000$. 


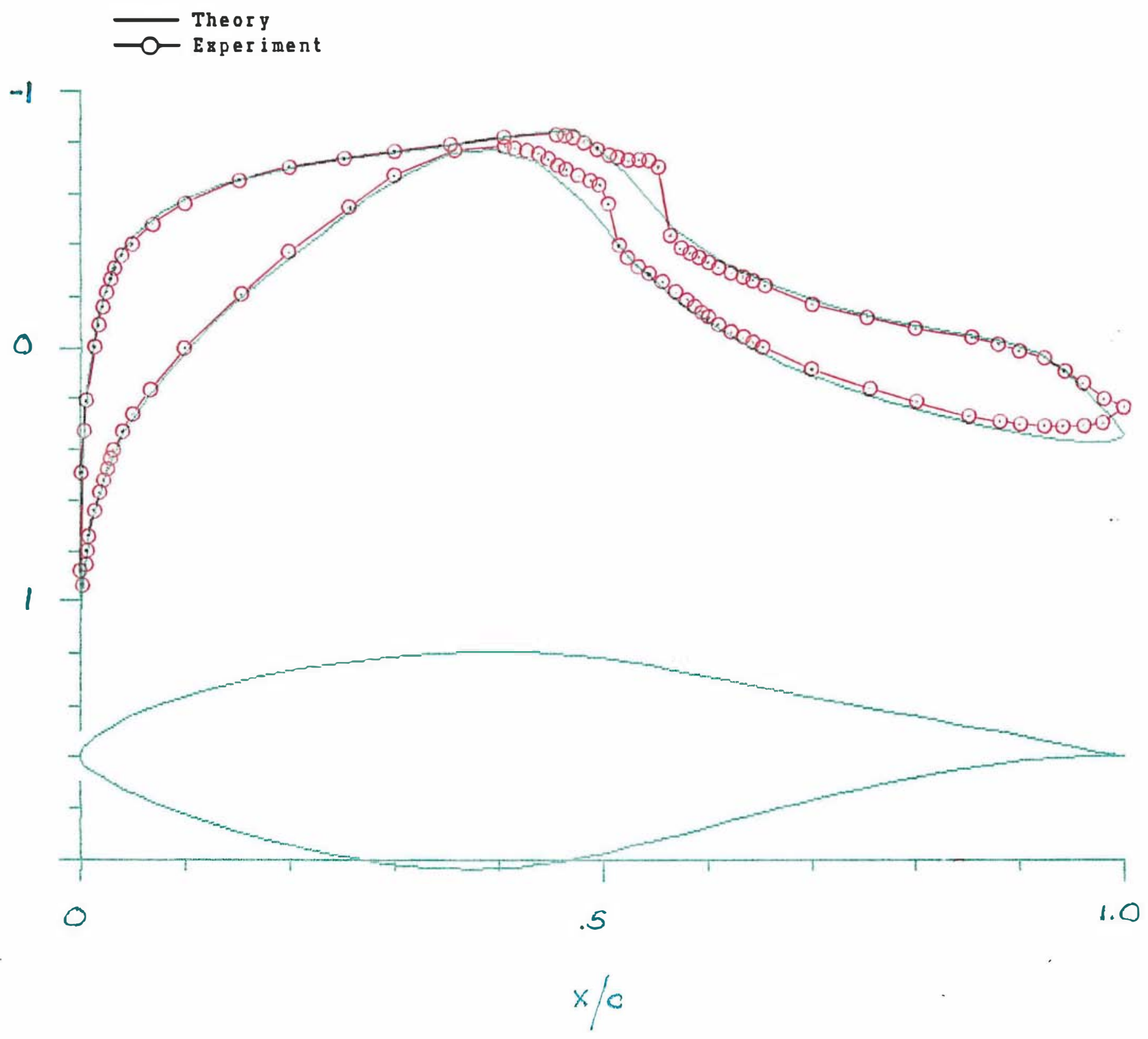

(a) $c_{2}=0.27$.

Figure 21.- Comparison of theoretical and experimental pressure distributions. 


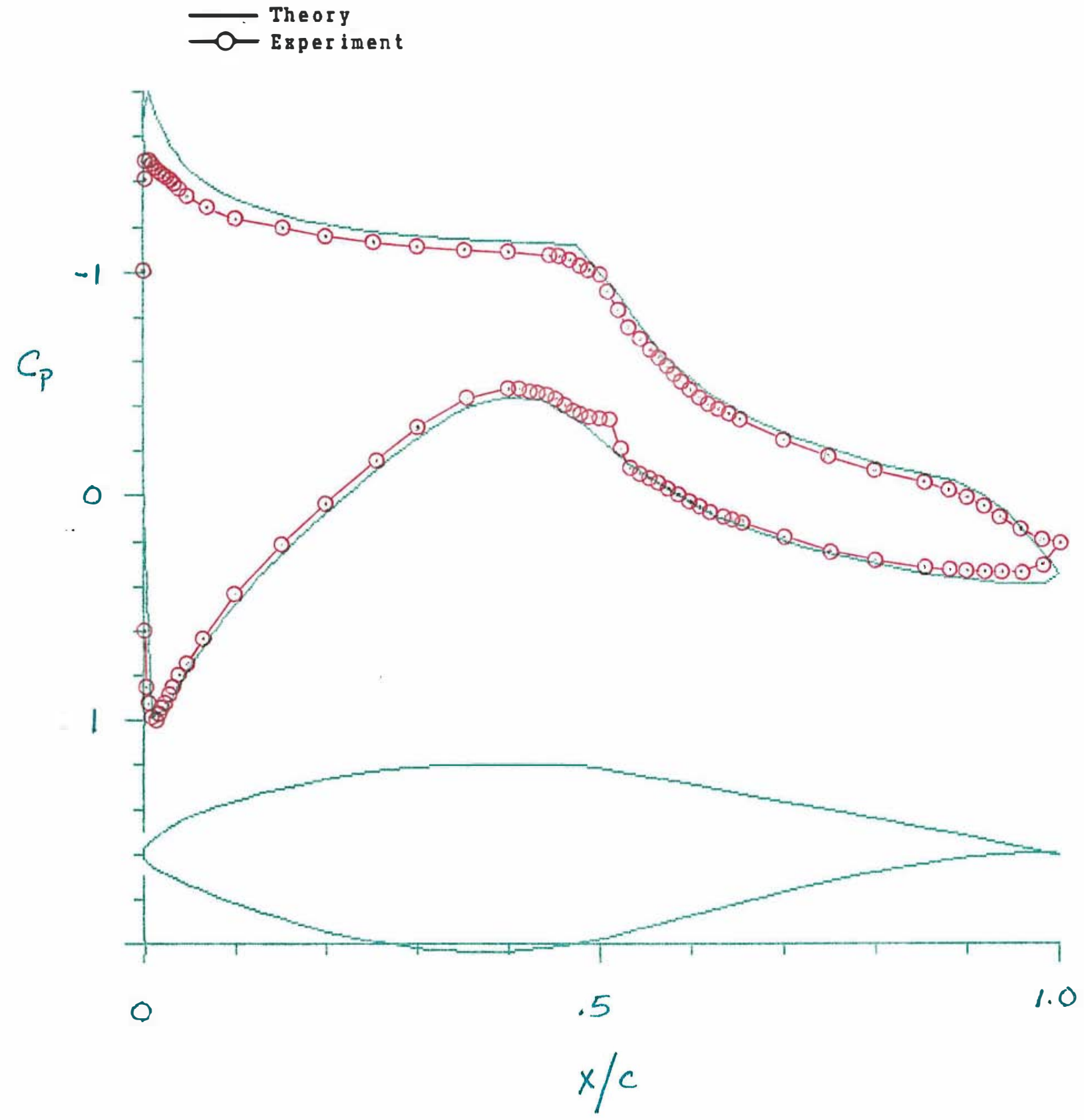

(b) $c_{2}=0.77$.

Figure 21. - Continued. 
Theory

O- Experiment

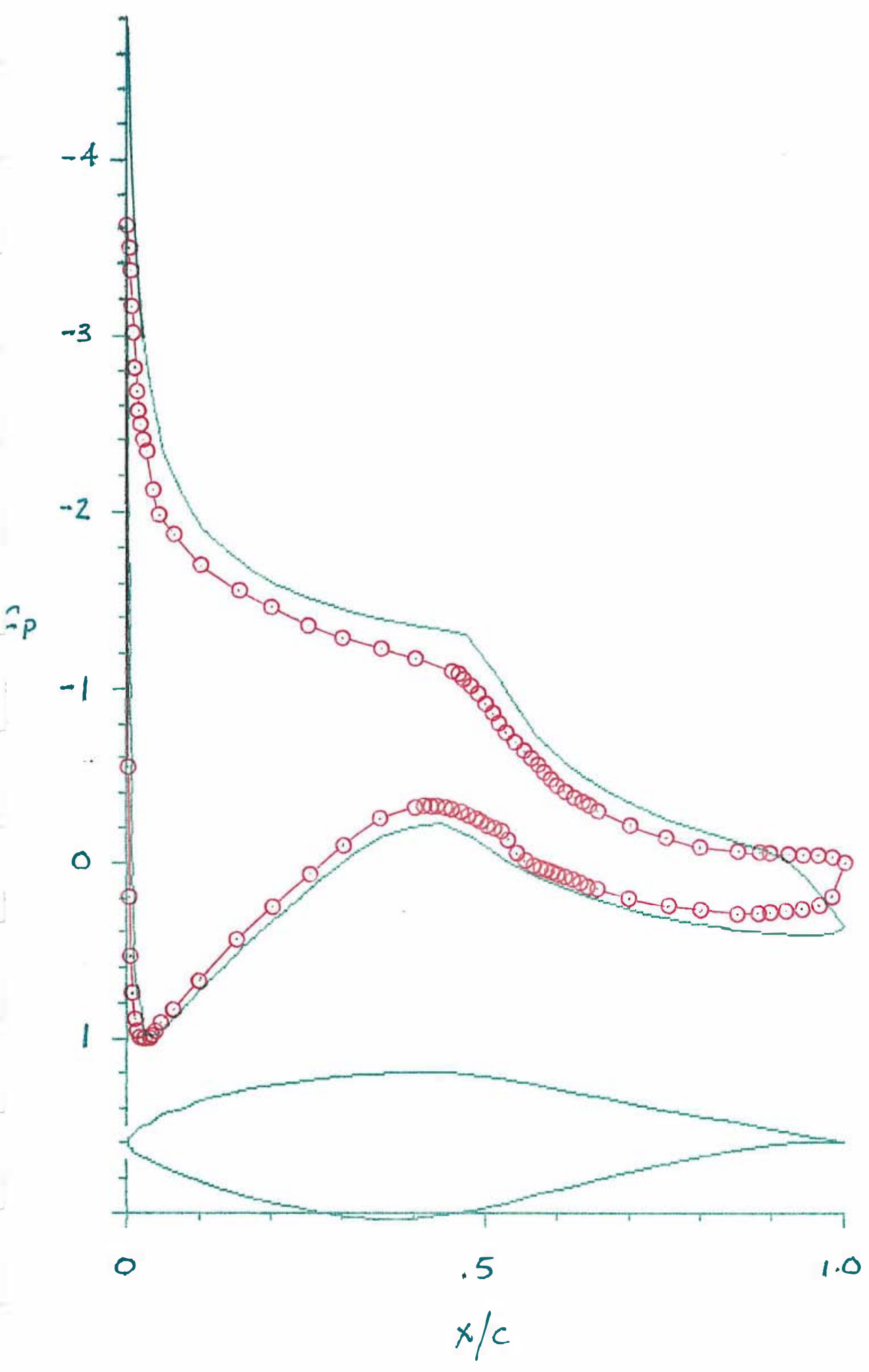

(c) $c_{2}=1.01$.

Figure 21. - Concluded. 


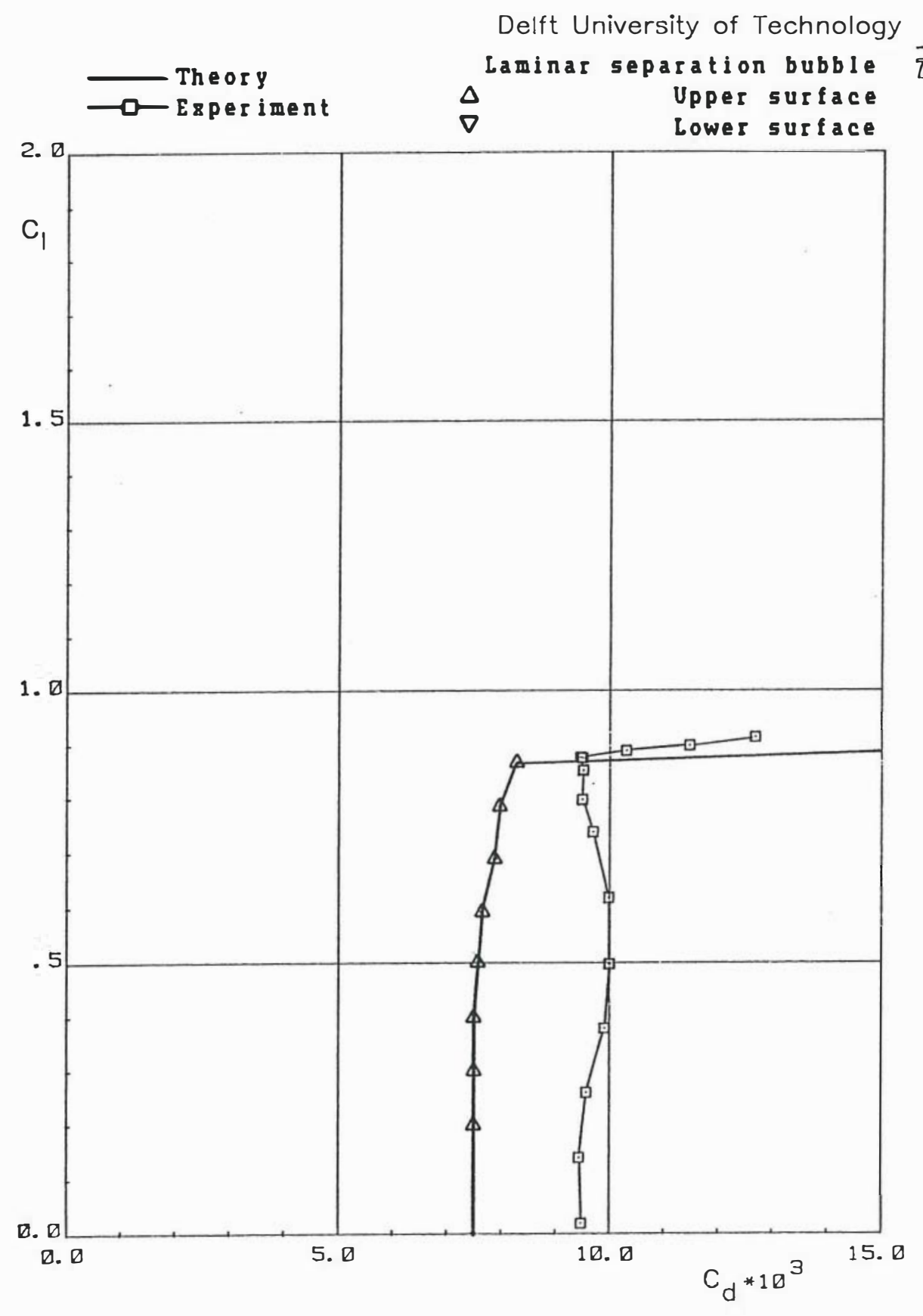

$\frac{\text { 几思 }}{T^{2} I^{2}}$ Low Speed Laborotory

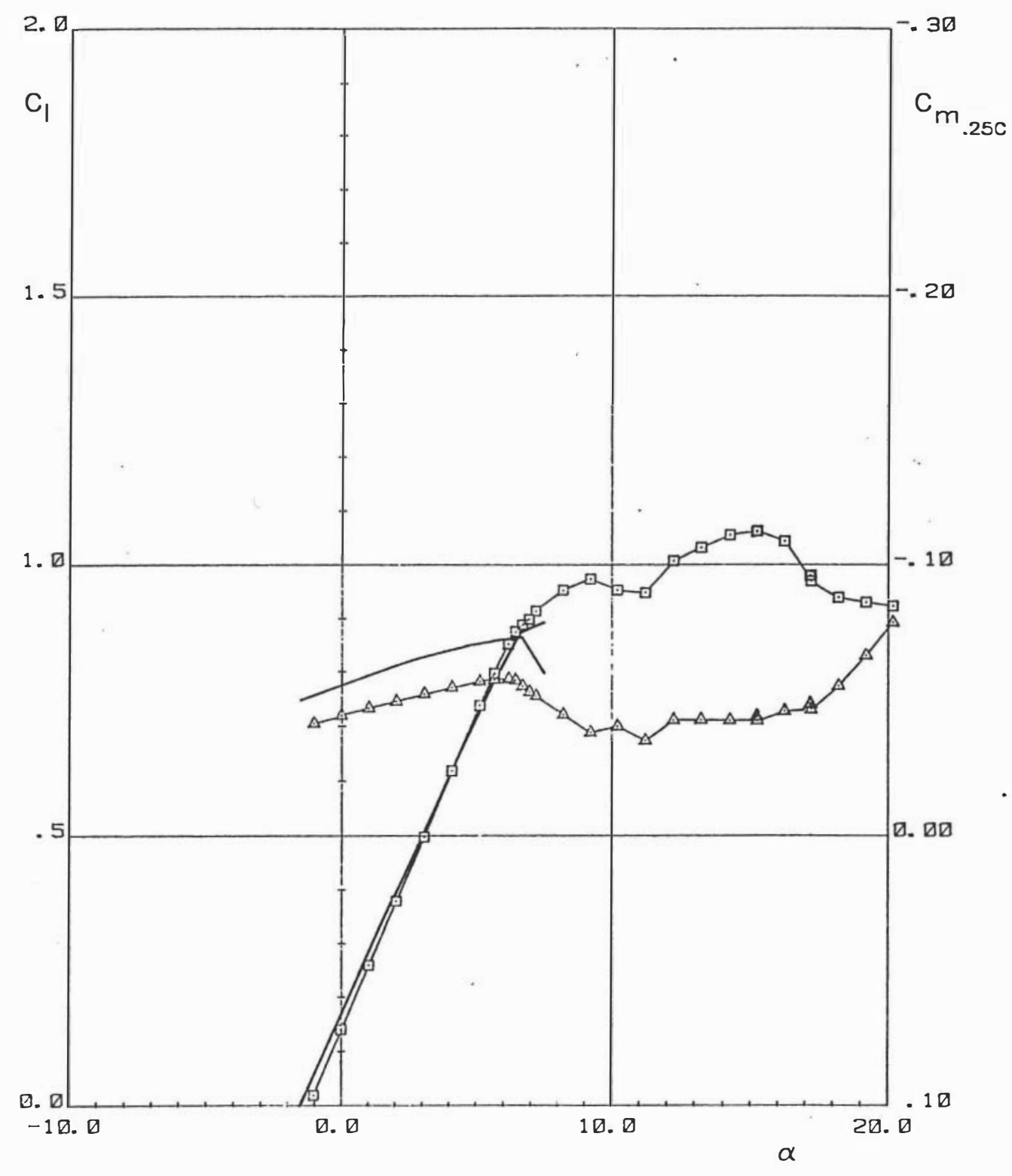

(a) $R=1,000,000$. 

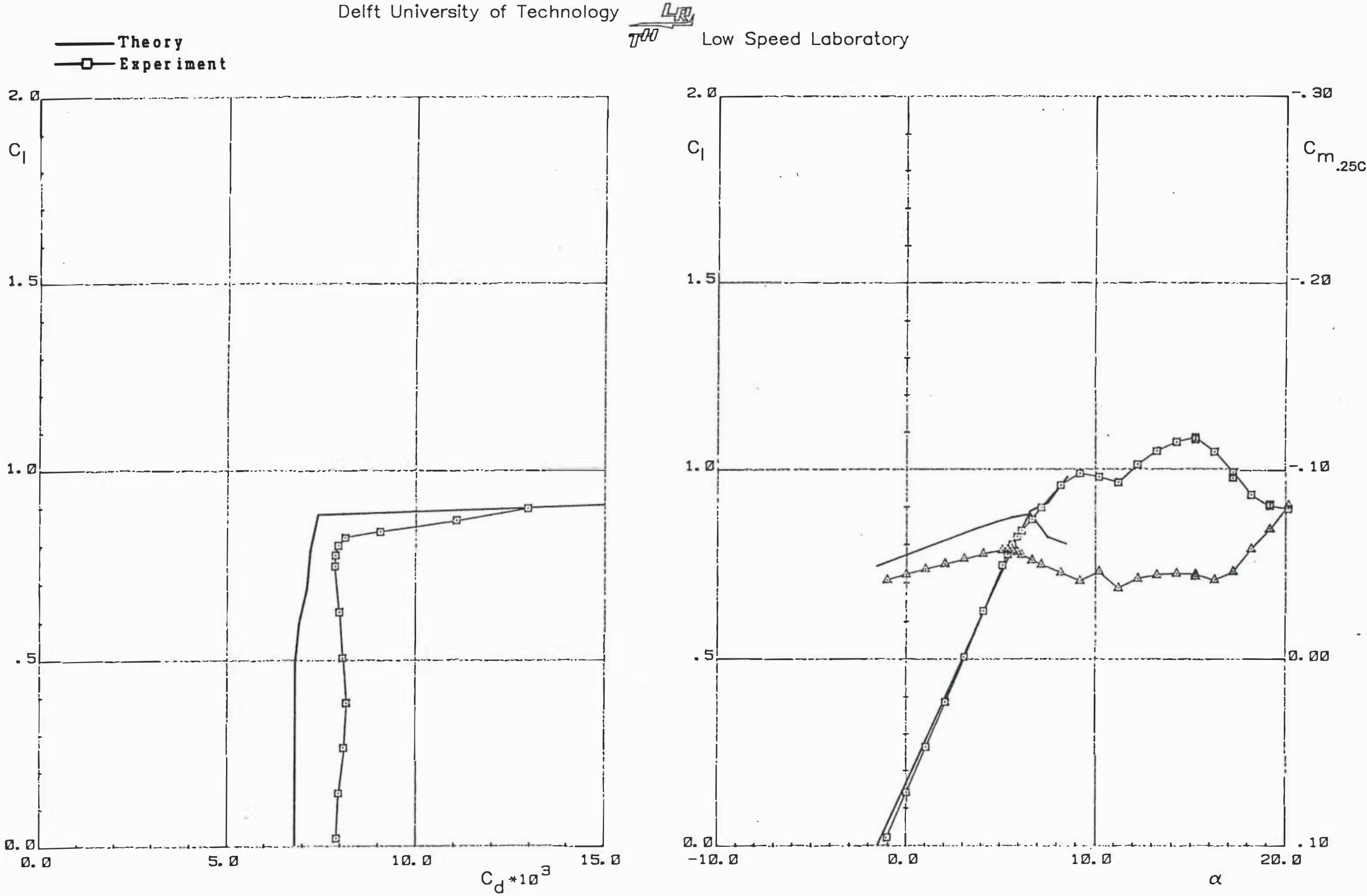

(b) $R=1,500,000$.

Figure 22. - Continued. 


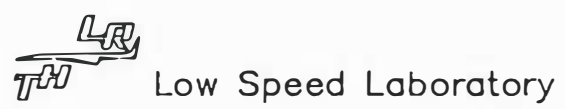

\section{- Theorg
$\square-$ Esperiment}

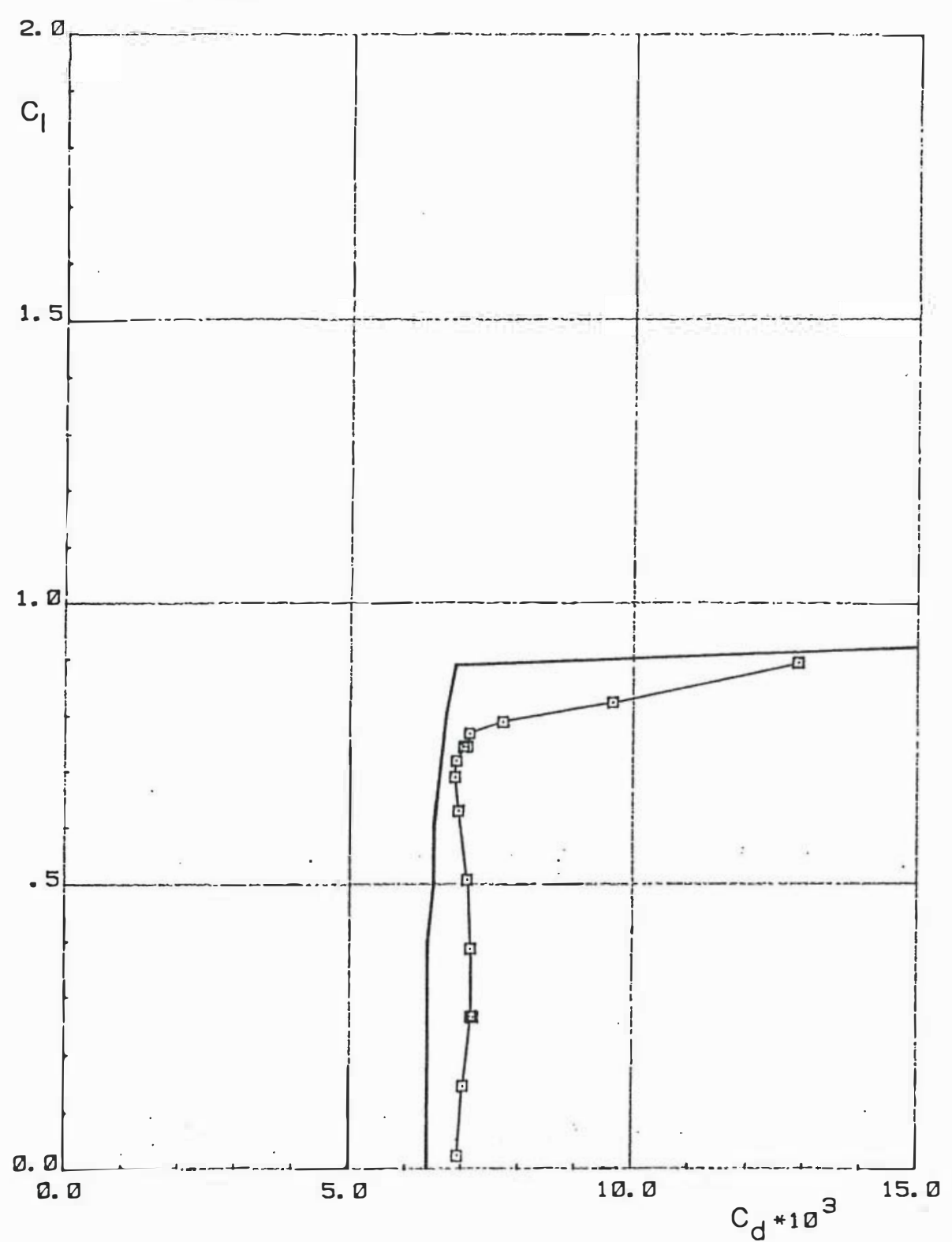

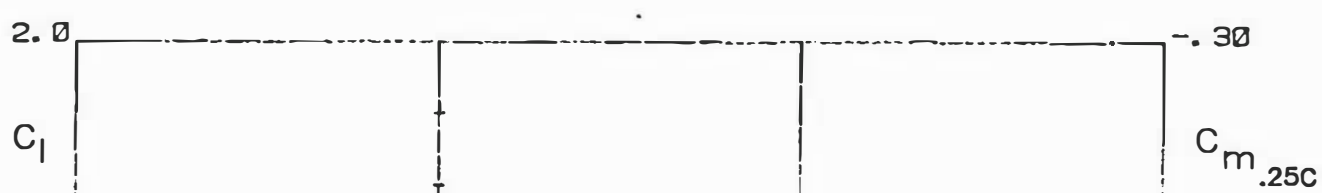

D. D

$-10.0$ 


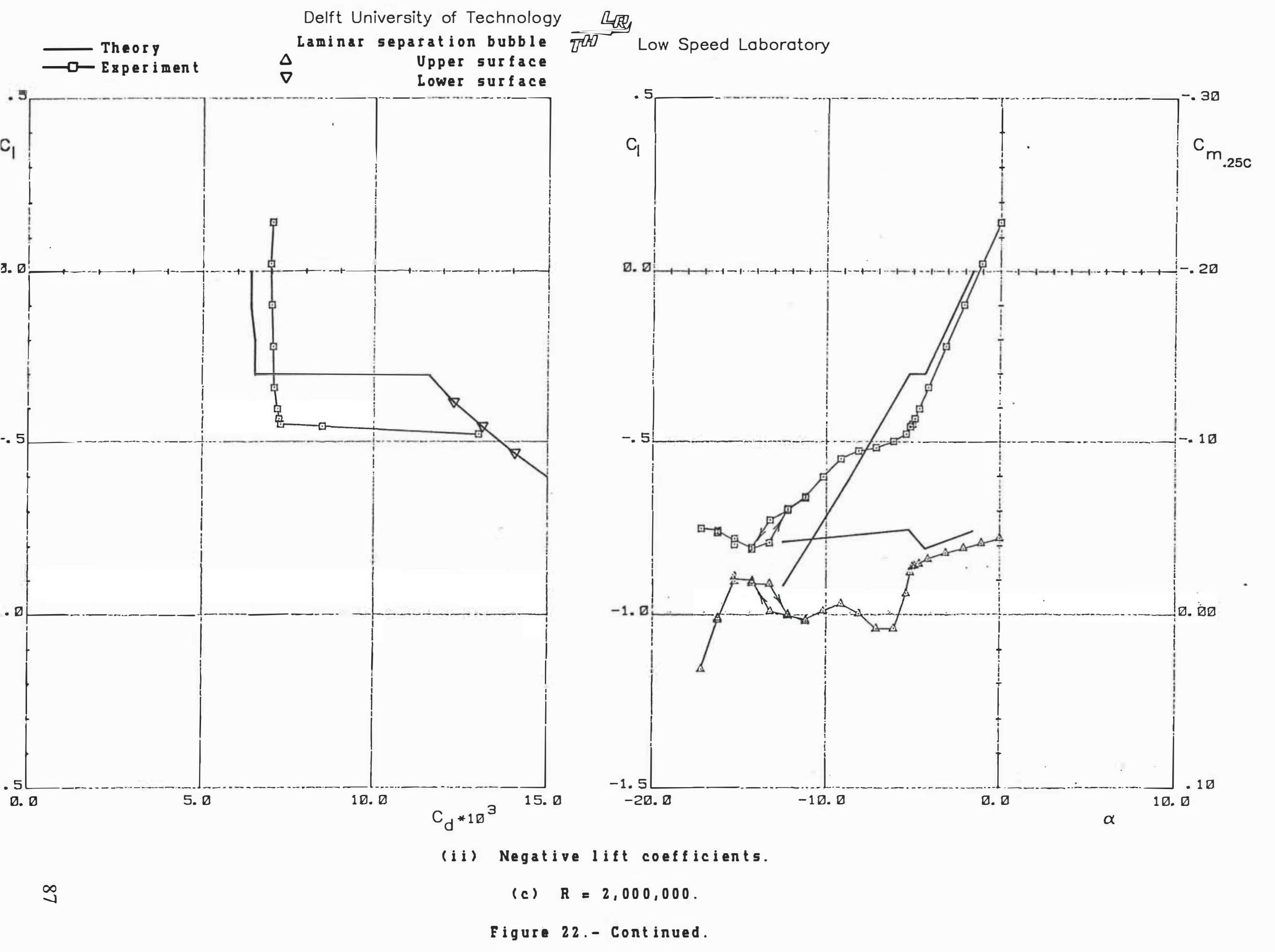




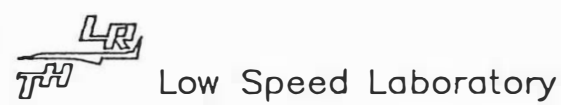

Theory —-Esperiment

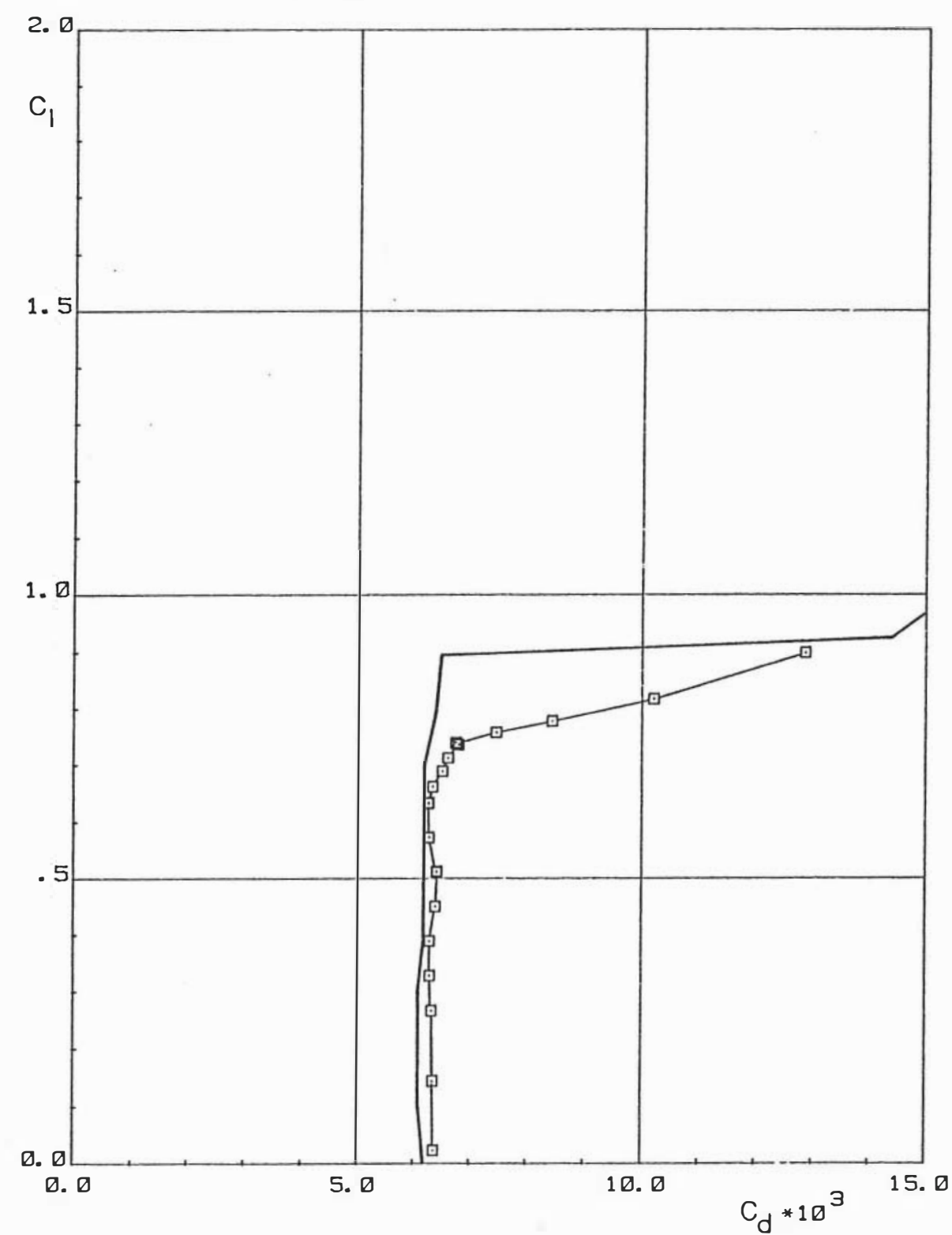

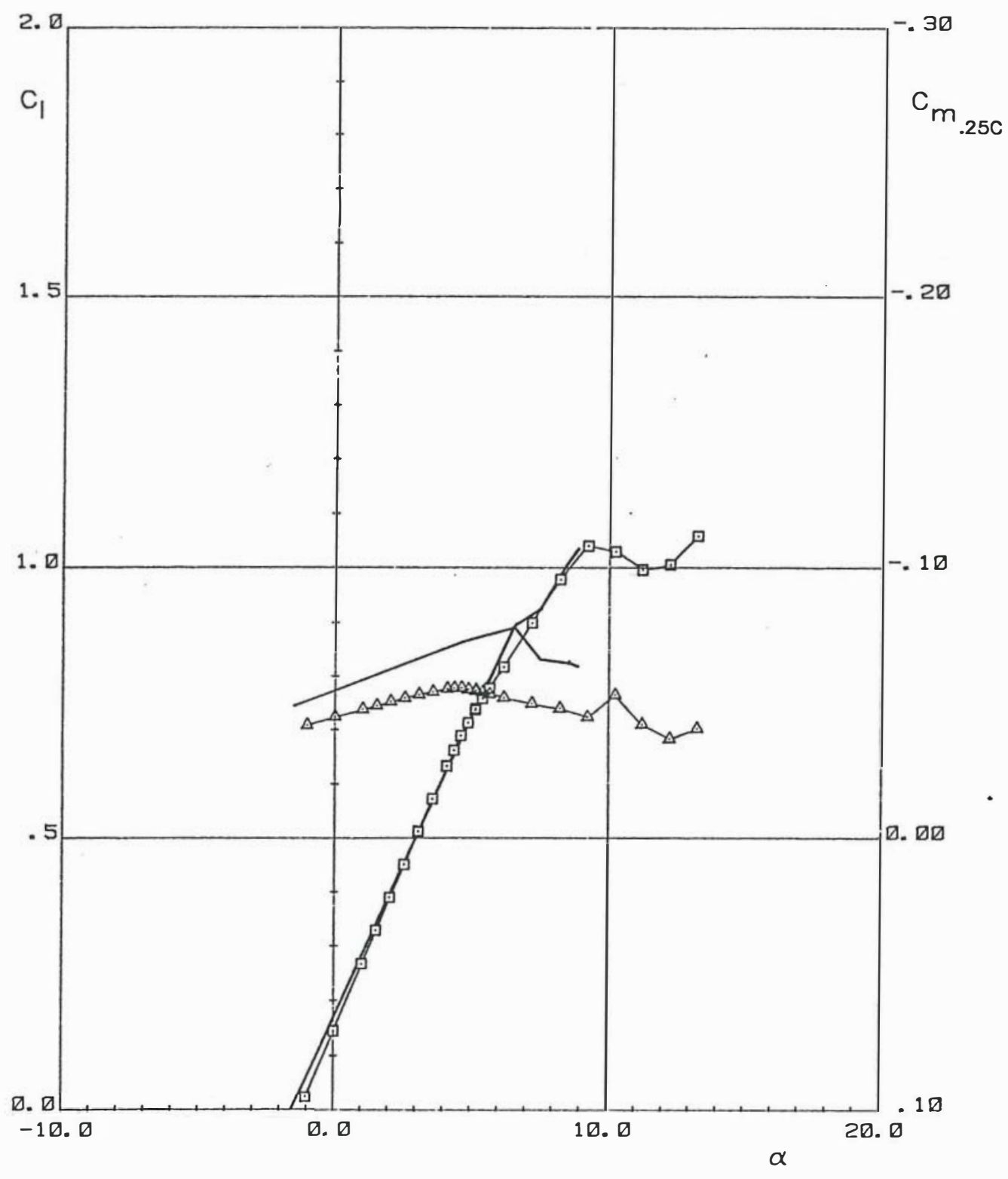

(d) $R=2,500,000$.

Figure 22.- Continued. 

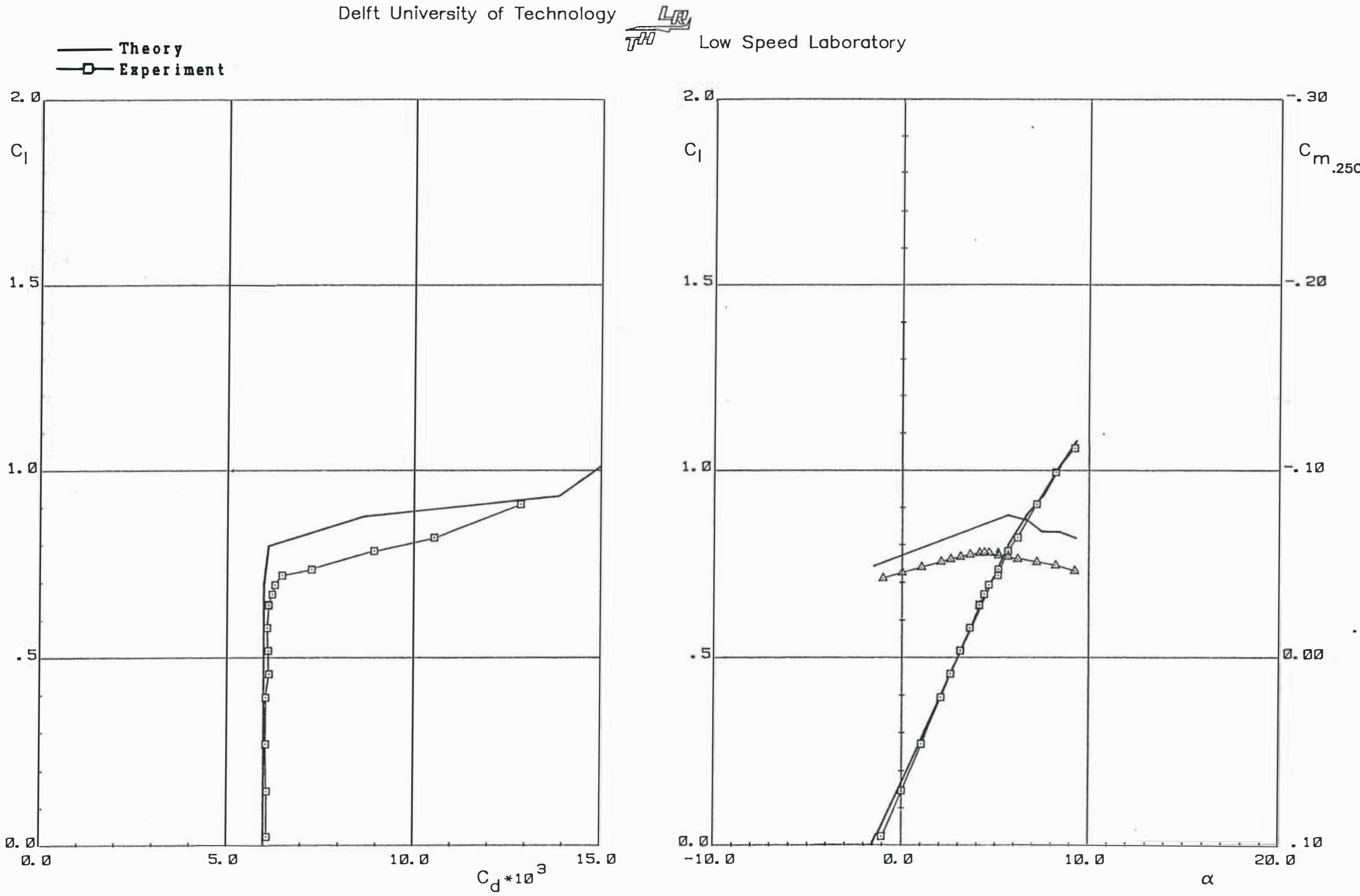

(e) $R=3,000,000$.

Figure 22.- Concluded. 
$\bar{\tau}^{20}$ Low Speed Laboratory

$\longrightarrow$ Esperiment

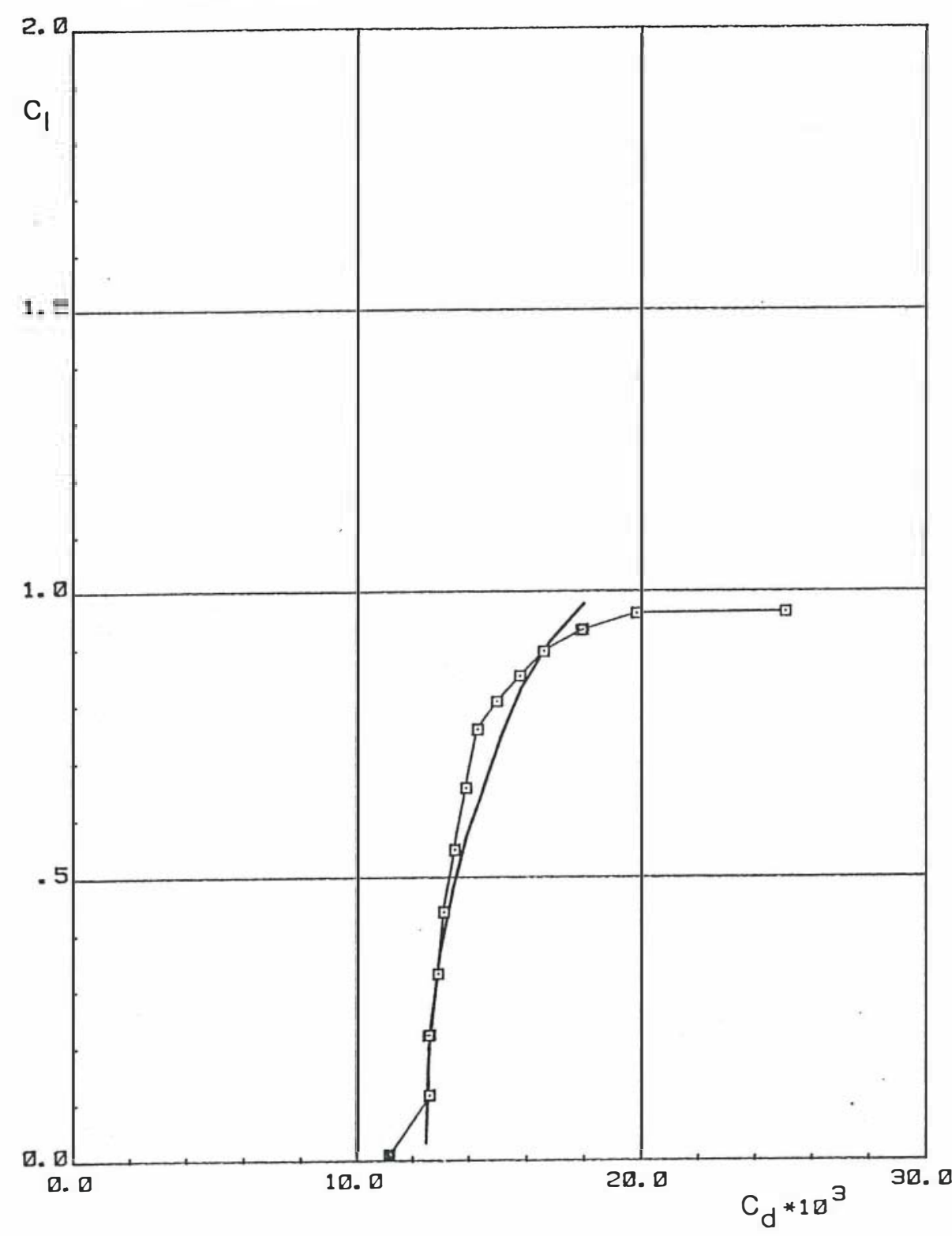

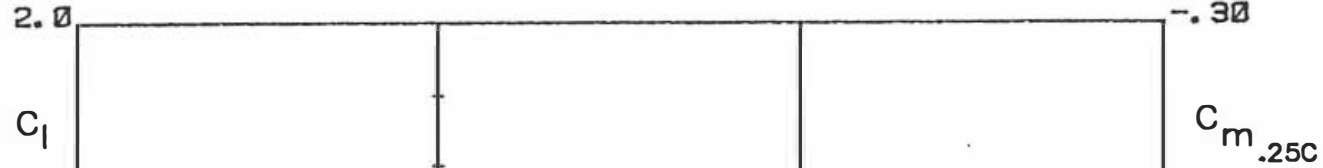

จ.

ㅁ. ㄴ. 1 10. D

(b) $R=1,500,000$

Figure 23. - Continued. 
Theory - Experiment

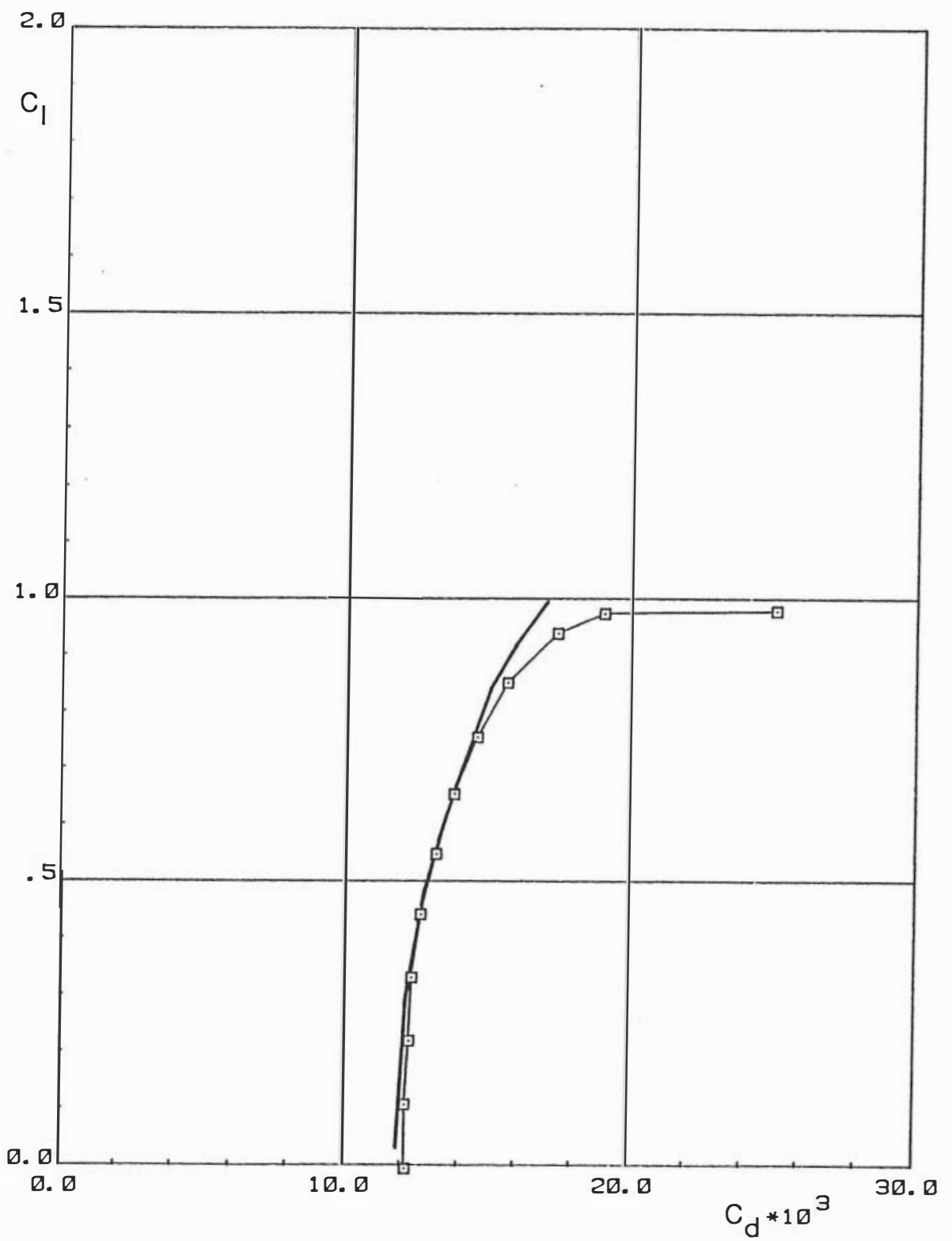

Delft University of Technology

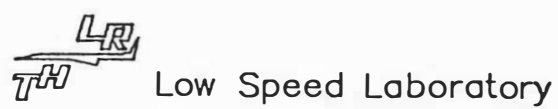

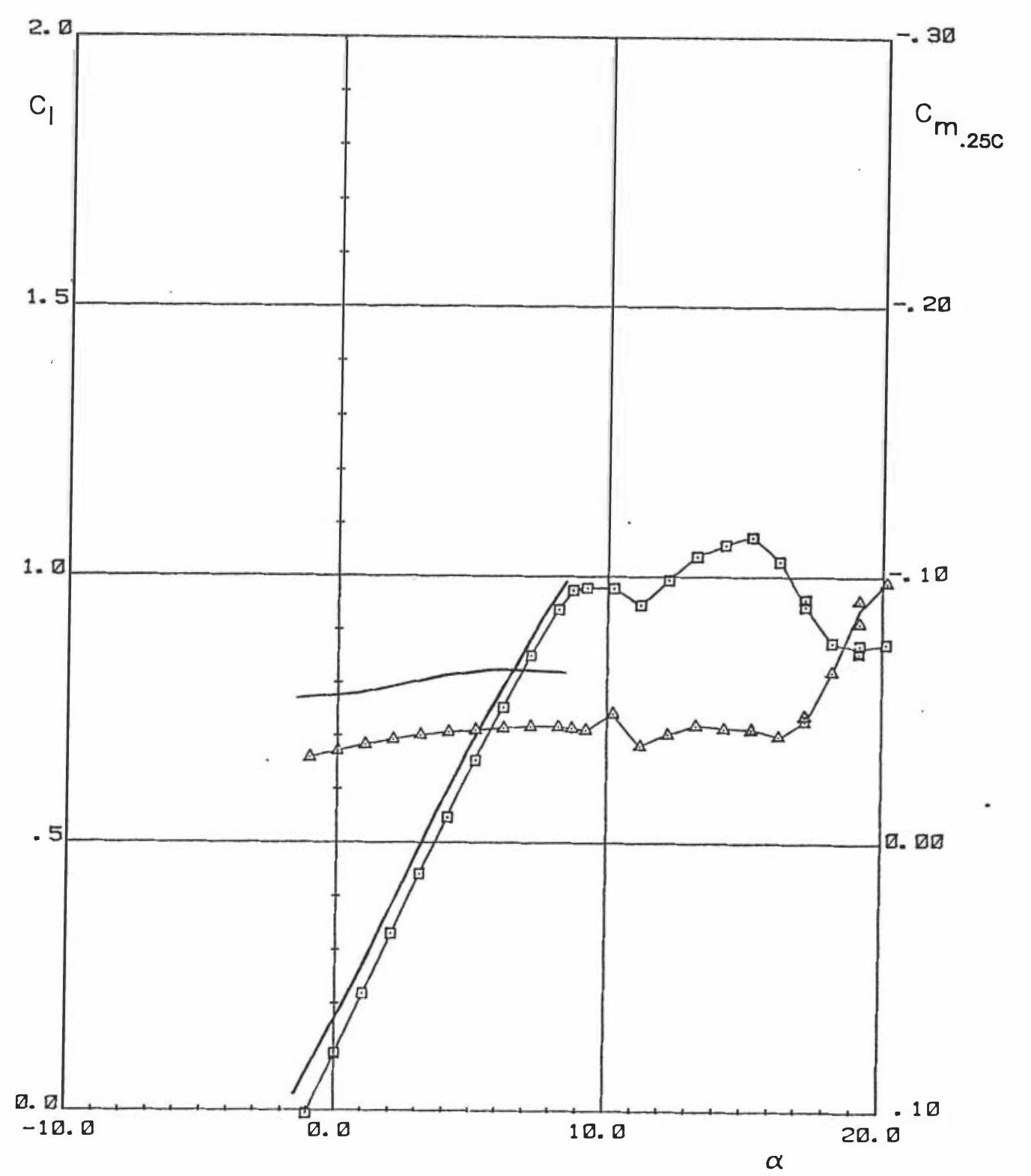

(i) Positive lift coefficients.

N

(c) $R=2,000,000$.

Eis 23 ont d. 
Delft University of Technology

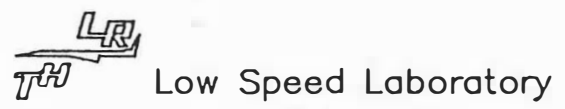

Theory

-Esperiment

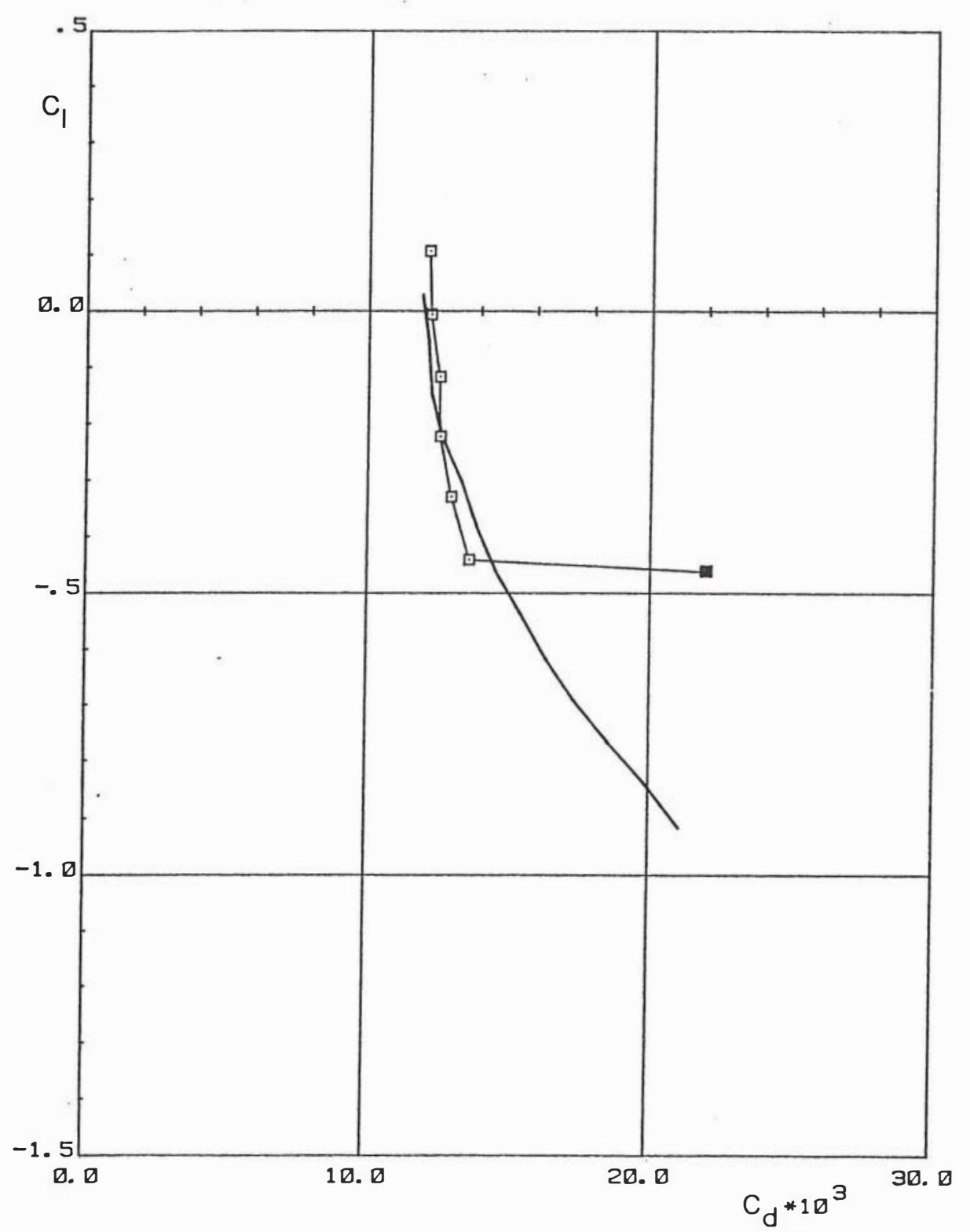

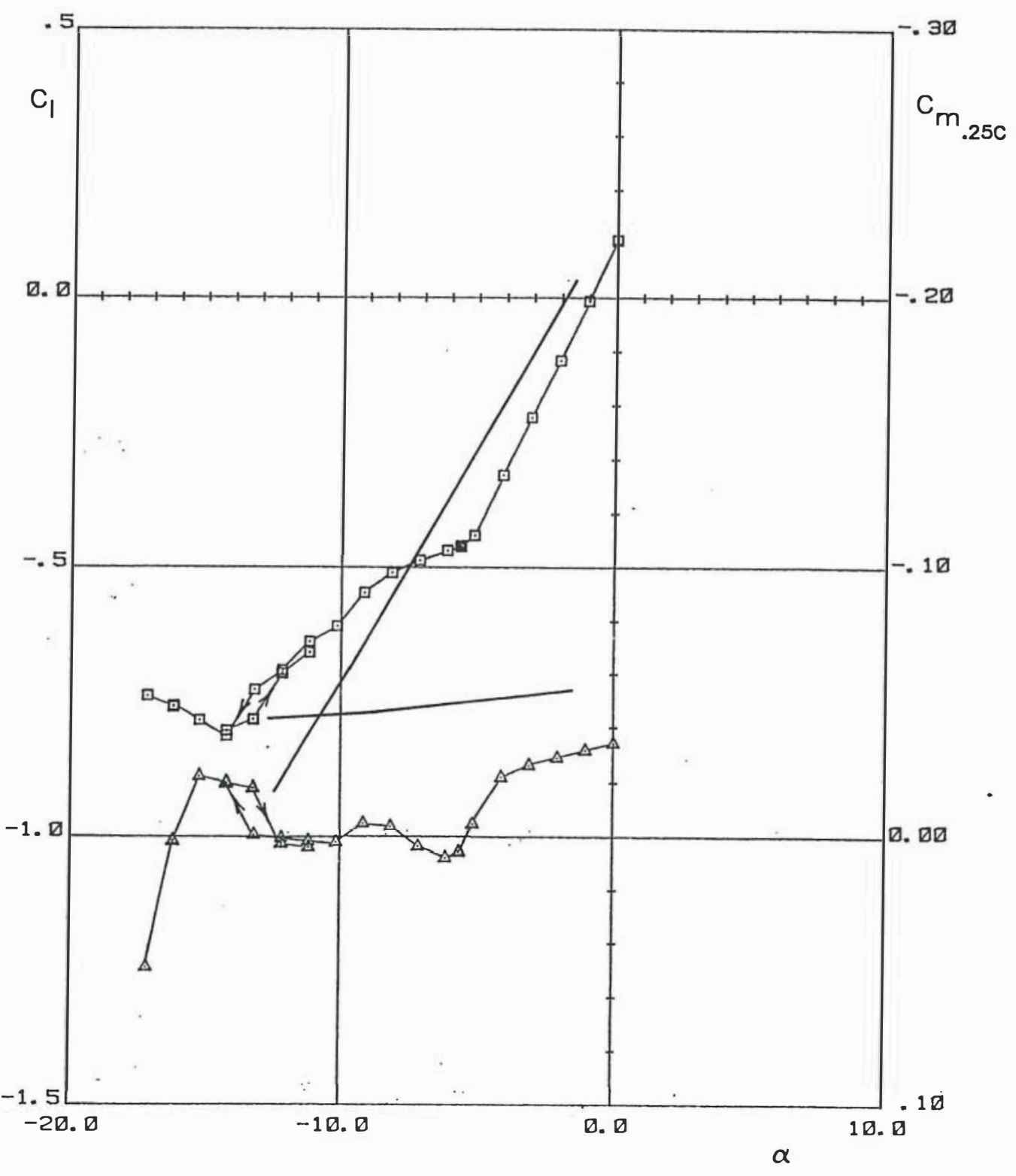

(ii) Negative lift coefficients.

(c) $R=2,000,000$.

Figure 23.- Continued. 
Delft University of Technology

Theory

- Experiment

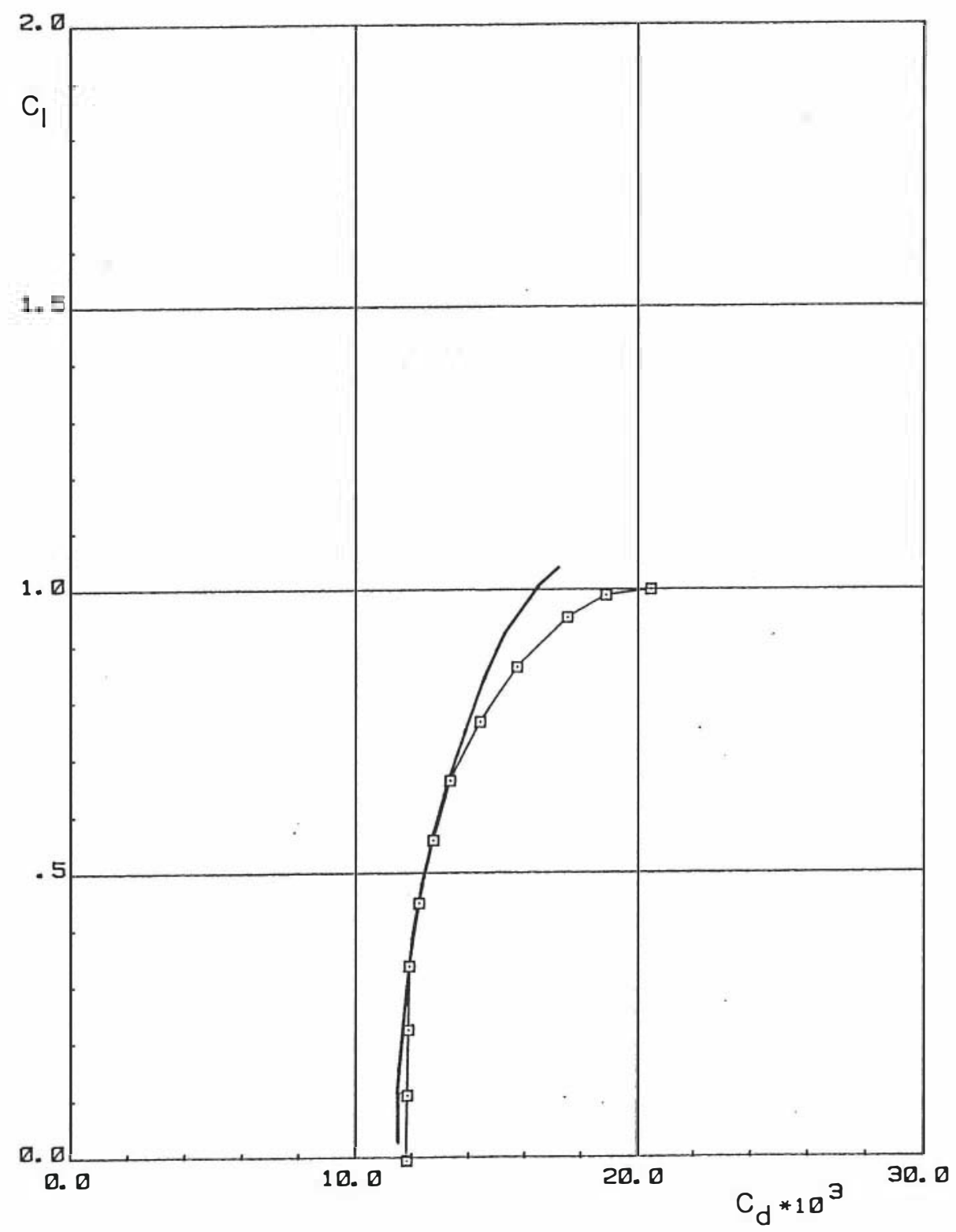

Low Speed Laboratory

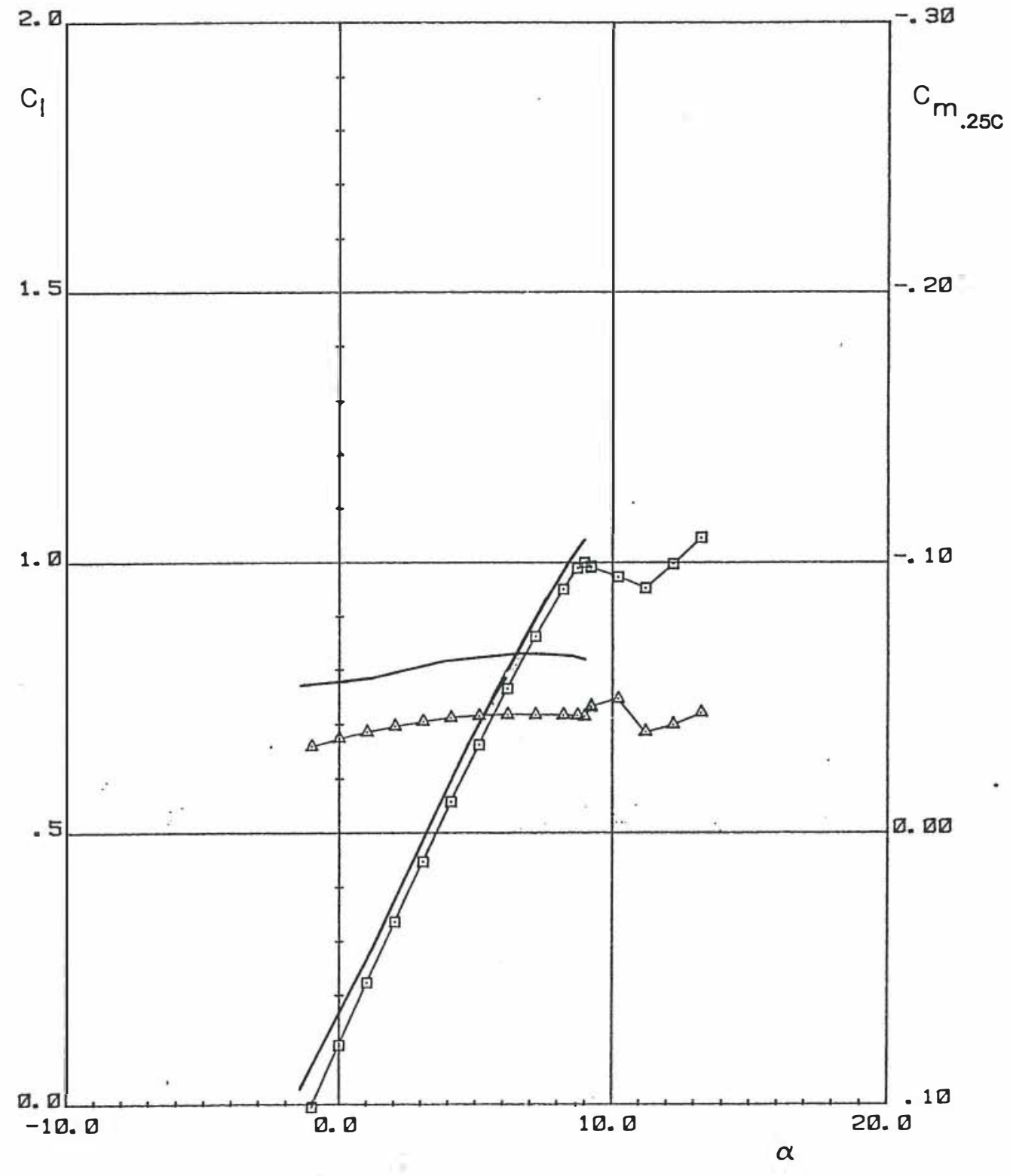


Theory

$\longrightarrow$ Eaperiment

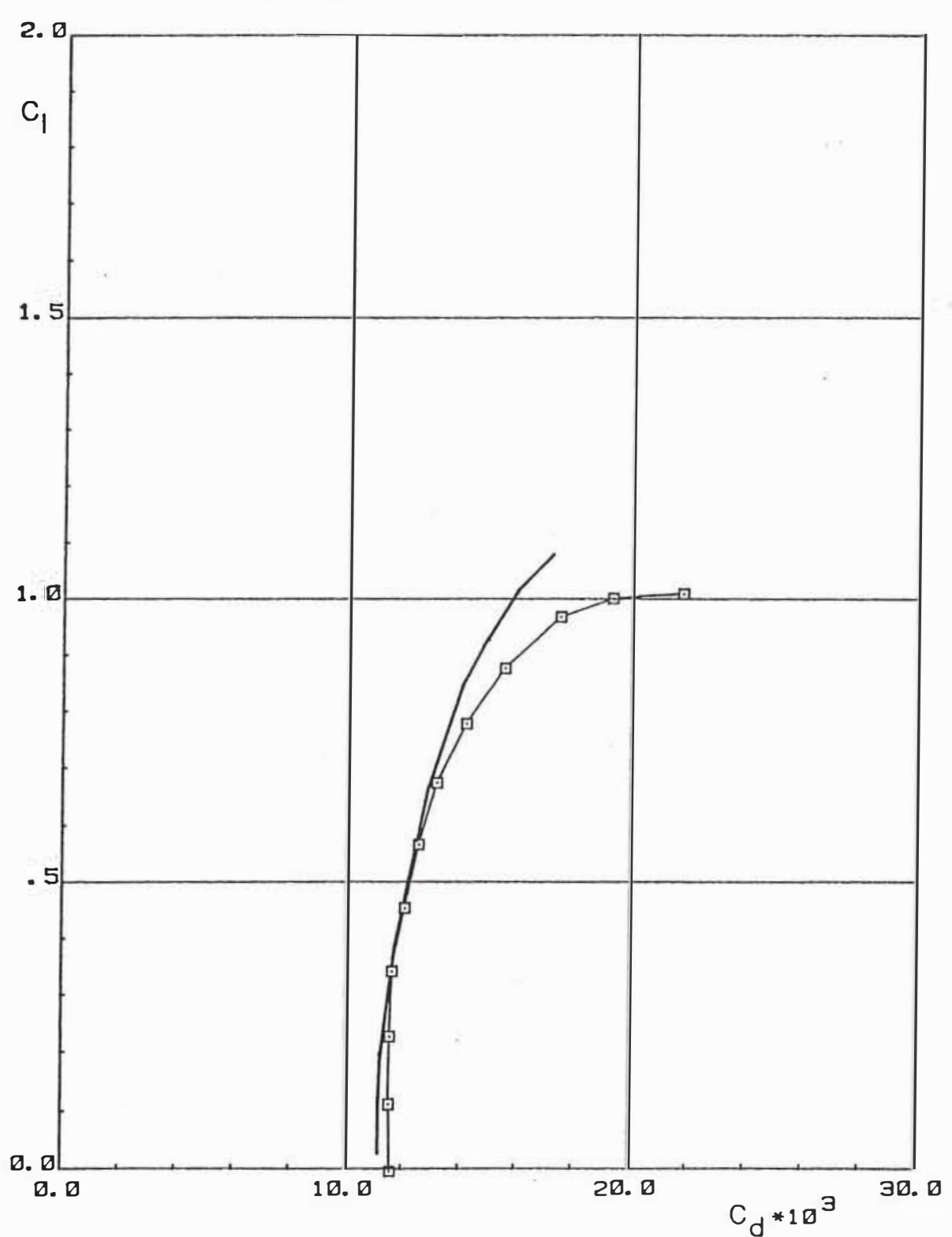

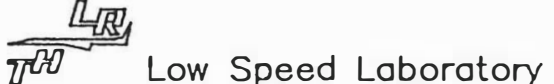

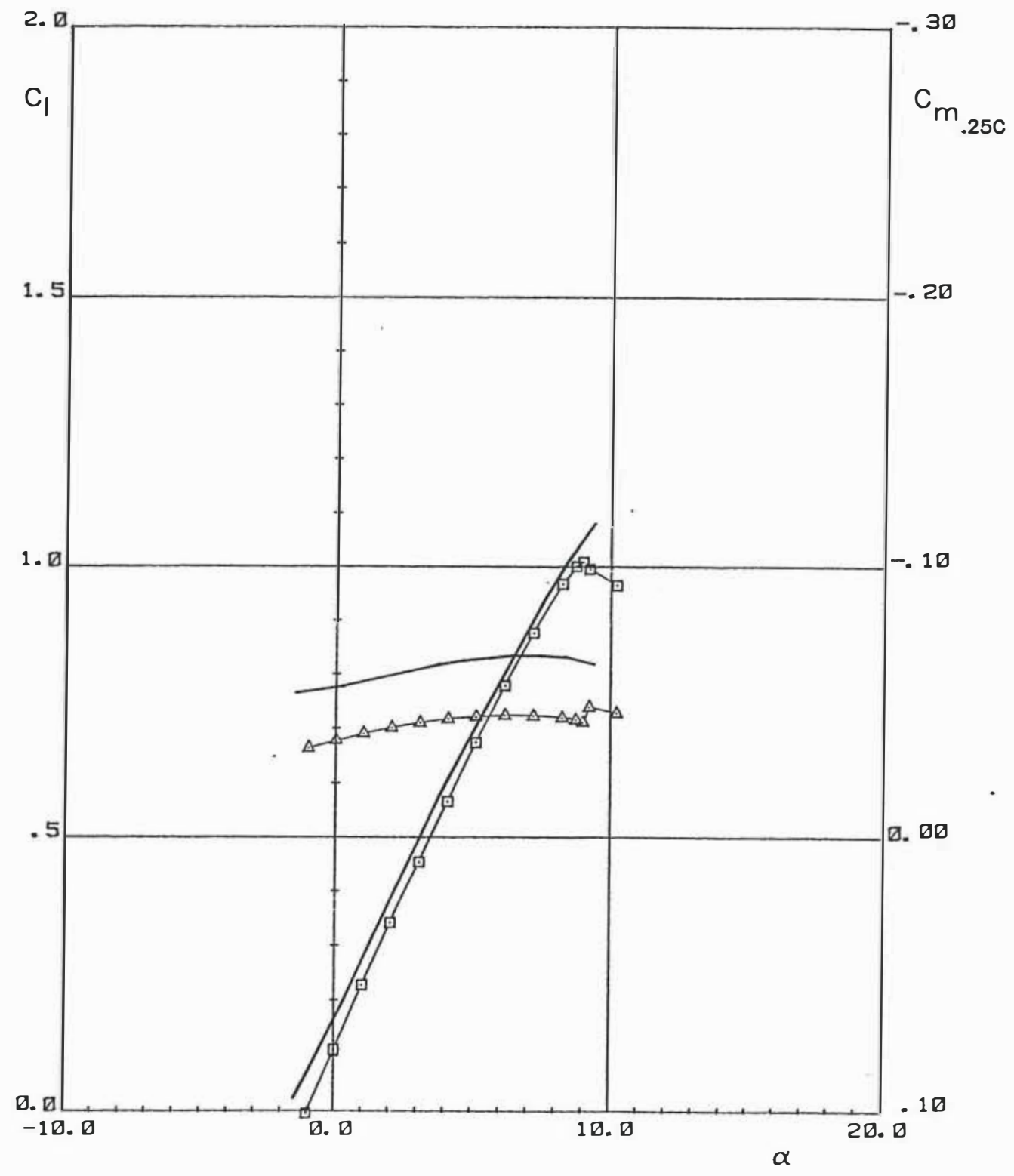

(e) $R=3,000,000$.

Figure 23. - Concluded. 

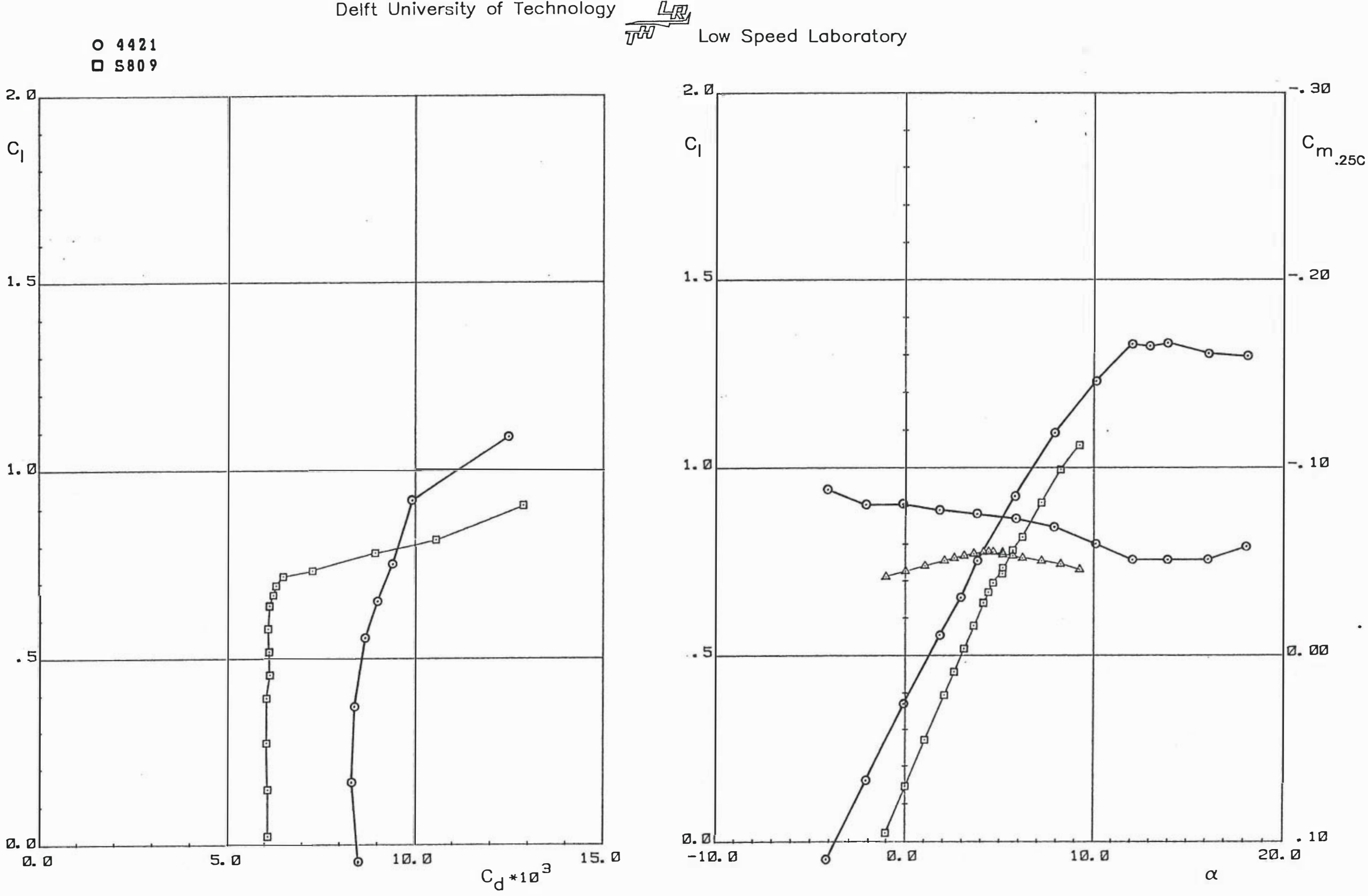

Figure 24. - Comparison of section characteristics of 5809 and NacA 4421 
023021

口 5809

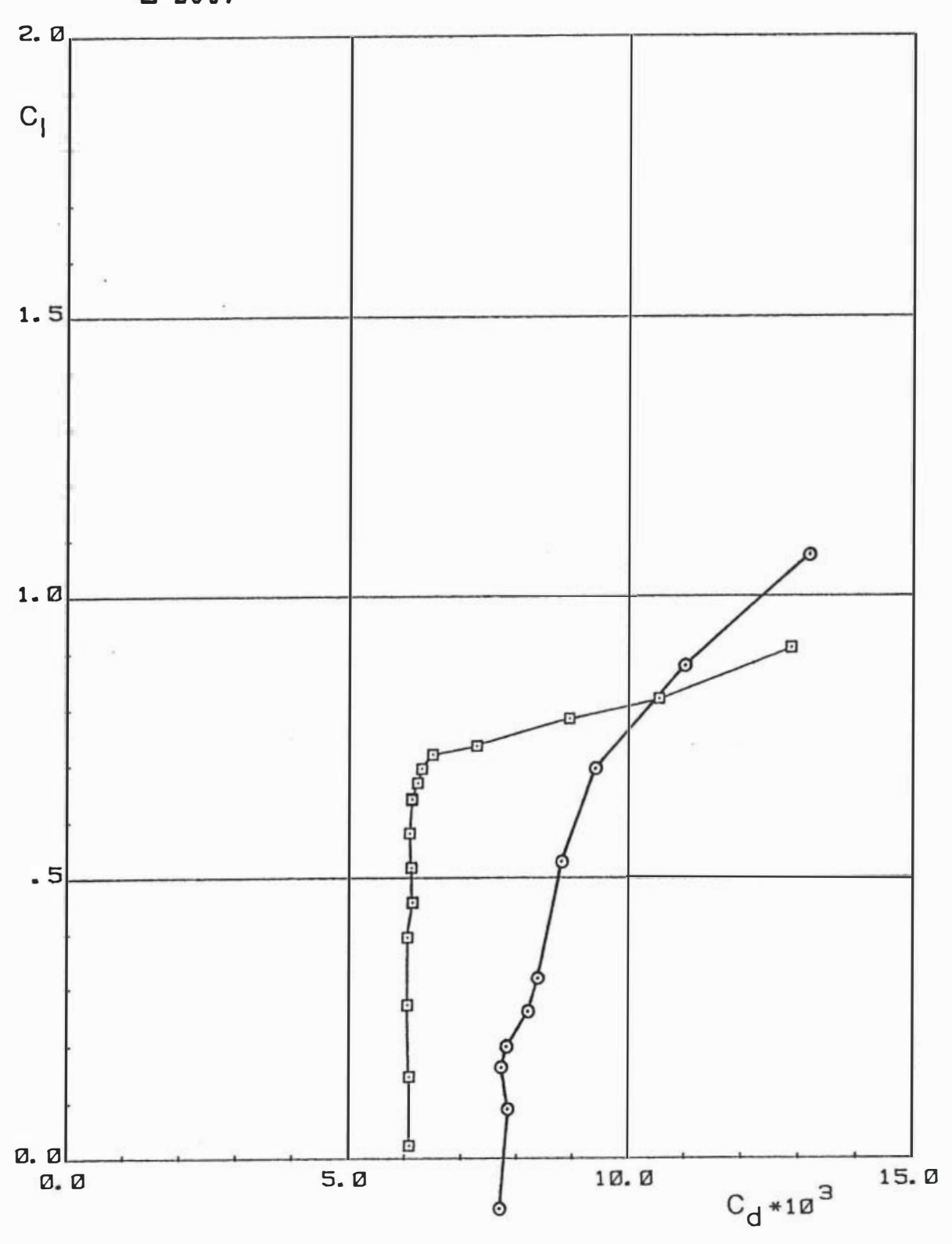

$\frac{\text { 哏 }}{2^{2}}$ Low Speed Laboratory

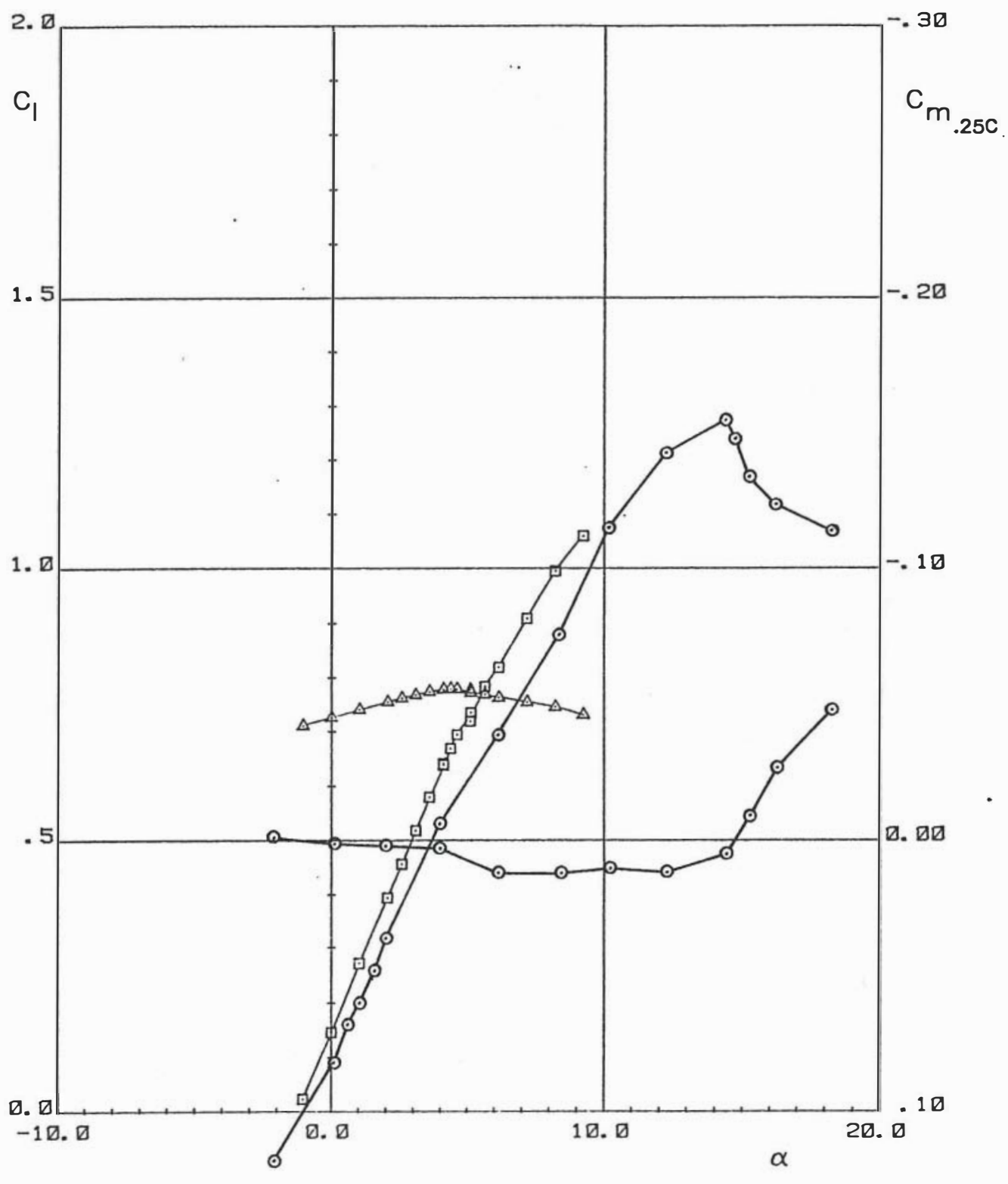

Figure 25.- Comparison of section characteristics of 5809 and NaCA 23021 


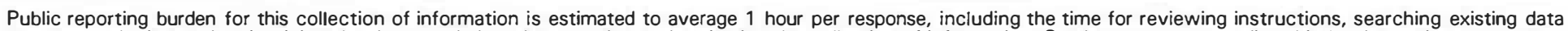

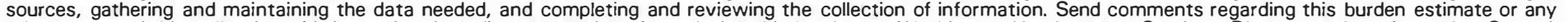

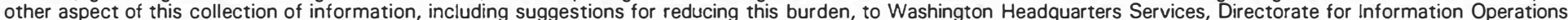

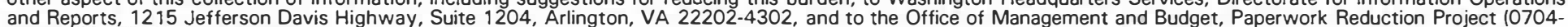
0188), Washington, DC 20503.

0188), Washington, DC 20503.

\begin{tabular}{l|l}
\hline 1. & $\begin{array}{l}2 . \\
\text { REPORT DATE } \\
\text { January } 1997\end{array}$ \\
&
\end{tabular}

\section{TITLE AND SUBTITLE}

Design and Experimental Results for the $\$ 809$ Airfoil

6. $A \cup T H O R(S)$

Dan M. Somers

7. PERFORMING ORGANIZATION NAME(S) AND ADDRESS(ES)

Airfoils, Incorporated

State College, Pennsylvania

9. SPONSORING/MONITORING AGENCY NAME(S) AND ADDRESS(ES)

National Renewable Energy Laboratory

1617 Cole Blvd.

Golden, CO 80401-3393
3. REPORT TYPE AND DATES COVERED

Subcontract Report
5. FUNDING NUMBERS

C: HK-4-04148-01

TA: WE711110

8. PERFORMING ORGANIZATION REPORT NUMBER
10. SPONSORING/MONITORING AGENCY REPORT NUMBER

SR-440-6918

DE97000106

11. SUPPLEMENTARY NOTES

NREL Technical Monitor: James Tangler

12a. DISTRIBUTION/AVAILABILITY STATEMENT

National Technical Information Service

U.S. Department of Commerce

5285 Port Royal Road

Springfield, VA 22161

12b. DISTRIBUTION CODE

UC-1213

13. ABSTRACT (Maximum 200 words)

An $21 \%$ thick, laminar-flow airfoil, the S809, for horizontal-axis wind turbine applications, has been designed and analyzed theoretically and verified experimentally in the low-turbulence wind tunnel of the Delft University of Technology Low Speed Laboratory, The Netherlands. The two primary objectives of restrained maximum lift, insensitive to roughness, and low profile drag have been achieved. The airfoil also exhibits a docile stall. Comparisons of the theoretical and experimental results show good agreement. Comparisons with other airfoils illustrate the restrained maximum lift coefficient as well as the lower profiledrag coefficients, thus confirming the achievement of the primary objectives.

14. SUBJECT TERMS

horizontal-axis wind-turbine airfoil
15. NUMBER OF PAGES

16. PRICE CODE

20. LIMITATION OF ABSTRACT

UL

\section{OF REPORT}

Unclassified

NSN 7540-01-280-5500
18. SECURITY CLASSIFICATION OF THIS PAGE Unclassified
19. SECURITY CLASSIFICATION OF ABSTRACT Unclassified
Standard Form 298 (Rev. 2-89) Prescribed by ANSI Std. 239-18 